University of Louisville ThinkIR: The University of Louisville's Institutional Repository

Electronic Theses and Dissertations

$5-2016$

\title{
The impact of Medicaid expansion on utilization of mental health services in west Louisville, Kentucky.
}

Susan Theresa Buchino

University of Louisville

Follow this and additional works at: https://ir.library.louisville.edu/etd

Part of the Other Public Health Commons

\section{Recommended Citation}

Buchino, Susan Theresa, "The impact of Medicaid expansion on utilization of mental health services in west Louisville, Kentucky." (2016). Electronic Theses and Dissertations. Paper 2417.

https://doi.org/10.18297/etd/2417

This Doctoral Dissertation is brought to you for free and open access by ThinkIR: The University of Louisville's Institutional Repository. It has been accepted for inclusion in Electronic Theses and Dissertations by an authorized administrator of ThinkIR: The University of Louisville's Institutional Repository. This title appears here courtesy of the author, who has retained all other copyrights. For more information, please contact thinkir@louisville.edu. 


\title{
THE IMPACT OF MEDICAID EXPANSION
}

\section{ON UTILIZATION OF MENTAL HEALTH SERVICES \\ IN WEST LOUISVILLE, KENTUCKY}

\section{By}

Susan Theresa Buchino

M.S.O.T., Spalding University, 2004

B.A., University of Notre Dame, 1997

\author{
A Dissertation \\ Submitted to the Faculty of the \\ School of Public Health and Information Sciences \\ of the University of Louisville \\ in Partial Fulfillment of the Requirements \\ for the Degree of
}

Doctor of Philosophy in Public Health Sciences

\author{
Department of Health Promotion \& Behavioral Sciences \\ University of Louisville \\ Louisville, KY
}

May 2016 
(C) 2016 by Susan Theresa Buchino

All rights reserved 



\title{
THE IMPACT OF MEDICAID EXPANSION ON UTILIZATION OF MENTAL HEALTH SERVICES \\ IN WEST LOUISVILLE, KENTUCKY
}

\author{
By \\ Susan Theresa Buchino \\ M.S.O.T., Spalding University, 2004 \\ B.A., University of Notre Dame, 1997 \\ A Dissertation Approved on
}

April 21, 2016

by the following Dissertation Committee:

Monica Wendel, Dr.P.H., M.A.

Dissertation Chair

Craig Blakely, Ph.D., M.P.H.

LaQuandra Nesbitt, M.D., M.P.H.

Patrick Pössel, Dr. rer. soc.

Liza Creel, Ph.D., M.P.H. 


\section{DEDICATION}

This dissertation is dedicated to the people whom I have served. Whether I met you in a homeless shelter, a clinic, a skilled nursing facility, a classroom, a community center, or your home, you have each graciously taught me about being human and needing help to be healthy. Being healthy shouldn't be a privilege. This is what I am fighting for. 


\section{ACKNOWLEDGMENTS}

I am grateful first to my parents, who taught me to be a curious learner and a compassionate contributor. Their beliefs in the importance of both education and service have been underlying factors in my acquisition of skills and motivation to promote health and social justice in my community. My dad has said, "Make your own luck." With that in mind, I have learned to be open to opportunity, as you never know when the right one will come your way—this is important, because it has certainly lead me here.

I am most lucky to have the mentorship of Dr. Monica Wendel, who did not hesitate to accept the position as chair of this dissertation committee even before her first day of work at UofL. I am grateful for her mentorship to achieve competence and confidence as a public health researcher. Monica, thank you for laughing with me through this process. You have ensured my mental health has always been in check as I worry about how Medicaid expansion has impacted the mental health of others. Despite the stress, we had a ball.

I extend thanks to each of my committee members: Dean Craig Blakely, who gave me the opportunity to participate in the evaluation of the local implementation of the Affordable Care Act; Dr. LaQuandra Nesbitt, who has always answered my million questions and agreed to continue on my committee even after moving from Louisville; Dr. Patrick Pössel, who provided expertise in psychology and challenged me to critically think through my research design; and Dr. Liza Creel, who ensured I had the proper tools for battling SPSS and claims data (persistence, Google, and wine). I appreciate your time, 
expertise, and patience throughout this project. I would like to also acknowledge Texas A\&M for sending half my committee to UofL at just the right time.

I would like to acknowledge Passport Health Plan for providing me with claims data, and Jill J. Bell, Dr. Jessica K. Beal, Dr. Steve Shamblen, and Kyle Tobbe for the time and resources they provided to assist me to interpret the data. I appreciate the time and expertise of my colleagues, Trinidad Jackson and Dr. Ryan Combs, who both assisted to validate my qualitative research process, and Dr. Sheila Schuster and Dr. Vicki Hines-Martin, who provided insight and advice as I approached this project. Thank you to the administrative and behavioral health staffs of Family Health Centers and Park DuValle Community Health Center for their assistance with participant recruitment.

I am thankful for all of my family and friends who have been loving and encouraging in so many ways. The past five years have been a crazy ride, through which I would not have made it without the Empire and the amazing friendships that can only occur in my old Kentucky home. I am privileged to have had the support of so many people as I completed this chapter of my life. Opportunities abound. Lucky, lucky me. 


\begin{abstract}
THE IMPACT OF MEDICAID EXPANSION ON UTILIZATION OF MENTAL HEALTH SERVICES IN WEST LOUISVILLE, KENTUCKY
\end{abstract}

Susan Buchino

April 21, 2016

Mental health is an essential component of overall health status, and mental illnesses are a leading cause of disability. In addition to expanding insurance coverage, the Affordable Care Act (ACA) reinforced parity for mental health services in insurance plans. This mixed-methods study assessed mental health service utilization by an urban and predominately African-American population following the successful implementation of the ACA and Medicaid expansion in Louisville, KY. Claims data from one Medicaid Managed Care Organization were analyzed to assess mental health care utilization patterns pre- and post- Medicaid expansion and determine differences in utilization rates between the Medicaid expansion population and other Medicaid beneficiaries, as well as differences in use of mental health services by geography across a Metropolitan region. Additionally, both mental health care providers and residents of the local community were interviewed regarding factors influencing use of mental health care.

The results of the study demonstrate that beneficiaries of Medicaid expansion have used their new health insurance to access mental health ambulatory care services, 
counseling, and psychotropic medications, but may be doing so at a lower rate than other Medicaid beneficiaries in their community. Eleven distinct themes emerged from the qualitative data. Both providers and members of the community cited ongoing barriers to accessing and utilizing mental health services, including a lack of providers, stigma, poor health literacy, and the influences of social determinants of health. However, they recognized a need for mental health promotion within the toxic stress of their environment.

The results of this study provide evidence supporting the continuation of policies that promote access to mental health care by reducing the burden of cost. This study also informs understanding of specific community needs that include persistent barriers beyond the scope of ACA. Thus, other policies and strategies are also needed to create health system transformation and foster a culture of health that prioritize mental health care. 


\section{TABLE OF CONTENTS}

\section{PAGE}

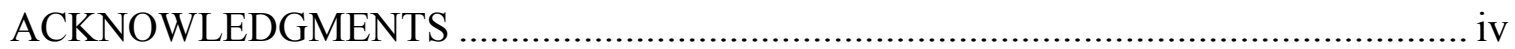

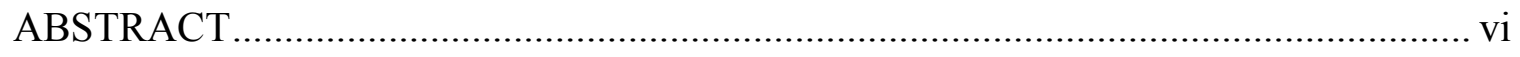

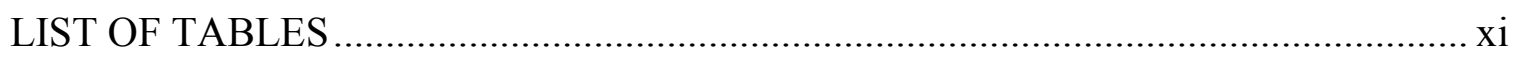

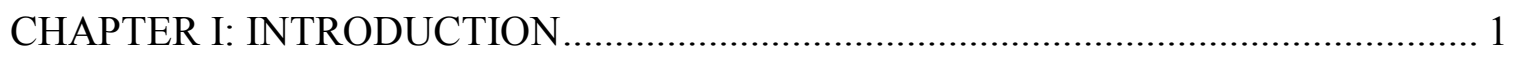

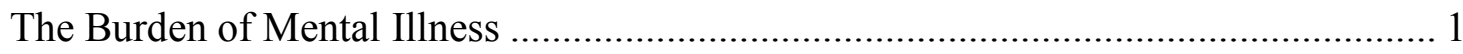

Disparities in Risk and Access to Mental Health Care ................................................... 5

The Role of Health Insurance in Health ................................................................. 9

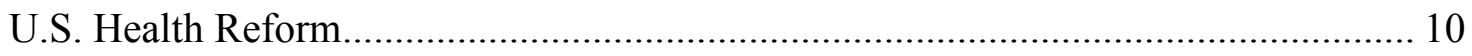

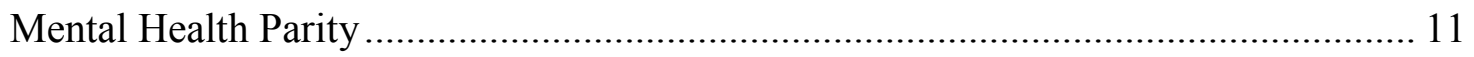

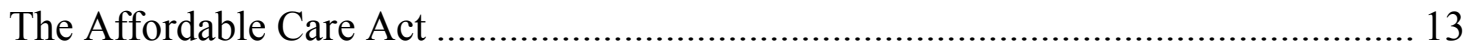

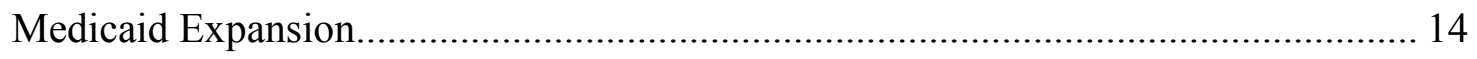

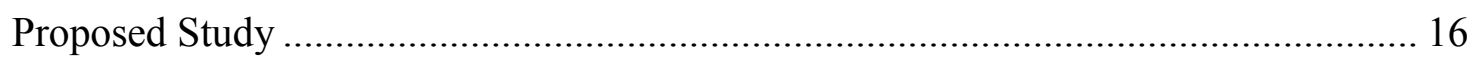

Operational Definitions................................................................................... 19

CHAPTER II: REVIEW OF THE LITERATURE ………………………………...... 23

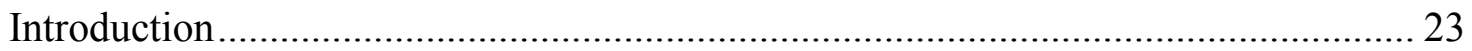

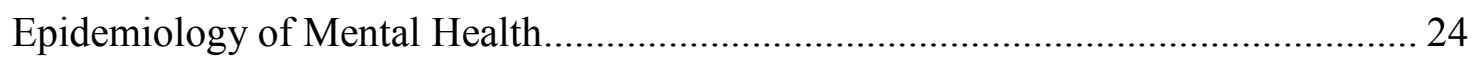


Impact of Health Insurance on Access and Utilization............................................ 33

Factors Influencing Use of Mental Health Services ................................................. 35

Affordable Care Act Outcomes Studies.................................................................. 40

Medicaid Expansion Outcomes Studies.............................................................. 41

Mental Health Utilization among Low Socioeconomic and Black Populations.......... 44

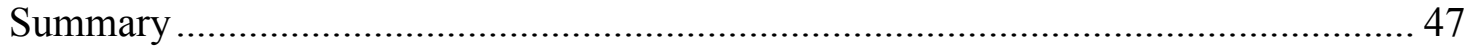

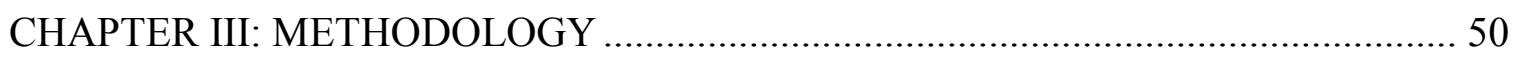

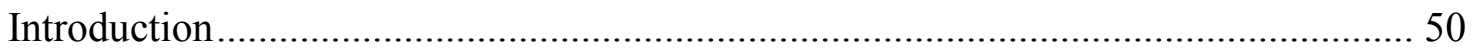

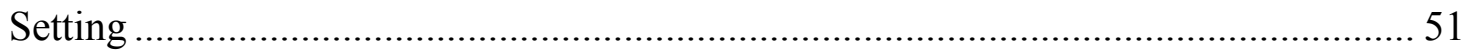

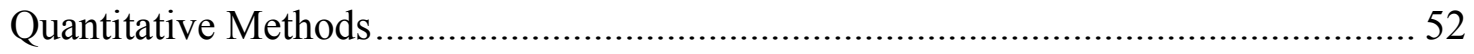

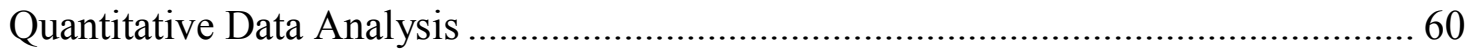

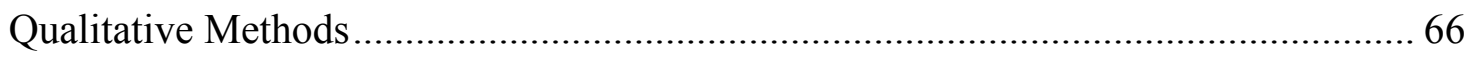

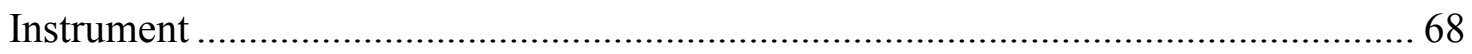

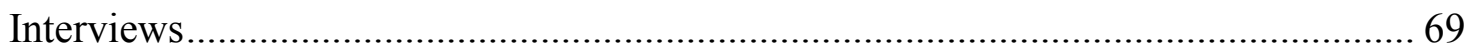

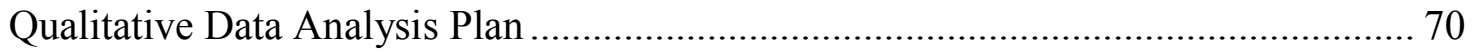

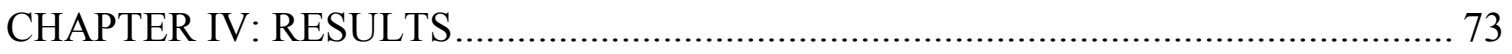

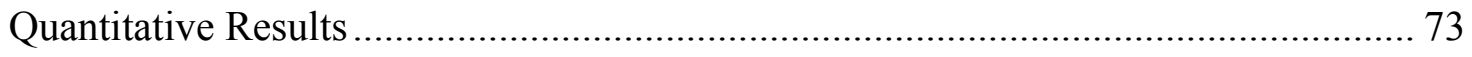

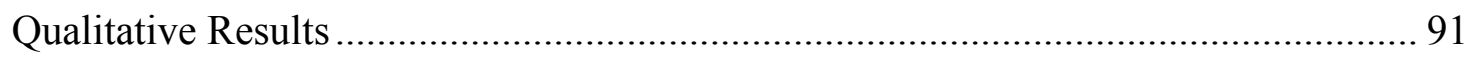

Need for Mental Health Services ...................................................................... 103 
Facilitators of Use of Mental Health Services

Barriers to Using Mental Health Services ............................................................ 104

Bureaucracy surrounding mental health care is a barrier to utilization ...................... 105

Other Factors That Influence Mental Health Service Utilization ................................ 107

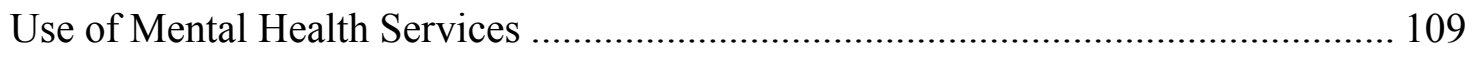

CHAPTER V: DISCUSSION AND CONCLUSIONS ………………………........... 113

The Impact of Medicaid Expansion on Utilization of Mental Health Services for

Residents of West Louisville Neighborhoods.......................................................... 113

Factors Other Than Health Insurance That Impact Utilization of Mental Health

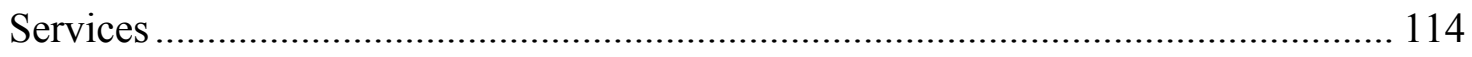

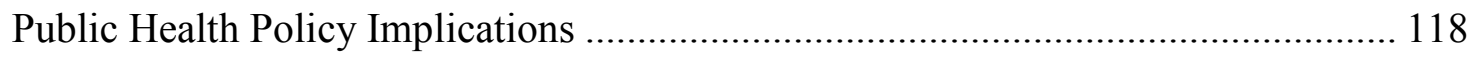

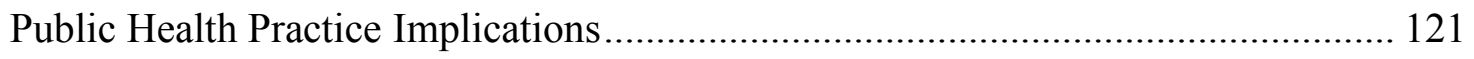

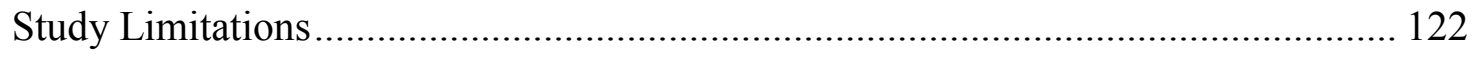

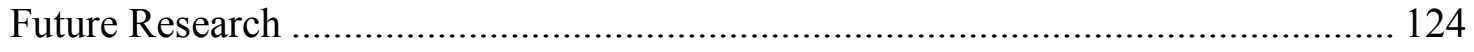

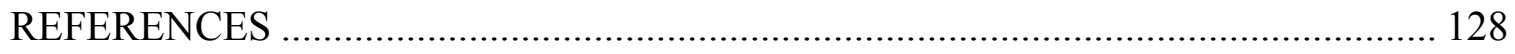

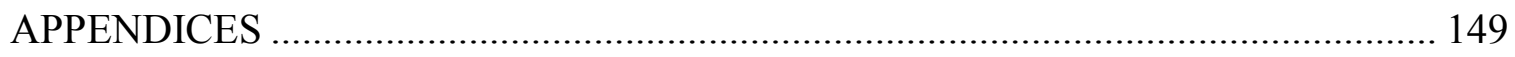

Appendix A: Provider Interview Topic Guide......................................................... 149

Appendix B: Consumer Interview Guide …………….................................... 150

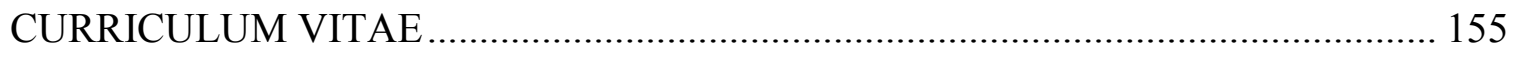




\section{LIST OF TABLES}

TABLE

PAGE

1. Any mental illness in the past year among adults, by race/ethnicity, 2008-2012, Annual

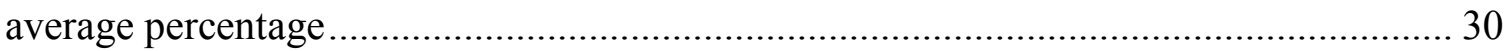

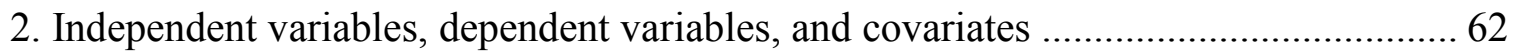

3. Descriptive Statistics for West Louisville Residents Who Made Claims to Passport

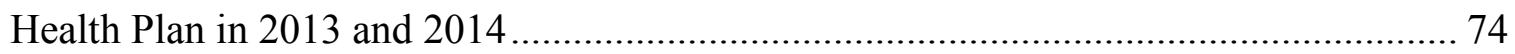

4. Results of Negative Binomial Regression Analysis, Likelihood of Ambulatory Care

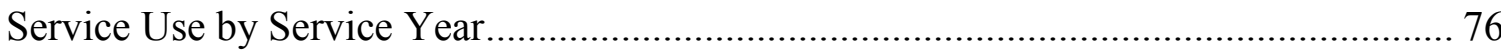

5. Results of Negative Binomial Regression Analysis, Likelihood of Counseling Use by

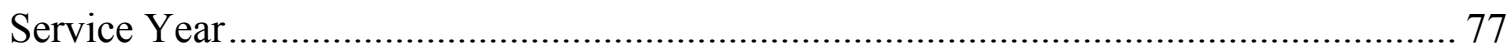

6. Results of Negative Binomial Regression Analysis, Likelihood of Medication Use by

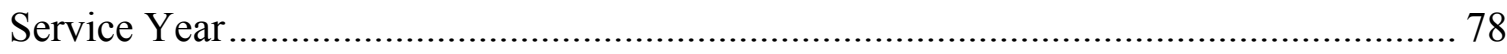

7. Descriptive Statistics for West Louisville Residents Who Made Claims to Passport

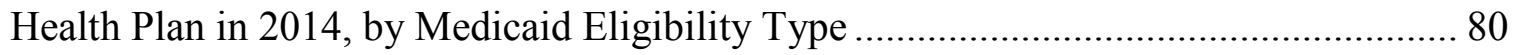

8. Results of Negative Binomial Regression Analysis, Likelihood of Ambulatory Care

Service Use by Medicaid Eligibility Type ............................................................ 82

9. Results of Negative Binomial Regression Analysis, Likelihood of Counseling Use by

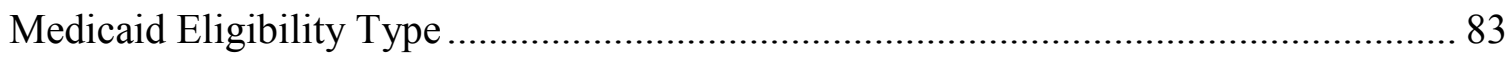


10. Results of Negative Binomial Regression Analysis, Likelihood of Medication Use by Medicaid Eligibility Type 84

11. Descriptive Statistics for Louisville Metro Residents Who Made Claims to Passport

Health Plan in 2014, by Geography. 86

12. Results of Negative Binomial Regression Analysis, Likelihood of Ambulatory Care Service Use by Geography 88

13. Results of Negative Binomial Regression Analysis, Likelihood of Counseling Use by Geography 89

14. Results of Negative Binomial Regression Analysis, Likelihood of Medication Use by Service Year. 90

15. Demographics of Consumer Interview Participants 92

16. Theme 1: Need for Mental Health Services 94

17. Theme 2: ACA has Positively Influenced Access 95

18. Theme 3: Bureaucracy is a Barrier to Utilization 95

19. Theme 4: Lack of Provider Availability is a Barrier to Access and Use 96

20. Theme 5: Stigma Persists in the West Louisville Community 97

21. Theme 6: Poor Health Literacy is Barrier to Utilization. 98

22. Theme 7: Community Resources impact Utilization 99

23. Theme 8: Support Systems Influence Utilization 100

24. Theme 9: Consumers in West Louisville Use Mental Health Services 101

25. Theme 10: Importance of the Therapeutic Relationship. 102 
26. Theme 11: Resistance to Mental Health Treatment............................................... 103 


\section{CHAPTER I}

\section{INTRODUCTION}

\section{The Burden of Mental Illness}

Mental health is an essential component of overall health status. The World Health Organization (WHO) describes mental health as "a state of well-being in which an individual realizes his or her own abilities, can cope with the normal stresses of life, can work productively and is able to make a contribution to his or her community" (WHO, 2014). Conversely, mental illness is defined as "a medical condition that disrupts a person's thinking, feeling, mood, ability to relate to others and daily functioning” (National Alliance on Mental Illness (NAMI), 2014). Mental illness can present in many different ways; commonly known mental health diagnoses include depression and bipolar disorder, anxiety disorders including post-traumatic stress disorder (PTSD), schizophrenia, personality disorders, eating disorders, and emotional and behavioral disorders (NAMI, 2016). In the United States (U.S.), these specific disorders are classified through the Diagnostic and Statistical Manual of Mental Disorders, Fifth Edition (DSM-5), the American Psychiatric Association's (APA) diagnostic tool, which suggests criterion by which a diagnosis is made. Unlike physical illnesses, there are few biological diagnostic tests for mental illness; the assignment of a diagnosis is based on an individual's self-report of symptoms, external observation of behaviors over time, and clinical judgment (Kapur, Phillips, \& Insel, 2012). Mental illness are a leading cause of 
disability (WHO, 2004b), as they notably interfere or limit performance in life activities, particularly social interactions and activities in the community (Mojtabai, 2011). These conditions can impact any person at any point in life, but are also associated with biological, social, and environmental risk factors, such as poor physical health, chronic stress, discrimination and oppression, poverty, and lack of access to educational and economic opportunities (Nguyen, 2014; WHO, 2014). Based on results of the National Survey on Drug Use and Health (NSDUH), the Substance Abuse and Mental Health Services Administration (SAMHSA) estimates that nearly one in five U.S. adults experienced mental illness in 2014, and 4.1 percent of the population is diagnosed with serious mental illness (SMI; Center for Behavioral Health Statistics and Quality, 2015). Since many of the conditions are chronic and may emerge by adolescence, a diagnosis of mental illness may mean a lifetime of impairment (Jones, 2013; Kessler et al., 2007).

Although mental illness is not a direct cause of death, individuals with mental illness experience higher premature mortality rates than those without a diagnosis. Studies have shown that individuals with SMI have a significantly decreased life expectancy of between 13 and 32 years due to preventable causes, including suicide, accidents, and physical illness (Colton \& Manderscheid, 2006; Piatt, Munetz, \& Ritter, 2010). Suicide, which is associated with symptoms of mental illness, was the tenth leading cause of death in 2010, claiming 38,364 American lives (Centers for Disease Control and Prevention (CDC), 2012).

The field of psychology and treatment of individuals with mental illness has a long history, although most clinical and pharmacological options have developed since 1960. Prior to this, individuals with mental illness were likely to be removed from society 
and held in publicly supported mental hospitals, known as asylums (Everett \& Lee, 2012). Because the symptoms associated with mental illness include atypical social interactions or emotional instability, individuals who presented with intrusive symptoms, such as hallucinations or agitation, were stigmatized and feared. Asylums were initially well-managed, structured, and therapeutic environments, but as the number of patients grew through the Nineteenth Century, asylums became known for overcrowded and inhumane conditions. The institutional era persisted until the mid-Twentieth Century, at which point asylums across the U.S. housed over 500,000 people (U.S. National Library of Medicine, 2006).

Deinstitutionalization, a period marked by the closure of state mental hospitals and mass movement of individuals with mental illness to other settings, was sparked by several events. First, mental health advocates sought support for benevolent care for this population (Everett \& Lee, 2012). Additionally, post-war optimism and concern for the cost of asylums served to facilitate a transition in attitude about the ability of individuals with mental illness to thrive in the community with outpatient services (Frank \& Glied, 2006). Pharmacology, which was introduced into the routine treatment of mental illness in the 1950s, supported these ideals by helping to eliminate symptoms and enabling the behaviors expected by society. Community-based mental health centers were established in 1963 with federal support and the intent to increase access to care (Frank \& Glied, 2006). While the deinstitutionalization strategies facilitated successful community living for some people, many individuals with SMI moved to nursing homes or prisons, while others became homeless as a result of their inability to function socially and maintain housing without intense supports. 
Most recently, mental health care has embraced a recovery model, defining recovery as "a process of change through which individuals improve their health and wellness, live a self-directed life, and strive to reach their full potential" (SAMHSA, 2011). Although treatment modalities range from high-intensity inpatient or residential care to occasional outpatient counseling, current models of mental health service delivery are more often community-based than institutional. Medication continues to serve as one of the most common forms of treatment for mental illness, either alone or in combination with counseling. Psychosocial treatment also includes non-medical options that promote community-integration, such as day programs, case management, and vocational rehabilitation. These services may serve as short-term care for acute problems or longterm to address the chronic nature of mental illness. Despite the increasingly promising prognosis and positive attitude toward mental illness in terms of treatment approaches, the social stigma of mental illness persists.

In 2013, direct health care spending for mental illness in the U.S. was estimated at \$113 billion (Mark, Levit, Vandivort-Warren, Buck, \& Coffey, 2011), which qualifies mental illness as one of the top five most costly medical conditions. However, the fact that individuals with mental disorders have higher unemployment rates and higher rates of arrest than those without (SAMHSA 2013), indicates that the indirect costs of mental illness, such as disability benefits, lost productivity, homelessness, and incarceration, are also significant. In 2002, the economic burden of mental illness in the U.S. was estimated at $\$ 300$ billion when both direct health care costs and indirect costs were calculated (Reeves et al., 2011). 
In addition to mental health care spending, mental illness incurs health care costs for somatic illnesses. Because mental illness can result in functional impairment, people experiencing mental illness are more likely to engage in personal behaviors that negatively influence physical health, such as smoking, substance abuse, poor nutrition, and limited physical activity, in addition to presenting with poor initiation for preventive practices and difficulty following through with health care provider recommendations (Parks, 2006). Data demonstrate that overall health status is inversely related to the severity of mental illness; adults with serious impairment due to mental illness are more than three times as likely to report fair or poor health status and almost twice as likely to experience a hospital emergency room visit as individuals without mental illness (Substance Abuse and Mental Health Services Administration, 2013). Notably, individuals with SMI have higher rates of prevalence for cancer, cardiovascular disease, obesity, and substance abuse (Colton \& Manderscheid, 2006). Additionally, 7.7 million adults with mental illness are also identified as having a co-occurring substance abuse disorder (Substance Abuse and Mental Health Services Administration, 2014b).

Furthermore, societal consequences of deinstitutionalization, such as homelessness and incarceration, impact health care costs indirectly, since individuals who are homeless or incarcerated are less likely to have continuity in care and achieve positive long-term health outcomes (Barrett, Fogel, Garrett, \& Young, 2011; Porter, 2014; Power et al., 1999; Spaulding et al., 2011). A 2008 survey of U.S. mayors concluded that mental illness is the third leading cause of homelessness (National Coalition for the Homeless, 2009), and 30 percent of individuals experiencing chronic homelessness meet the criteria for SMI (Office of National Drug Control Policy, 2016). Additionally, there is a strong 
link between mental illness and incarceration; NAMI estimates that between 25 and 40 percent of all Americans with mental illness will spend time in jail or prison during their lifetime (2004). Over half of all inmates in prisons and jails have symptoms of mental illness or a history of treatment for mental illness (James \& Glaze, 2006). However, despite the critical impact of mental health on overall health and the high societal costs that result from poor mental health, mental health care is not universally accessible.

\section{Disparities in Risk and Access to Mental Health Care}

Frank and Glied (2006) describe five distinct groups that may experience symptoms of mental illness or utilize services in a variety of ways. First, individuals diagnosed with severe and persistent mental illness live with a debilitating disease; this relatively small group incurs the highest direct and indirect costs. However, other individuals experience symptoms of mental illness that are not considered debilitating, but do impede function without treatment. Others may find their symptoms do not interfere with daily activity, and do not seek treatment. A fourth group of people experience symptoms consistent with mental illness, perhaps due to environmental stressors or life events, but who do not meet psychiatric diagnostic criteria. These individuals also benefit from pharmaceutical treatment or counseling. Finally, there are individuals who utilize counseling for self-discovery and conflict resolution, and not for definitive symptoms of mental illness. Consequently, published prevalence rates for mental illness vary, since measurement is dependent upon the construct used to identify an individual with mental illness.

Although mental health is influenced by a combination of social, psychological, biological, and environmental factors, poverty is the most highly correlated factor with 
poor mental health (Frank \& Glied, 2006; WHO, 2014). Not only are individuals who live in poverty at an increased risk of mental illness (Bruce, Takeuchi, \& Leaf, 1991; Hudson, 2005), but conversely people with mental illness are twice as likely as people without to have incomes under 150 percent of the Federal Poverty Level (FPL) (Donohue, Garfield, \& Lave, 2010). While unemployment is a risk factor associated with poor mental health and increased mortality, people who experience symptoms of mental illness are likely to remain poor and unemployed due to functional impairment. Additionally, individuals experiencing chronic physical illnesses and disability are at risk of mental illness. The population of individuals with mental illness therefore disproportionately receives public assistance, accounting for one-third of recipients of Social Security disability benefits (Social Security Administration, 2014a, 2014b; WHO, 2012).

The prevalence rates for mental illness are difficult to measure reliably, but it is generally accepted that mental illness in the U.S. is under-reported (Takayanagi et al., 2014). Overall prevalence rates for mental illness are higher for women than men (SAMHSA, 2014a), but rates for different diagnoses of mental illness vary (Garfield, 2011). Although mental illness spans the lifetime, it is most prevalent for individuals in their twenties, but perhaps more debilitating for older adults (Frank \& Glied, 2006). After reviewing the literature, Frank and Glied (2006) found no trending difference between race/ethnicity and lifetime prevalence of mental illness. However, the 2013 NSDUH findings demonstrate variances in past-year rates of any mental illness between races ranging from 12.3 percent among Asians and 28.1 percent among adults who identify with two or more races (SAMHSA, 2014a). 
More significantly, other reports state that there are differences in mental health service use (SAMHSA, 2015) and in distribution of mental health expenditures (Le Cook, Manning, \& Alegria, 2013) for different racial and ethnic groups. For example, in 2013 it was estimated that 19.3 percent of Whites and 16.9 percent of Blacks experienced mental illness (SAMHSA, 2014a) but estimates of mental health service utilization were nearly twice as high for Whites as for Blacks (SAMHSA, 2015). These results suggest there may be disparities in access to care.

Access to health care is broadly defined as the ability to obtain timely and appropriate health services to achieve optimal health outcomes (Millman, 1993). A variation in the presentation of symptoms, functional impairment, and perceived need influences both the definition of an individual with mental illness and access to mental health services. Data demonstrate a gap in the need for mental health care and access to mental health services (WHO, 2011), with the highest rate of unmet need in the uninsured adult population (Roll, Kennedy, Tran, \& Howell, 2013).

Traditionally, mental health care has been provided separately from physical health care despite evidence that mental health and physical health are intimately linked. Within this divided system, only one-fifth of adults with diagnosable mental illness see mental health providers for treatment, while equally as many see general medical practitioners for mental health services (Garfield, 2011). Furthermore, it is estimated that mental health care only receives 6.1 percent of total health spending (Mark et al., 2011), and expenditures for mental health care have grown at a slower rate than other health care expenses. Ultimately, it is estimated that as many as 40 to 60 percent of adults with 
diagnosable disorders do not receive needed mental health services (Barry, 2004; Druss et al., 2007; SAMHSA, 2014a).

Barriers to mental health care have been linked to factors associated with low socioeconomic status, education, and employment. Until recent health reform policies for parity were implemented, health insurance plans have provided paltry coverage for mental illness in comparison to coverage of physical illnesses (SAMHSA, 2013). Therefore, even when individuals are covered by health insurance, they have been forced to pay more out-of-pocket for the treatment of mental illness than for other serious diseases. Cost has been documented as the largest barrier to mental health care (SAMHSA, 2014a); other notable barriers include perceptions of mental illness and the need for care, or logistical difficulties such as a lack of time or knowledge of service location (SAMHSA, 2014a).

Whitley and Lawson (2010) suggest that there are multiple reasons beyond health insurance and logistics that create racial disparities in health care. Of significance, both patient and provider perceptions present cultural barriers that create a sense of discrimination and stigmatization of mental health services. These findings speak to issues of workforce diversity and cultural competency, as well as community attitudes. Furthermore, location of residence influences health and access to health care (Greater Louisville Project, 2013; Radley, How, Fryer, McCarthy, \& Schoen, 2012). This issue runs deeper than the distance one must travel to access services, but reflects more broadly on access to resources and opportunities, and the multiple social determinants of health that result in disparity. 


\section{The Role of Health Insurance in Health}

Research indicates that cost is the most significant barrier to health care utilization (Fang, Yang, Ayala, \& Loustalot, 2014; Fayanju, Kraenzle, Drake, Oka, \& Goodman, 2014; Mojtabai, Chen, Kaufmann, \& Crum, 2014). Medical debt plagues more than one in five U.S. families and is associated with unmet medical need (Sommers \& Cunningham, 2011). In a commentary, Stillman and Tailor (2013) report on patients who delay care and face certain death instead of treatment because the financial barriers associated with heath care costs. Although both the insured and uninsured face medical bills, the highest financial barriers to care are for individuals who do not have insurance coverage.

Uninsurance is associated with poor health and increased mortality (Hadley, 2007; Rosenberg, Kroon, Chen, Li, \& Jones, 2014; Wilper et al., 2009). Uninsured individuals are less likely to seek care, particularly preventive services, and are less likely to have a usual source of care (Berdahl, Friedman, McCormick, \& Simpson, 2013; Fox \& Shaw, 2014). When uninsured individuals are sick, they are more likely to delay initiating care, waiting until symptoms worsen. They are also less likely than insured individuals to receive ongoing care per recommendations if they do initiate treatment, and therefore are less likely to have positive health outcomes following treatment (Hadley, 2007).

Furthermore, without a usual source of care, uninsured individuals are more likely to utilize emergency resources, which are more costly than outpatient office visits.

Conversely, health insurance coverage generally results in better health outcomes due to increased use of preventive services, improved continuity of care, and increased follow through with recommended treatment, since insurance assists to alleviate the 
financial burden associated with health care (Bernstein, Chollet, \& Peterson, 2010). Additionally, insurance coverage is associated with higher quality of care because of the procedures covered and the higher likelihood of thorough examination during a provider visit (Hu, Shi, Rane, Zhu, \& Chen, 2014). Medicare, which provides universal coverage for U.S. adults over age 65 , has offered evidence that individuals who have been chronically uninsured prior to receiving coverage demonstrate a significant increase in use of preventive care, such as cancer screenings (McWilliams, Zaslavsky, Meara, \& Ayanian, 2003). Likewise, state-based Children's Health Insurance Programs (CHIP) have demonstrated increased utilization of outpatient and preventive services following program expansion (Haggins, Patrick, Demonner, \& Davis, 2013; Howell, Trenholm, Dubay, Hughes, \& Hill, 2010).

Despite overwhelming evidence that insurance greatly improves access to care and outcomes, affordable health insurance has been limited in the U.S.; group health insurance is frequently tied to the employment benefit structure, and public insurance has required specific eligibility determinations beyond income. This is a critical factor contributing to health disparities; uninsured individuals are more likely to be ethnic and racial minorities, with lower education levels, and of low socioeconomic status (Berdahl et al., 2013; Dalton et al., 2014; Fang et al., 2014; Hadley, 2007). These same demographics are associated with poorer health outcomes (Franks, Muennig, Lubetkin, \& Jia, 2006; Muennig, Franks, Jia, Lubetkin, \& Gold, 2005).

\section{U.S. Health Reform}

Efforts at national health care reform have been aimed to address the fact that the U.S. rates poorly in quality, access, and cost of health care compared to other developed 
countries (Fuchs \& Emanuel, 2005; Oberlander, 2012). In 2009, health care costs rose to consume over 17 percent of the gross domestic product (Hartman, Martin, Lassman, Catlin, \& the National Health Expenditure Accounts, 2014), yet Americans continued to be confronted with barriers to accessing care and experience poor health outcomes. Moreover, the U.S. ranks behind other industrialized countries in measures of healthy lives, quality of care, health care efficiency, equity across population groups, and individual financial access to services (McCarthy, How, Fryer, Radley, \& Schoen, 2011).

Specific attempts at reform have concentrated on the health insurance industry, with the goal to achieve universal coverage within an accountable system. Employersponsored insurance programs began in the early Twentieth Century as a benefit to recruit and retain workers. Meanwhile, public insurance has been offered to targeted vulnerable populations. However, there have consistently been groups of people who have either been ineligible for employer-sponsored insurance or who could not afford the out-of-pocket costs associated with insurance, but who did not qualify for public assistance. More recently, the concept of underinsurance has arisen; individuals with inadequate coverage are at risk of high out-of-pocket expenditures for use of the health care system, which impacts their decisions to utilize services despite enrollment in an insurance plan (Farley, 1985). In 2010, more than 81 million Americans were uninsured or underinsured (McCarthy et al., 2011).

\section{Mental Health Parity}

Historically, health insurance policies have limited access to mental health care by offering less coverage for treatment of mental illness than other medical conditions (SAMHSA, 2013), or by requiring a higher amount of cost-sharing (Barry, Huskamp, \& 
Goldman, 2010). For example, Barry (2004) cites 1998 Medicare statistics in which costsharing for enrollees was 50 percent for mental health services, but only 20 percent for medical and surgical outpatient services. This disparity in coverage has impacted not only treatment for behavioral health following diagnosis, but also screening for common disorders, such as depression and anxiety (Garfield, Lave, \& Donohue, 2010).

However, in the past two decades, the U.S. has presented multiple means of health care reform in an attempt to rectify inadequate access to services through barriers imposed by health insurance. Over time, individual states enacted versions of parity laws, each differing in the specific requirements of insurance plans or diagnoses and populations covered (Barry et al., 2010). At the federal level, Congress passed the Mental Health Parity Act in 1996, which required that annual or lifetime limits imposed on mental health care costs should be no more restrictive than those for medical and surgical benefits. The effect of this law was minimal though, when insurers responded by imposing tighter restrictions on other elements of coverage, such as limiting the total number of inpatient days or outpatient visits allowed, while maintaining compliance with the expense limits (U. S. General Accounting Office, 2000).

President Clinton advocated for mental health parity in 1999, when he directed the Federal Employees Health Benefits Program to include comprehensive coverage for all diagnoses listed in the DSM (Barry et al., 2010). Mental health parity was not actively addressed again until 2008, when Congress passed the Paul Wellstone Mental Health Parity and Addiction Equity Act (MHPAEA) to regulate both treatment limits and financial allowances in benefits covering mental illness and substance abuse. Although MHPAEA is much more comprehensive than its 1996 predecessor, it does not mandate 
mental health benefits for every health insurance plan; the regulations only apply to group insurance plans of 50 employees or more with mental health and substance abuse benefits, and the law did not specify which conditions must be covered (Barry et al., 2010). Despite years of advocacy to increase mental health coverage, barriers to coverage have persisted for most Americans, contributing to a gap between availability of mental health services and the need for care, and an associated trend of increased disability for individuals with mental illness who do not receive care (Mojtabai, 2011).

\section{The Affordable Care Act}

The Patient Protection and Affordable Care Act (ACA) was passed by Congress and signed into U.S. law by President Obama in March 2010, with the primary intent to increase access to quality and affordable health care through health insurance reform. The ACA expands health insurance coverage by mandating individual enrollment, requiring employer provision of benefits, and increasing opportunities for eligibility and financial assistance with health insurance premiums. Additionally, ACA regulates both private and public insurance plans offered in health insurance marketplaces by requiring that each plan offer specified essential health benefits, such as preventive care and mental health and substance abuse treatment. Therefore, even individuals who were previously enrolled in health insurance plans may have gained mental health benefits they did not have prior to ACA implementation. Frank, Beronio, and Glied (2014) estimate that 62 million people experienced increased coverage for care of mental health and substance abuse disorders. 
ACA expands upon the parity requirements of MHPAEA by not only requiring mental health treatment, but also by eliminating lifetime and annual dollar limits to coverage. However, Frank et al. (2014) also point out that because parity only requires mental health and substance abuse benefits to match those offered for medical and surgical benefits, coverage may still not include the long-term needs or full range of evidence-based treatment options for mental health and substance abuse disorders.

\section{Medicaid Expansion}

Medicaid is the largest payer for mental health services (Centers for Medicare and Medicaid Services (CMS), 2015). Enacted with Medicare legislation in 1965, Medicaid provides public assistance with health insurance to vulnerable populations, including people age 65 and older, individuals with disabilities, children, pregnant women, and low-income parents of dependent children. Although it is governed by federal parameters, states have been provided options in implementation, and Medicaid programs vary significantly by state. In 2010, over 57 million people were covered by Medicaid (Henry J. Kaiser Family Foundation, 2015). However, low-income childless adults have always been categorically ineligible for Medicaid coverage.

The ACA provides states with the option to expand Medicaid to include adults with incomes up to 133 percent of the FPL, based on the federally determined Modified Adjusted Gross Income (MAGI) methodology. Unlike traditional Medicaid regulations, eligibility for this coverage is determined by income alone (although there are eligibility regulations regarding citizenship and qualified immigration status that do persist). Additionally, the ACA mandates that state Medicaid plans must meet federally regulated minimum coverage requirements and adjust enrollment procedures to increase 
accessibility. Expanded Medicaid programs receive full federal funding for the first three years of implementation then later require state cost-sharing, but at a lower rate than the established 30 percent for mandatory Medicaid eligibility groups. Since ACA implementation, the U.S. has seen a 16.8 percent increase in Medicaid enrollment (Henry J. Kaiser Family Foundation, 2015).

Experts suggest that with the implementation of the ACA, Medicaid will increase its role in providing coverage for individuals with mental illness (Donohue et al., 2010). Prior to ACA-prompted expansion, it was estimated that as many as 11 percent of individuals eligible for MAGI Medicaid report fair or poor mental health (Bazelon Center for Mental Health Law, 2014). After Massachusetts expanded coverage in 2006, researchers found that residents expressed fewer days in poor physical health, fewer days in poor mental health, and fewer days with health-related functional limitations (Courtemanche \& Zapata, 2014). Initial data in Oregon following Medicaid expansion in 2008 revealed an increase in use of health care services, reduction of self-reported financial strain, and lower depression rates (Baicker et al., 2013). These positive results have given rise to the anticipation of increased use of mental health services and resultant positive health outcomes following Medicaid expansion through ACA implementation.

However, although the impact of health insurance on access to health care is wellestablished, it is merely one factor involved in access; other financial and non-financial factors also impact both access and utilization of health care services (Andersen \& Newman, 1973; Call et al., 2014). Although ACA and MHPAEA have increased the number of individuals who are insured and receive mental health benefits, research suggests that structural and social barriers to treatment may persist, especially in 
communities that already experience significant health disparities (Gelberg, Andersen, \& Leake, 2000; Mojtabai et al., 2011). These barriers potentially mitigate the impact of increased coverage, serving to maintain status quo rather than promoting mental health through use of mental health services. This implies that additional strategies may be required in this community to alleviate mental health disparities.

\section{Proposed Study}

In a recent report on mental health parity and disparities, Mental Health America (MHA) posed the question "Even after getting insurance, can people with mental health needs get access to care?" (Nguyen, 2014, p. 7). This research project contributes to the body of literature that answers MHA's question by assessing mental health service utilization by a disparate population following the implementation of ACA and enrollment of over 138,000 Louisville residents in Medicaid. The results of the study will demonstrate the extent to which beneficiaries of Medicaid expansion have used their new health insurance and report any perceived obstacles that may prevent service utilization. Additionally, the results of this study will provide evidence and understanding of specific community needs to inform recommendations for effective policies and strategies for the improvement of local community mental health.

\section{Purpose of the Study}

A major aim of ACA is to increase use of services by requiring insurance coverage, thus reducing undiagnosed and untreated conditions (Dixon \& Hertelendy, 2014). Together ACA and MHPAEA are designed to offer financial protection through expanded insurance coverage and improved insurance content, thereby increasing the number of individuals who can access mental health treatment through their health 
insurance plans. Kentucky has consistently ranked in the bottom 10 percent of national health metrics, including $50^{\text {th }}$ for poor mental health days (United Health Foundation, 2014). Additionally, 20.4 percent of Kentucky residents were uninsured when ACA passed. Recognizing this, in 2013, under KRS 205.520 ("Medical Assistance Act," 2005), Kentucky Governor Steven Beshear capitalized on the provisions of ACA by expanding Medicaid to use the MAGI methodology. Just prior to that, in 2011, Kentucky Medicaid expanded managed care coverage throughout the state using contracted agencies, and in 2012, Governor Beshear issued an executive order to create a state-run health benefits exchange. These new policies have altered the landscape of Kentucky health care. Jefferson County, which encompasses Louisville, is uniquely positioned as Kentucky's largest and most diverse urban environment, with plentiful health resources and yet documented disparity within the community (Crutcher, 2013; Greater Louisville Project, 2013). According to 2010 Medicaid billing data, 33,348 adults in Jefferson County, Kentucky, were identified with a diagnosis of mental illness (M. T. Childress, 2012). However, a recent report issued by MHA estimates that only 45.6 percent of any adults with mental illness in Kentucky receive treatment (Nguyen, 2014). Specifically, residents of the nine neighborhoods considered Louisville's West End (Crutcher, 2013; see Figure 1): Algonquin, California, Chickasaw, Park DuValle, Park Hill, Parkland, Portland, Russell, and Shawnee, present higher rates of morbidity and mortality than other neighborhoods within the county, as well as discrepancies in the social determinants of health (Greater Louisville Project, 2013). Residents of West Louisville, the majority of whom are Black, are more likely to be unemployed and are less likely to have a college education than East Louisville neighborhoods, and the 
median income is less than half in the West End than it is in the East End (Crutcher, 2013). Moreover, there are fewer hospitals, health care providers, and pharmacies on record in West Louisville than there are in East Louisville (Crutcher, 2013). Both racial disparities and low socio-economic status are risk factors for poor mental health and an unmet need for mental health treatment (Brown, Schulberg, \& Madonia, 1996; Kessler \& Neighbors, 1986).

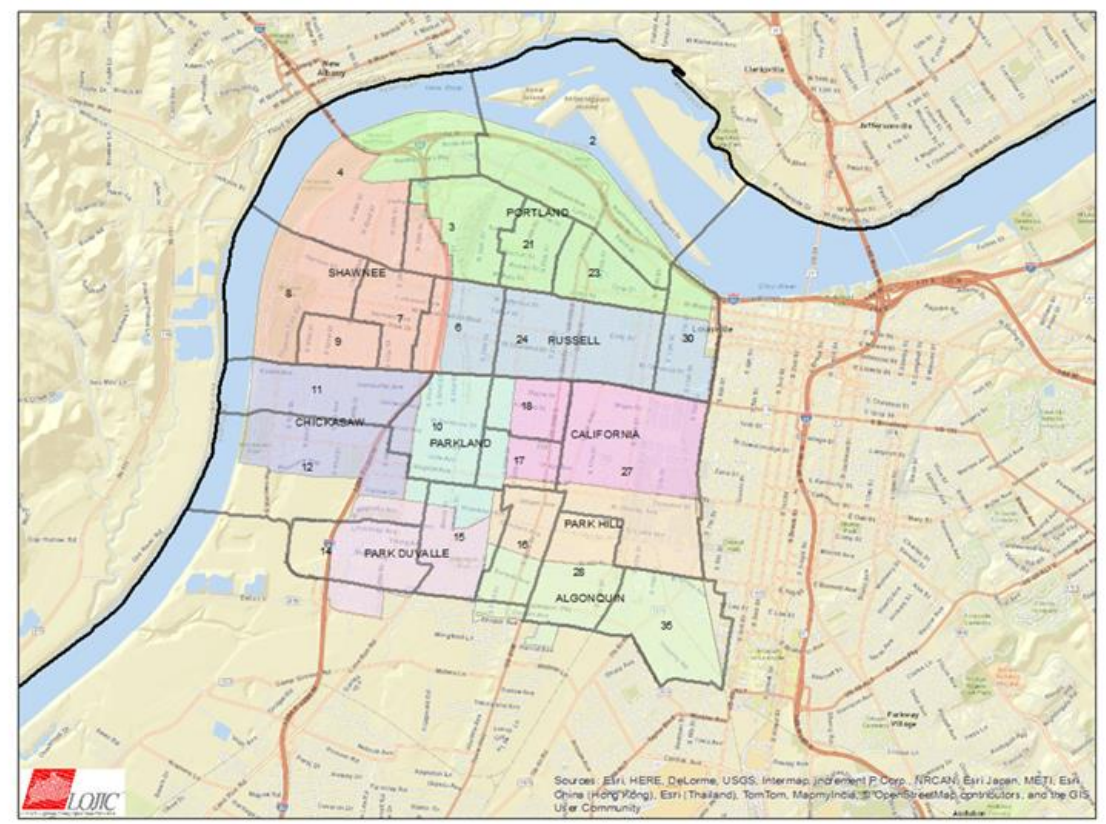

Figure 1. West Louisville neighborhoods (LOJIC, 2015).

This study seeks to answer two research questions:

Research Question 1: How does Medicaid expansion through ACA impact utilization of mental health services for residents of West Louisville neighborhoods?

Research Question 2: What factors besides health insurance impact utilization of mental health care?

The purpose of this research is to inform public health policy and practice. The implementation of the ACA and Medicaid expansion may have differential effects on 
varying subpopulations, and thus requires examination and feedback to refine the system. As the local community creates policies, implements health literacy programs, and expends resources, it is imperative to target persisting barriers to utilization of health care services as well as to improve inequities. Specifically, additional interventions may be needed to assist low-income Black populations like West Louisville in benefitting from increased coverage.

Since research indicates that individuals who do not receive intervention by mental health professionals are more likely to experience increased disability as symptoms impair function to a greater extent over time (Mojtabai, 2011), the long-term health outcomes of the community depend on public health interventions to reduce the unmet need for mental health care. This study will determine the extent to which ACA implementation and Medicaid expansion have impacted use of mental health services in the West Louisville population, what other factors or unintended consequences of the new law play a role in service use for this population, and how additional policies and strategies can be applied to increase service use and positively impact health outcomes in the future.

\section{Operational Definitions}

This study focuses on adults with "any mental illness" (AMI) as defined by SAMHSA as "having a diagnosable mental, behavioral, or emotional disorder in the past year that met DSM criteria," excluding developmental or substance abuse disorders (SAMHSA, 2014b), p.5). The intention of this study is to specifically capture how Medicaid expansion has impacted use of mental health services. Under traditional Medicaid, individuals would only qualify for coverage if their diagnosis indicated 
disability. However, many individuals with mental health needs do not experience a disabling illness, and therefore would not have qualified for coverage prior to Medicaid expansion. Additionally, use of the definition of AMI in this study will enable the examination of mental health services used by individuals whose primary diagnosis may be physical illness, but who may also receive treatment for comorbid indicators of mental illness.

As noted, the SAMHSA definition of AMI does not include developmental disabilities nor substance abuse. According to the International Statistical Classification of Diseases and Related Health Problems, tenth revision (ICD-10), developmental disorders include disorders of psychological development, such as those of speech and language and scholastic skills and pervasive developmental disorders (WHO, 1993). Furthermore, Medicaid benefits for substance abuse were introduced with the implementation of ACA in 2014; unlike evaluation and treatment for other behavioral health disorders, evaluation and treatment for substance abuse disorders is not part of the control group dataset (pre-ACA), and should be examined distinctly from services that were covered both before and after ACA implementation.

In addition to using the SAMSHA definition of AMI, this study excludes additional diagnoses due to the Medicaid payment structure in Kentucky. Individuals with organic and traumatic brain injury and intellectual and developmental disabilities are eligible for Medicaid through Kentucky Medicaid waiver programs. Medicaid waiver claims are not processed through Managed Care Organizations (MCOs) like all other Kentucky Medicaid claims, and therefore are not included in the dataset for this study. Additionally, Medicaid expansion is available only to adults ages 18 through 64 . 
Therefore, in this study, "mental illness" excludes dementia since this diagnosis is most prevalent in the older adult population eligible for Medicare, and may or may not be also eligible for Medicaid. Likewise, the definition of mental illness excludes behavioral and emotional disorders with onset typically occurring in childhood and adolescence, such as separation anxiety disorder and academic underachievement disorder, since these diagnoses should not occur in individuals over 18. 


\section{CHAPTER II}

\section{REVIEW OF THE LITERATURE}

\section{Introduction}

Although mental health is an integral component of overall health status, it has historically been treated, insured, and studied independently of physical health (Davidson, Judd, Jolley, Hocking, \& Thompson, 2000; SAMHSA, 2013). This distinction has played a role in the stigmatization of mental health care and the health disparities of individuals who experience mental illness (Corrigan, Druss, \& Perlick, 2014). Since the diagnosis of mental illness depends on self-report of symptoms, access to, and use of mental health care (Frank \& Glied, 2006; Kapur et al., 2012), the prevalence of mental illness is difficult to measure reliably. However, it is generally accepted that mental illness in the United States (U.S.) is under-reported and under-diagnosed (Takayanagi et al., 2014), but is a leading cause of disability and health care costs even so (Center for Behavioral Health Statistics and Quality, 2015; Mark et al., 2011; WHO, 2004b).

Within the known numbers of AMI, prevalence spans the lifetime and rates vary among racial and ethnic groups. But sources note that poverty is substantially linked with mental illness, regardless of gender and race/ethnicity (Bruce et al., 1991; Frank \& Glied, 2006; WHO, 2014). 
Disparities exist across socioeconomic status; however, literature suggests that the disparity is in access to care rather than the risk of a mental illness (Chen \& Rizzo, 2010; Le Cook et al., 2013). In fact, prior research on access and utilization of mental health services has found that cost of care, specifically due to lack of health insurance, has been the most prohibitive factor for those seeking services (Rowan, McAlpine, \& Blewett, 2013). Yet there are also non-cost barriers to mental health care (Mojtabai et al., 2011). Understanding exactly which barriers impact a particular population is important because with adequate treatment, individuals with mental illness can lead productive and fulfilling lives.

The ACA, enacted in 2010 and fully implemented in 2014, presents new opportunities for access to treatment of mental illness because of the law's provisions for increasing rates of insurance and including mental health parity in insurance plans. Yet state policies prior to ACA that addressed uninsurance rates have not reduced health disparities (Amri, Stronks, Bordeianou, Sylla, \& Berger, 2014). Furthermore, the ACA does not address any persisting non-cost threats to health care access.

Kentucky has impressed the nation by embracing the ACA's provisions for a state-run health benefit exchange and Medicaid expansion while citing Kentucky's trend of poor health outcomes. This includes the fact that 19.5 percent of Kentucky adults present with AMI, nearly a point higher than national average (Nguyen, 2014), and Kentuckians rank $50^{\text {th }}$ nationally in poor mental health days (Kentucky Department for Public Health, 2013). Furthermore, statistics also reveal that only 45.6 percent of adults in Kentucky with AMI receive treatment (Nguyen, 2014). Two years post-ACA implementation, Jefferson County, Kentucky, boasts 170,624 newly insured individuals, 
138,572 of whom have enrolled in Medicaid coverage due to low-income (Kentucky Office of Health Benefit and Health Information Exchange (KOHBHIE), 2016). By examining Medicaid claims data, this study provides an opportunity to understand the impact that ACA has had on use of mental health services within a disparate population in Jefferson County. Additionally, the qualitative aspect of this study aids in identifying non-cost barriers to utilization and contributes a foundation for expansion on local policies that provide access to needed mental health care.

\section{Epidemiology of Mental Health}

The prevalence of mental illness is substantial; nearly one-fifth of American adults have experienced mental illness within the past year, and nearly half of Americans will experience a mental illness over the course of his or her lifetime (Center for Behavioral Health Statistics and Quality, 2015; Kessler, Berglund, et al., 2005). The epidemiology of mental health is difficult to define, and it is recognized that most counts are not accurate. Measures of individuals with mental illness have varied due to three sets of metrics: symptoms and signs of disorders defined by the DSM; mental health-related difficulties with functioning (typically self-reported); and consumers of health services who have received treatment for a mental health condition. It is well-documented that the number of consumers of mental health services does not consistently match the number

of individuals diagnosed with mental illness (Druss et al., 2007; Gonzalez et al., 2008). Furthermore, within the counts of mental illness, prevalence may be divided into classifications of any mental illness, serious mental illness (SMI), mental illness including or not including substance abuse disorders, or specific diagnoses or classes of 
mental illness. Most recent epidemiology reports of specific diagnoses are based on criteria within the DSM-IV-TR, which was issued in 2000; DSM-5 was issued in 2013.

Commonly used data sources to estimate the prevalence of adults with diagnosable mental illness include the National Survey on Drug Use and Health (NSDUH) by SAMHSA, the National Comorbidity Survey Replication (NCS-R), and the National Epidemiologic Survey on Alcohol and Related Conditions (NESARC) by the National Institute on Alcohol Abuse and Alcoholism. The NSDUH is conducted annually, and consists of in-home interviews of approximately 45,000 American adults (Bagalman \& Napili, 2014). The NCS-R was conducted February 2001 to April 2003 as a survey of 9,000 adults regarding "any mental illness," which was defined as 19 specific diagnoses (Kessler et al., 2004). Although sometimes analyzed independently, NCS-R data are also pooled with that of the National Latino and Asian American Study (NLAAS) and the National Survey of American Life (NSAL), to form the Collaborative Psychiatric Epidemiology Surveys (CEPS) (Inter-university Consortium for Political and Social Research, n. d.). The NESARC was conducted in two waves from 2001 to 2002 and 2004 to 2005 through face-to-face, computer-assisted personal interviews of over 43,000 participants (Grant \& Dawson, n. d.). While each of these large surveys is targeted specifically to address questions regarding mental illness, they all exclude individuals who are homeless or institutionalized, military personnel on active duty, and non-English speaking individuals. Removing these vulnerable populations from the survey suggests that the prevalence of mental illness is underestimated.

Mechanisms for the surveillance of mental illness also include the use of screening instruments or questions regarding mental illness within larger population 
health surveys. For example, the Patient Health Questionnaire (PHQ-8 or PHQ-9), which detects symptoms of depression (Kroenke, Spitzer, \& Williams, 2001), and the Kessler-6 psychological distress scale (Kessler et al., 2003) have been used as modules within the Medical Expenditure Panel Survey (MEPS) administered by the Agency for Healthcare Research and Quality (AHRQ) (AHRQ, 2016), and the Behavioral Risk Factor Surveillance Survey (BRFSS), the National Health Interview Survey (NHIS), and the National Health and Nutrition Examination Survey (NHANES), all of which are conducted routinely by the CDC (CDC, 2016a, 2016b, 2016c). Other times, surveys such as BRFSS and NHANES address "mentally unhealthy days" by asking respondents to consider the numbers of days during the past 30 in which their mental health was not good. Population surveys can be complimented with administrative data from provider surveys, which report diagnosis codes and treatment codes that reflect diagnosed mental illness and use of services, and may capture some of the subpopulations that are excluded in population surveys. Additionally, SAMHSA sponsors an annual survey of mental health care facilities, which includes data on the use of mental health treatment (Center for Behavioral Health Statistics and Quality, 2014).

Using NHIS data from 1999 through 2010, Rowan et al. (2013) examined a rise in the percentage of adults ages 18 to 64 with moderate mental health problems and in the percentage of individuals with SMI. Most recently, SAMHSA concluded that according to 2013 NSDUH data, the 12-month prevalence of AMI excluding substance use disorders is 18.5 percent among American adults (2014a). This estimate includes 10 million adults with SMI, which equates to 4.2 percent of the U.S. population (SAMHSA, 2014a). Analysis of NCS-R data indicates that the 12-month prevalence of AMI 
including substance abuse disorders is 24.8 percent (Kessler, Chiu, Demler, Merikangas, \& Walters, 2005), and lifetime prevalence is 46.4 percent (Kessler, Berglund, et al., 2005). Of those diagnosed, 45 percent of individuals have two or more diagnosable conditions (Kessler, Chiu, et al., 2005), and adults with SMI represent as many as 5.8 percent of the population (Druss et al., 2009). These survey findings are echoed in BRFSS data, in which 40 percent of respondents indicate serious psychological distress (CDC, 2011), and the total population averages 3.5 poor mental health days within the past 30 (Reeves et al., 2011). Furthermore, NSDUH data provide evidence that 3.9 percent of Americans reported experiencing suicidal thoughts within the past year, and 0.6 percent of the population attempted suicide (SAMHSA, 2014a).

A lack of uniformity and accuracy among the myriad of surveys and data sources regarding mental illness impacts the knowledge base by which the magnitude of disease is reported. Prevalence rates have been measured and reported differently, both by data sources and according to varied definitions of mental illness. It is therefore difficult to define the extent of mental illness as a public health problem with precision. Even using conservative estimates, however, it is clear that mental illness is a significant public health issues in the U.S.

\section{Distribution of Disease}

The existing body of literature contains prevalence rates and distributions for some classes and sub-types of mental illness, but not others. Internationally, public health interventions have focused on anxiety disorders, depression and depressive symptomatology, conduct disorders and violence, eating disorders, and suicide prevention (WHO, 2004a). The U.S. Preventive Services Task Force has identified that 
depression, substance abuse, and suicide are the most imperative mental health issues for targeted screenings (U.S. Preventive Services Task Force, 2016). Therefore, this literature review highlights only a few of the many disorders listed in the DSM while following the operational definition of AMI for this study.

Anxiety disorders have been identified as the most prevalent group of mental illness in U.S., with a 12-month prevalence of 18.1 percent and a lifetime prevalence of 28.8 percent (Kessler, Berglund, et al., 2005; Kessler, Chiu, et al., 2005; Martins et al., 2012). Anxiety disorders are frequently comorbid with physical and other mental health conditions, and may increase days in which a person experiences disability or poor health-related quality of life (Anesetti-Rothermel \& Sambamoorthi, 2011). Prevalence estimates reflect that women experience anxiety disorders at a higher rate than men (McLean, Asnaani, Litz, \& Hofmann, 2011). Although there is no consistent association between race/ethnicity and anxiety, post-traumatic stress disorder (PTSD) stands out with substantial differences between racial and ethnic groups in terms of lifetime prevalence, in which Blacks present with conditionally higher risk for the disorder than Whites, Latinos or Hispanics, or Asians (Alegria et al., 2013; Asnaani, Richey, Dimaite, Hinton, \& Hofmann, 2010; Roberts, Gilman, Breslau, Breslau, \& Koenen, 2011).

Although the 12-month prevalence of mood disorders is cited as 9.5 percent (Kessler, Berglund, et al., 2005), one mood disorder-major depression disorder-is reported as a leading cause of disability placing significant burden on society with a lifetime prevalence of 16.6 percent (Kessler, 2012; Kessler, Berglund, et al., 2005). Furthermore, major depressive episodes have been reported as the most prevalent lifetime syndrome (Kessler, Petukhova, Sampson, Zaslavsky, \& Wittchen, 2012) and linked to 
increased substance use (SAMHSA, 2014a). Interestingly, men and women report different symptoms of depression, which may impact an individual's acknowledgement of symptoms and ultimate detection of a disorder (Martin, Neighbors, \& Griffith, 2013). Both anxiety disorders and mood disorders are estimated to have higher prevalence rates in adults ages 18 through 64 than either children and adolescents or older adults (Kessler et al., 2012).

Impulse control disorders, which include conduct disorders, have a 12-month prevalence of 8.9 percent and a lifetime prevalence of 24.8 percent (Kessler, Berglund, et al., 2005; Kessler, Chiu, et al., 2005). They have not been found to have significantly different prevalence rates among race/ethnicity (Breslau et al., 2006), but are generally more common in men (Kessler et al., 2006). Impulse control disorders are highly correlated with substance dependence (Glantz et al., 2009).

Eating disorders are relatively less common than other disorders. The lifetime prevalence rate for each of the recognized eating disorders is less than four percent (Hudson, Hiripi, Pope, \& Kessler, 2007). However, despite a lifetime prevalence rate of 0.9 percent in women and 0.3 percent in men, anorexia nervosa was once associated with the highest mortality rate for a mental disorder (Harris \& Barraclough, 1998; Hudson et al., 2007). Eating disorders are more often diagnosed in women than in men and are commonly comorbid with other psychiatric disorders (Hudson et al., 2007).

\section{Disparities by Income and Race/Ethnicity}

Beyond the distribution of individual diagnoses, there is variation among racial and ethnic groups in U.S. population in the prevalence of AMI. Individuals who identify with two or more races are noted to experience both AMI and SMI at higher rates than 
individuals of one race/ethnicity (SAMHSA, 2014a). Table 2 illustrates the annual average percentage of AMI in the past year among adults, listed by race/ethnicity. Although the rates for each group are much smaller, there is similar variation in the racial/ethnic distribution among adults who have co-occurring mental illness and substance abuse disorders (SAMHSA, 2014a)

Table 1

Any mental illness in the past year among adults, by racelethnicity, 2008-2012, Annual average percentage (SAMHSA, 2015)

\begin{tabular}{ccccccc}
\hline $\begin{array}{c}\text { U.S. } \\
\text { Population }\end{array}$ & White & Black & $\begin{array}{c}\text { American } \\
\text { Indian or } \\
\text { Alaska } \\
\text { Native }\end{array}$ & Asian & $\begin{array}{c}\text { Two or } \\
\text { More } \\
\text { Races }\end{array}$ & Hispanic \\
\hline 18.5 & 19 & 16.8 & 22.7 & 13.4 & 24.9 & 15.3 \\
\hline
\end{tabular}

Though mental illness can impact any person, regardless of race/ethnicity, income, or education, research suggests a direct relationship between mental illness and social and economic disadvantage (Bruce et al., 1991; Hudson, 2005; Martins et al., 2012). In fact, in 2013, AMI was higher for individuals who were unemployed or employed part-time than for those employed full-time, and was highest in individuals whose income was below the FPL (SAMHSA, 2014a). The rate of AMI was also higher for adults on Medicaid than for individuals covered by private insurance plans (SAMHSA, 2014a).

Kessler and Neighbors (1986) concluded that race/ethnicity and income are interactive in predicting psychological distress, which the authors measured through the 
presentation of depressed mood and somatic indicators of anxiety and depression. Their analysis displayed larger differences in mental health between low-income White and Black adults than those with higher incomes. Breslau and colleagues (2005) examined the differences in lifetime prevalence and the chronic nature of anxiety and mood disorders between racial and ethnic groups. They identified that although Blacks have lower lifetime prevalence than Whites in both mood disorders and anxiety disorders, Black individuals are more likely to experience persistent mental illness longer than two years. A second study specified that lower lifetime risk of mental illness among Blacks begins in childhood and a lower lifetime risk is more pronounced among individuals with lower levels of education (Breslau et al., 2006).

\section{Utilization of Mental Health Services}

Mental health treatment has become more accessible over time. In the midTwentieth Century, individuals requiring psychiatric treatment received care from specialists within an inpatient institution. However, treatment today occurs in general hospitals, nursing homes, and schools in addition to community mental health centers (CMHCs) and specialized outpatient mental health clinics. The capacity for service has expanded to specialty-trained psychiatrists, psychologists, advance practice mental health nurses, counselors, and social workers. Nationally, the average workforce availability of mental health providers is one mental health provider for 790 residents; the states with highest access have workforce availability ratio of one provider for less than 350 residents (Nguyen, 2014). Additionally, people with chronic conditions, including depression and anxiety, utilize primary care providers for treatment more than specialty services (Hofer, Abraham, \& Moscovice, 2011). In fact, mental health care has become 
common enough that it is estimated that primary care practitioners prescribe more psychotropic drugs than psychiatrists (Barry, 2004).

Even still, only an estimated 40 to 45 percent of American adults with AMI utilize services (Nguyen, 2014; SAMHSA, 2014a), and 19.3 percent of adults with AMI perceive an unmet need for mental health care (SAMHSA, 2014a). McAlpine and Mechanic (2000) used 1997-1998 data from the Healthcare for Communities Study, in which respondents answered screening questions regarding mental health status and utilization of outpatient specialty mental health care, emergency services, inpatient stays, and use of primary care. Their analysis indicated that people with SMI use the health care system twice as much as people with other mental disorders, and 20 times more than people with no mental illness disorders. However, 60 percent of respondents who indicated symptoms of SMI did not receive needed care. The authors also found that any insurance increases use of specialty care, as does the perceived need for care.

When Eisenberg, Hunt, Speer, and Zivin (2011) examined use of mental health services more closely, they found that 21.8 percent of their sample used either psychotropic medication or counseling, although 80.1 percent visited a health provider for any reason. Furthermore, only 17 percent of individuals who had discussed medication use with a provider followed through to take the medication, and more than two-thirds of individuals reported non-clinical counseling or support. These studies indicate that mental health services are underutilized, such that a large portion of the population does not receive needed care. 


\section{Impact of Health Insurance on Access and Utilization}

The premise of the ACA is to reduce the national uninsurance rate of nearly 18 percent in order to increase access to care, and ultimately to positively impact long-term health outcomes (Kaiser Commission on Medicaid and the Uninsured, 2013). Access to health care has been measured through a variety of metrics, including the ability to identify a routine source of care other than an emergency department, unmet care needs, or delays in care (Clemans-Cope, Long, Coughlin, Yemane, \& Resnick, 2013; Kenney, McMorrow, Zuckerman, \& Goin, 2012), while use of health care can be assessed by inpatient care, outpatient and emergency department visits, and prescription drug fills (Clemans-Cope et al., 2013). The first decade of the new millennium, just prior to ACA enactment, displayed an increasing trend of non-elderly adults experiencing declines in access to health care because of both cost and non-cost factors (Clemans-Cope et al., 2013).

Cost has been identified as the largest barrier to accessing health care services (Call et al., 2014), but one that can be reduced through health insurance coverage. A review of the literature supports the premise that health insurance coverage is linked to increased access and utilization of health care services, particularly primary care (Hofer et al., 2011; Kenney et al., 2012). Research has also found that the lack of health insurance may increase the risk of mortality by 40 percent (Wilper et al., 2009). Among individuals experiencing a moderate mental health problem, individuals without insurance report cost as a barrier to care nearly twice as often as individuals with private insurance, and 2.5 times as often as individuals on public insurance plans (Rowan et al., 2013). 
The effect of insurance may vary across the population and within communities, because health care utilization depends on characteristics of the coverage offered, including cost-sharing, patient requirements, availability of providers, and managed care practices (Buchmueller, Grumbach, Kronick, \& Kahn, 2005). Studies therefore tend to compare public insurance, such as Medicare or Medicaid, to private insurance options and uninsurance. For example, Buchmueller et al. (2005) reviewed the literature to broadly conclude that Medicaid beneficiaries are more likely to use general outpatient services, preventive care, and reactive ambulatory care than individuals with private insurance. Their findings are due in part to the tendency of Medicaid consumers to present with poor health status and the requirement of cost-sharing by private plans. Similarly, Medicaid beneficiaries use health care services more than individuals who are uninsured, and are less likely to report an unmet need for care. This has been demonstrated through the Household Component of the MEPS, which has been a source for the examination of differences between health outcomes of consumers with Medicaid coverage and individuals who are uninsured (Clemans-Cope et al., 2013).

Although health insurance generally is associated with increased access, the interaction of health insurance and the health care system results in a variation in care options for some consumers, particularly for those insured through Medicaid. Primary care providers have lamented the burden of caring for the Medicaid population due to low reimbursement rates (compared to Medicare); administrative complexities of claims processing and delays in reimbursement; complexity of Medicaid patients' problems, including behavioral health issues and social service needs; and limited referral options to specialists and behavioral health services (Long, 2013). If the burden of providing 
services outweighs the benefits and causes providers to limit their participation in Medicaid, consumer utilization of services will also decline due to the inability of the health care workforce to meet the demand for services (Perloff, Kletke, \& Fossett, 1995; Perloff, Kletke, Fossett, \& Banks, 1997).

There is a strong link between health insurance and health outcomes, presumably due to the impact that health insurance has on the personal financial burden of obtaining services, and the access to health care that coverage provides. However, Medicaid benefits differ from those of other insurance plans, and the characteristics of Medicaid beneficiaries, including their risk factors for illness, differ from individuals using the private market. Therefore, an increase of health insurance coverage among Americans by the ACA and Medicaid expansion may have varying effects on access to and utilization of health care services.

\section{Factors Influencing Use of Mental Health Services}

Use of health care is not influenced merely by health insurance; indeed, many factors impact an individual's health behavior. Andersen and Newman (1973) present a framework of factors associated with utilization of health care, which includes social, systemic, and individual factors (see Figure 2). The authors expand the list of influencing factors at every level, but emphasize that each aspect of this triad of factors holds equal weight in the context of health service utilization. Although provisions of ACA reduce systemic factors of uninsurance (and hence the financial burden of care) and mental health provider networks (adding theoretical resources to the health services system), the law does not address social and individual determinants. Non-cost factors, such as the inability to schedule an appointment during open office hours, long waits for 
appointments, poor health insurance and health system literacy, and limitations in transportation or childcare also impact health care utilization (Call et al., 2014; Kenney et al., 2012). Furthermore, the historical sensitivity, stigma, and differentiation of mental health from physical health results in the need to examine factors specifically influencing mental health service utilization.

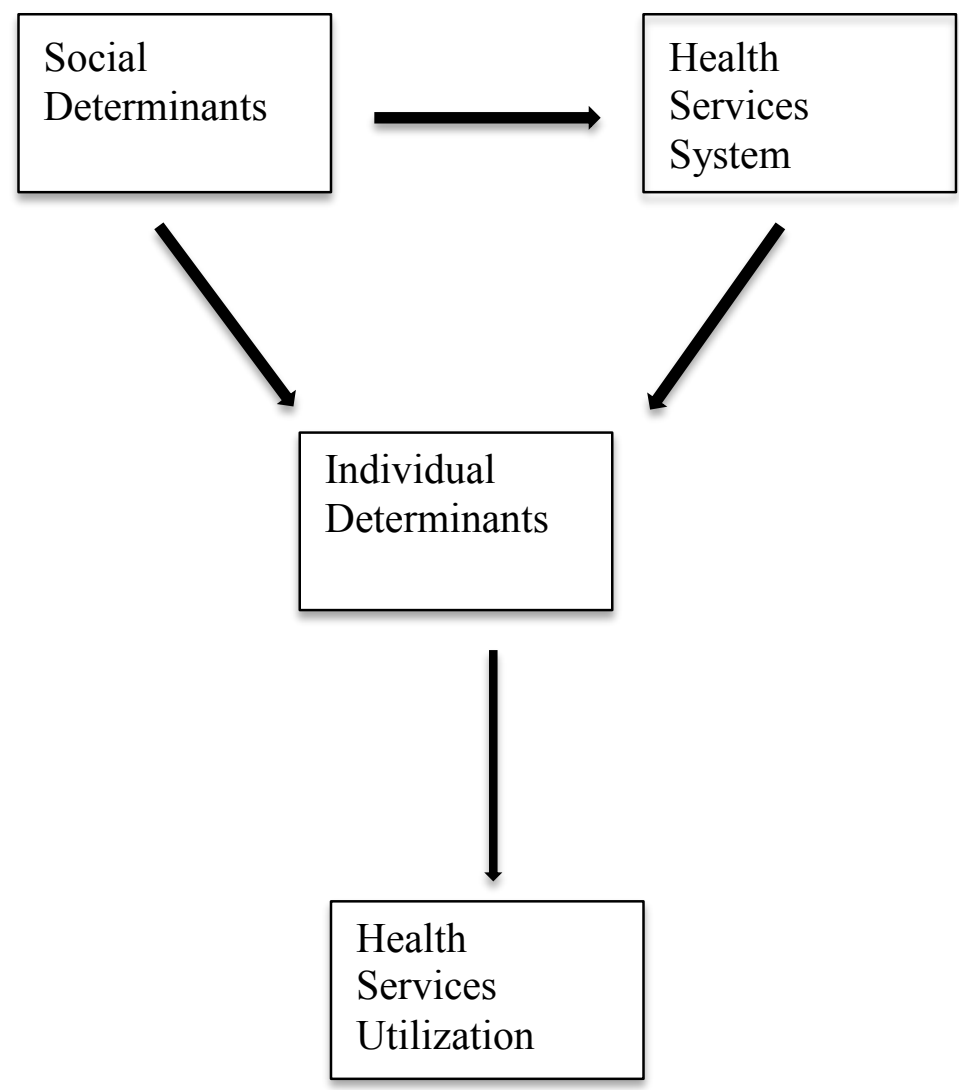

Figure 2. Framework for viewing health services utilization (Anderson \& Newman, 1973).

As with physical health services, cost has appeared as the largest barrier to use of mental health services, and unmet need persists nationally (Center for Behavioral Health Statistics and Quality, 2015; Mojtabai et al., 2011). However, only cost and barriers associated with poverty, such as a lack of transportation, distance, or office hours that 
might cause a person to lose pay from work have been significantly different for individuals with and without insurance (Alegria et al., 2008; Mojtabai et al., 2014), except in terms of medication adherence, whereby individuals on public insurance are more likely to discontinue use of psychotropic medication (Hodgkin, Volpe-Vartanian, \& Alegria, 2007). Of those covered by public insurance, the movement to managed care has not made a difference in use of mental health services when compared to fee-for-service programs (Bigelow, McFarland, MCCamant, Deck, \& Gabriel, 2004).

Beyond cost, other structural barriers influence an individual's access to and use of mental health services. Thomas, Ellis, Konrad, Holzer, and Morrissey (2009) found that nationally, nearly one in five counties has an unmet need for mental health professionals. The availability and convenience of mental health care, transportation, and childcare can facilitate utilization of services (Mojtabai et al., 2014; Mojtabai et al., 2011). Medication adherence may be driven by adverse drug reactions or efficacy, long wait times for prescription fills, or the complexity of the medication regiment (Laba, Essue, Kimman, \& Jan, 2015; Lucca, Ramesh, Parthasarathi, \& Ram, 2015; Wheeler, Roberts, \& Neiheisel, 2014).

Individual perceptions, health literacy, and personal skills can impact use of mental health services. Low health literacy and education can result not only in misperceptions or ignorance about community treatment resources, but also impacts the ability to recognize symptoms of mental illness (Alegria et al., 2008). Thus, individuals may not associate stress with depression or anxiety, or may doubt the existence of a mental illness, and thus report a lower perceived need for care (Abrams, Dornig, \& Curran, 2009; Mojtabai et al., 2011). In fact, results of the NCS-R suggest that as many 
as one-third of individuals who receive treatment do not perceive they need care (Druss et al., 2007). Low health literacy and education additionally influence one's understanding of insurance benefits or navigating the health care system (Eisenberg et al., 2011; Mesidor, Gidugu, Rogers, Kash-MacDonald, \& Boardman, 2011). Results of the NSDUH suggest that many consumers simply do not know where to go for services (SAMHSA, 2014a). Furthermore, symptoms of mental illness can interfere in one's cognitive abilities for planning, scheduling, and following through with appointments or prescriptions (Lucca et al., 2015; Mesidor et al., 2011; Trivedi, 2006). These complexities may inhibit individuals from connecting with needed services.

Barriers to treatment also include stigma and discrimination, whether real or perceived, such as worry and embarrassment regarding what others would think in the event that mental health services were used (Barry, 2004; Byers, Arean, \& Yaffe, 2012). Individuals may fear being hospitalized for mental illness or being forced to take medications or go to the hospital because of a cultural perception that a person should be able to handle problems on one's own (Bryant, Greer-Williams, Willis, \& Hartwig, 2013; Mojtabai et al., 2014; Sareen et al., 2007). Additionally, individuals have expressed beliefs about treatment effectiveness or a mistrust of providers that impact their willingness to seek care (Alegria et al., 2008; Byers et al., 2012; Eisenberg et al., 2011). Although the majority of individuals who use mental health services do seek treatment without urging from others (Druss et al., 2007), social networks can facilitate use of services through trusted relationships and friends or family who can attest to the benefits of mental health treatment (Eisenberg et al., 2011). In a qualitative study of primary care providers and administrators, Chung et al. (2012) cited the provider-patient 
relationship as key factors influencing mental health treatment. Integration of mental health and primary care services also promotes use of mental health services, especially when co-location of providers results in a personal introduction by the referring provider (Horevitz, Organista, \& Arean, 2015). Likewise, a significant other can positively influence the use of mental health services; despite a high prevalence of non-use overall in adults over 55 year old, having a partner increased an individual's motivation to seek professional help (Byers et al., 2012). Support from family members is also associated with higher medication adherence (Ramirez Garcia, Chang, Young, Lopez, \& Jenkins, 2006).

Two qualitative studies examine clinicians' and health care administrators' perceptions of consumers' barriers to mental health treatment, reinforcing findings from other studies. Of note, clinicians and administrators observed stigma-related patient resistance, symptom-related difficulties such as planning or denial, transportation limitations, and financial barriers to patient participation in a mental health care plan (Chung et al., 2012; Mesidor et al., 2011). However, systemic and service delivery issues also serve as obstacles to consumers' ability to utilize mental health services. Chung et al. (2012) found that provider referral options, reimbursement issues, and education constrained primary care providers' ability to appropriately assist patients with their mental health care needs. After interviewing providers in a mental health care setting, Mesidor et al. (2011) reported that mental health budget cuts and provider competency influence an organization's ability to meet comprehensive patient needs. Both studies reported that clinicians may be faced with time limitations that prohibit them from 
adequately meeting patient needs, and that organizations face challenges in serving a diverse range of consumers because few providers are fluent in foreign languages.

The utilization of mental health services is not only influenced by cost, but also by social and individual determinants, and availability of services within the health care system. Although health insurance reduces the financial burden of health care, other factors remain and continue to limit an individual's use of mental health care. Barriers and facilitators may be unique to a community, and individuals of low socioeconomic status often encounter more barriers and unmet need.

\section{Affordable Care Act Outcomes Studies}

ACA was signed into law in March 2010 and has been implemented in stages. The elements of the law with the greatest impact on increased health insurance coverage were not fully implemented until January 1, 2014. Therefore, outcome studies examining the impact of ACA on access, utilization, and health outcomes are still in the early stages.

Since September 2010, young adults ages 19 through 25 have been able to retain coverage under their parents' private health insurance plans. Considering that this group is relatively healthy, Mulcahy et al. (2013) used data from emergency department claims for serious conditions from 2009 through 2011 to determine the rate of change in insurance coverage after the law went into effect. They compared the group of young adults to adults ages 26 through 31, who had not yet benefitted from ACA provisions. Their research found that private insurance paid for more emergency department visits and the percentage of uninsured visits fell significantly for the younger adults. These results indicate that the dependent coverage provision under ACA did in fact have a positive impact on insurance coverage for young adults, offering more financial 
protection to this group.

\section{Medicaid Expansion Outcomes Studies}

Medicaid is the largest single payer for mental health services, covering more than 20 percent of national spending on all mental health services (Barry, 2004). The ACA gives states the option to expand Medicaid to individuals at or below 138 percent of the FPL, which means that the number of individuals eligible for mental health benefits will also grow. Several states expanded Medicaid prior to ACA and have been able to examine outcomes over time. Other states expanded Medicaid as soon as ACA was implemented and now have several years of experience on which to reflect.

Most notably, Oregon devised a lottery system for 10,000 additional Medicaid spots in 2000. Following implementation, Allen, Baicker, Finkelstein, Taubman, and Wright (2010) completed mail and telephone surveys, in-person interviews, and health screenings to describe the population of new enrollees following Oregon Medicaid expansion and some of the difficulties of the expansion process. Applicants for health insurance were older and likely to report fair or poor health. Survey results revealed consumer confusion regarding income eligibility for coverage. As many as 10 percent of surveys were returned due to bad addresses, revealing the difficulty communicating with the population. Baicker et al. (2013) completed a quasi-experimental study of over 12,000 Oregon residents to compare participants in Medicaid expansion with individuals who were placed on the waiting list. Medicaid coverage was linked to a reduction in financial strain from medical expenses, as well as an increase in use of office visits and medications. Additionally, individuals with Medicaid coverage received more preventive 
care and screening, resulting in an increase in the diagnosis of depression for that group. However, improvements in health outcomes were not detectible after two years.

Outside of Oregon, Sommers, Baicker, and Epstein (2012) explored the results of Medicaid expansion in New York, Maine, and Arizona, comparing mortality rates with neighboring non-expansion states. Their findings indicate that over five years, Medicaid expansion significantly decreased uninsurance rates. Furthermore, residents of these states experienced a reduction in mortality rate, significant decrease in delay of care due to cost, and significant increase in self-reported health status as excellent or very good.

Massachusetts health reform, known as Commonwealth Care and enacted in 2006, has resulted in nearly universal health insurance coverage throughout the state. In 2010, Zhu, Brawarsky, Lipsitz, Huskamp, and Haas (2010) reported that Commonwealth Care significantly reduced the uninsurance rate, but that access to a primary care provider and self-reported health status did not change. Other reports note that out-of-pocket fees have continued to be a barrier, despite insurance coverage (Clark et al., 2011; Maxwell, Cortes, Schneider, Graves, \& Rosman, 2011). More recent studies have noted changes in access and outcome trends: Maxwell et al. (2011) and Miller (2012) cite increased utilization of preventive care and primary care; Courtemanche and Zapata (2014) observed self-reported data indications of reductions of poor health days, poor mental health days, and days with health limitations; and Sommers, Long, and Baicker (2014) found a reduction in mortality rates. However, racial and socioeconomic disparities persist throughout the state despite the implementation of Commonwealth Care, as the policy has had similar impacts on Whites as it has minority populations (Amri et al., 2014; Maxwell et al., 2011; Sommers, Long, et al., 2014; Zhu et al., 2010). 
Golberstein and Gonzales (2015) used MEPS data to examine trends in use of mental health services and expenditures during the decade prior to ACA implementation, noting that 17 states expanded Medicaid at some capacity during that time. They determined that increasing Medicaid eligibility did not significantly alter the use of mental health services, including emergency, inpatient, and ambulatory care, as well as prescription drug use. The researchers surmise that utilization was impacted by managed care, provider shortages, and use of safety-net providers. However, Medicaid expansion was associated with decreased out-of-pocket spending for individuals who identified psychological distress.

Sommers et al. (2013) have examined states' experiences of implementing Medicaid expansion within the first 18 months after ACA was signed. They conducted semi-structured interviews with 11 state officials from six states that implemented Medicaid expansion. Two of several unanticipated themes that arose through these interviews were the persistent barriers to coverage and access despite the new law and the critical need for behavioral health services for newly covered individuals. Quantitative analysis of enrollment trends among four of those six states found that enrollment gradually increased with time, and individuals who enrolled within the first year presented with health-related functional limitations (Sommers, Kenney, \& Epstein, 2014). However, other noted trends varied from state to state. Together, these two studies indicate that implementation of Medicaid expansion through the ACA will have different challenges for different regions and populations, and new enrollees have significant health care needs. 
States have implemented Medicaid expansion over the last decade with mixed results. Health insurance coverage has relieved the financial stress of medical costs for some of America's most vulnerable residents, resulting in positive health outcomes. Although use of mental health services in the Medicaid expansion population has not been studied extensively, preliminary research indicates that insurance coverage is not the only influencing factor for mental health care utilization by the newly insured population. Moreover, Medicaid expansion has not yet impacted a substantial reduction in health disparities.

\section{Mental Health Utilization among Low Socioeconomic and Black Populations}

Racial disparities in health and health care exist and persist across the U.S. (AHRQ, 2014). Although cost is the most cited reason for not using mental health services, there are multiple reasons individuals offer for not seeking care, each impacting racial and ethnic groups differently (SAMHSA, 2015). Compared with other racial and ethnic groups, Whites are more likely to have access to health care due to factors such as insurance status, income, and education (Kirby, Taliaferro, \& Zuvekas, 2006). Blacks are less likely to have health insurance than Whites, and less likely to use health professionals regardless of insurance status (Chou, Tulolo, Raver, Hsu, \& Young, 2013). More specifically, one-fifth of Blacks are uninsured, and another one-third of Blacks have Medicaid coverage (Kaiser Commission on Medicaid and the Uninsured, 2013). However, despite similar insurance coverage across populations is similar, as it has been since health reform in Massachusetts nearly a decade ago, racial/ethnic and socioeconomic disparities in access to health care persist (Zhu et al., 2010).

Although disparities exist between Whites and Blacks in many health conditions, 
mental health care may present racial differences due to the cultural history of mental health treatment and associated stigma. Hatzenbuehler, Phelan, and Link (2013) report that stigma, or the negative labeling and segregation of individuals diagnosed with certain health conditions, is associated with increased stress and linked to health inequalities. It is estimated that Black adults are approximately half as likely as Whites to use mental health services, regardless of gender, age group, income range, insurance status, symptom severity, or specific service (AHRQ, 2014; Byers et al., 2012; Center for Behavioral Health Statistics and Quality, 2015; Eisenberg et al., 2011; Gonzalez et al., 2008). However, Black adults report more psychosocial stressors than Whites (Bailey, Patel, Barker, Ali, \& Jabeen, 2011), and there are links between the experience of racism and psychological distress (Karlsen \& Nazroo, 2002). In fact, Blacks present with poorer general health and greater functional impairment as a result of mental illness (Brown et al., 1996).

Analysis of national survey data has demonstrated that Black adults are less likely than White adults to have had any mental health visit in the past year and ultimately have a lower total mental health expenditures (Cook, McGuire, \& Miranda, 2007). Racial and ethnic differences may impact the cultural differences of mental health symptoms or problems, and therefore the help-seeking process. For example, Black and Hispanic individuals are less likely to identify their own mental health symptoms, and may not perceive a need for mental health services (SAMHSA, 2015; Zuvekas \& Fleishman, 2008). Furthermore, research suggests that under-detection of mental illness by providers may contribute to disparities; clinicians may not identify mental illness in minority populations since symptom presentation may vary across racial and ethnic groups 
(Alegria et al., 2008).

The literature also presents differences between racial and ethnic groups in patterns of utilization and care within the continuum of psychiatric services offered. Black adults who access care are less likely to receive adequate or quality care (Alegria et al., 2008). This population is more likely to seek treatment from a primary care provider, often presents with somatic symptoms of mental illness, and may vocalize a preference for counseling over medications (Bailey et al., 2011; Brown et al., 1996). Not only are Blacks less likely to use psychotropic medication regardless of symptom severity (Gonzalez et al., 2008), but multiple studies reinforce that Blacks have high rates of psychotropic medication nonadherence (Diaz, Woods, \& Rosenheck, 2005; Gilmer et al., 2004; Olfson, Marcus, Tedeschi, \& Wan, 2006). This may be attributed to the fact that minorities may be less likely to engage in conversations about medications with their physicians (Hodgkin et al., 2007). Additionally, the most recent data from SAMHSA indicates higher hospitalization rates for Black adults than White adults (Center for Behavioral Health Statistics and Quality, 2015). This warrants further investigation of racial disparities regarding voluntary commitment for receipt of inpatient treatment and education regarding outpatient service options.

The intersectionality of race/ethnicity and socioeconomic status also impacts utilization of mental health services. Poorer mental health is associated with individuals with incomes below 200 percent of the FPL (SAMHSA, 2014a). Research suggests that one's financial situation while growing up is associated with use of services; affluent individuals are more likely to use services, even when access to care is similar for all individuals within a community (Eisenberg et al., 2011). But when Kessler and 
Neighbors (1986) found a larger racial difference in the population at lower socioeconomic levels, they reported that the interaction of poverty and discrimination result in greater psychological distress for Blacks. They suggest that Blacks of low socioeconomic status have less access to resources for coping with stress. Other researchers suggest that impoverished Black individuals have less control over their health status and a greater number of stressful life events (Brown et al., 1996).

In addition to the impacts of poverty and uninsurance on health care utilization, there are several social and cultural differences in the trends of mental health care utilization among Blacks and Whites. These differences ultimately result in different health outcomes. Therefore, health disparities are rooted not only in financial barriers to the receipt of health care services, but also the structural and societal factors that influence care-seeking behaviors.

\section{Summary}

Over the past decade, multiple studies have examined the impact of Medicaid expansion on health care access, service utilization, and health, and have found that racial and socioeconomic health disparities persist. However, existing literature has only minimally examined these concepts specific to mental health. The literature reflects a large range of barriers to utilizing mental health services, and there is a recognizable unmet need for mental health care. Furthermore, the known barriers to service use reflect racial differences in mental health outcomes. The intent of the ACA is to resolve some of the barriers to access and use of health services; however, as a new policy, there are limited studies specific to the impact of the ACA. This study seeks to contribute to the larger body of knowledge by examining the impact that ACA and Medicaid expansion 
has had on utilization of mental health services by a traditionally disparate population, and making evidence-based policy recommendations to enhance population health outcomes. 


\section{CHAPTER III METHODOLOGY}

\section{Introduction}

Two years since the implementation of the ACA and Medicaid expansion, 138,572 residents of Jefferson County, Kentucky, have enrolled in Medicaid coverage (KOHBHIE, 2016). Nine neighborhoods of Louisville Metro, which aligns with Jefferson County, have historically been challenged with high poverty rates and health disparities (Crutcher, 2013; Greater Louisville Project, 2013). Yet Medicaid expansion specifically benefits individuals in poverty, extending health insurance to those with low-income who might otherwise not afford coverage. The purpose of this study is to examine the impact of health insurance, specifically Medicaid expansion, and other factors on utilization of mental health services by residents of West Louisville neighborhoods. The results of this exploratory study can be used to inform local policies and public health practice to reduce health disparities of this vulnerable population.

This study utilized a mixed methods design with two distinct questions:

Research Question 1: How does Medicaid expansion through ACA impact utilization of mental health services for residents of West Louisville neighborhoods? 
Hypothesis 1: The likelihood of mental health service utilization among West Louisville residents is different pre-ACA implementation from post-ACA implementation.

Hypothesis 2: The likelihood of mental health service utilization among West Louisville residents is different among the Medicaid expansion population compared to the traditional Medicaid population, but still varies by group. Hypothesis 3: The likelihood of mental health service utilization among Medicaid-enrolled West Louisville residents is different from that of the Medicaid-enrolled population who reside elsewhere in Louisville Metro. Non-directional hypotheses were chosen because other studies reflect that the Medicaid expansion population uses health care services more within the first year of coverage (Finkelstein et al., 2012) but this may not be true with mental health services for a population that experiences health disparities (Cook et al., 2007; Zhu et al., 2010).

Research Question 2: What factors besides health insurance impact utilization of mental health care by West Louisville residents?

Hypothesis: Additional factors that impact utilization of mental health care for this population include the availability of services; social networks; the logistics of the socio-economic environment, such as scheduling, transportation, and childcare; stigma; and health literacy.

This study was approved by the University of Louisville Institutional Review Board. Quantitative analysis of Medicaid claims data addressed question one, and a qualitative component explored answers to question two. 


\section{Setting}

The West End of Louisville, Kentucky, consists of nine neighborhoods (Crutcher, 2013): Algonquin, California, Chickasaw, Park DuValle, Park Hill, Parkland, Portland, Russell, and Shawnee. These neighborhoods are historical and self-identified residential communities (A Place in time: The story of Louisville's neighborhoods, 1989). Although they do not coincide directly with zip codes, the nine neighborhoods closely overlap with twenty-two 2010 U.S. Census Tracts. These 22 Census Tracts have routinely been used locally to provide data from the American Community Survey describing the population in West Louisville (Kentucky State Data Center, personal communication, July 31, 2015).

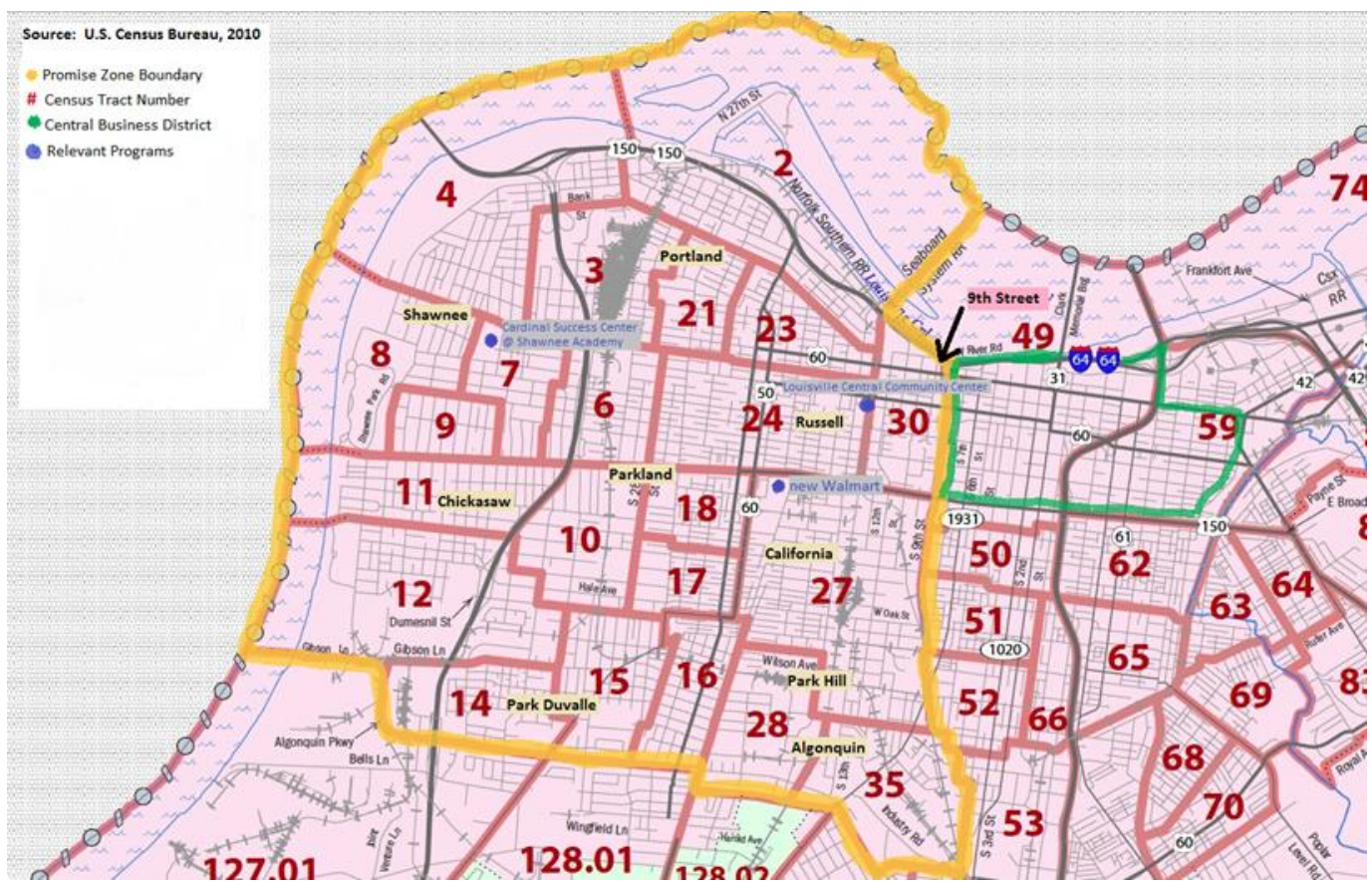

Figure 3. Map of West Louisville with Census Tract overlay (LOJIC, 2015; United States Census Bureau, 2012). 


\section{Quantitative Methods}

The purpose of the quantitative portion of this study is to understand the utilization of mental health services by West Louisville residents. In this study, insurance coverage served as a proxy for access to health care, since Medicaid expansion theoretically removed the influence of cost, the most substantial barrier to accessing services (Call et al., 2014), for individuals who benefit. Stratification of the results by geography and Medicaid type offered insight into established patterns of usage within the Jefferson County community and the impact that new policies have had on accessing mental health care.

\section{Data source}

Claims data were accessed with permission from Passport Health Plan, a Managed Care Organization (MCO) that contracts with Kentucky Medicaid to provide coverage throughout the Commonwealth of Kentucky. The full dataset included all claims to the health plan for the years 2013 and 2014 for individuals residing in the zip codes of Jefferson County. At the initiation of Medicaid expansion, Passport Health Plan covered approximately 68 percent of all individuals enrolled in Medicaid managed care within Jefferson County (Kentucky Cabinet for Health and Family Services, 2016). Passport Health Plan has continued to enroll the majority of the market share for the region.

The dataset was transferred for analysis by encrypted email in two files, one containing the claims data with beneficiary demographics, and the other containing only a unique identifier claim key, primary diagnosis code, and secondary diagnosis code. Each claim had been assigned a unique member identifier as well as the unique claim 
key, in order to track the claims by individual user. Because data had been de-identified for confidentiality, information technology personnel at Passport Health Plan geospatially referenced each individual with latitude and longitude points using home address.

\section{Limitations of the Used Dataset}

Although the dataset represents a large proportion of the Medicaid population in Jefferson County, there are several limitations of the data that should be noted. One limitation of claims data is the inability to determine the reason a medication was prescribed, even when the primary and secondary diagnoses are provided. This study assumes that medications that fall within a standardized range of psychotropic medication codes were prescribed for the purpose of addressing mental illness. A second limitation of this dataset is that it includes only the primary and secondary diagnoses for each individual, and not the full list of diagnoses assigned. This prohibits examination of any link between service utilization and diagnoses that may be listed for an individual beyond the first two. For example, this sample will not associate a mental illness diagnosis with an individual whose primary and secondary diagnoses are chronic physical health conditions and receives treatment for a tertiary diagnosis of anxiety or depression.

A third limitation of this dataset is the categorization of provider type. In

Kentucky, MCOs are permitted to subcontract behavioral health services. Therefore, the provider data field indicates "behavioral subcontractor" for any service provided by psychologists, social workers, and marriage and family therapists. Moreover, the data field does not specify when a service has been provided by a physician or nurse practitioner. Claims made by a primary care provider are not listed as behavioral subcontractor, nor are office visits designated to be psychiatric in nature. Therefore, 
although primary care providers prescribe psychotropic medications (Beardsley, Gardocki, Larson, \& Hidalgo, 1988), these claims cannot be identified through the data and provider type cannot be used as an indicator of mental health service provision. This prohibits examination of links between services utilized and provider type and statistical analysis of mental health workforce demand. Furthermore, although the dataset includes a field for provider location, this is often a single site within a hospital or clinic system (such as the location of the billing office) and not the actual site of service. Thus, it is impossible to determine provider-level characteristics associated with utilization.

Another limitation is the inability to identify the prior care behaviors of newly enrolled individuals, since claims data only indicate behaviors of those who are enrolled and use services. Since many of the individuals in the Medicaid expansion population were previously uninsured, they were subject to use of free or reduced cost services provided by public, non-profit, or indigent care service providers. If they did have prior health insurance, their claims would be to that insurance company, and are therefore not available in the Passport Health Plan dataset. Additionally, the Medicaid expansion population is dissimilar to the population of individuals who qualify for traditional Medicaid and who have had insurance coverage over time (Gold et al., 2014). Finally, despite a drastic drop in uninsurance, not all Kentuckians are insured. Therefore, the population of insured persons who utilize services is not necessarily representative of the general population eligible for Medicaid in Kentucky.

\section{Data cleaning procedures}

After receipt of the original two data text files, data were merged into one file. The number of claims in the original dataset did not match the number of claims in the 
diagnosis dataset, with a difference of 27,846 cases. Those additional observations in the diagnosis dataset included a claim key, but no corresponding claim code in the original dataset, and therefore no additional information about the claim. Thus, those 27,846 cases with diagnosis only were excluded from analysis. The total number of claims available in the original dataset was $3,446,912$.

To prepare for analysis, data were sorted to ensure the claim met eligibility criteria by date of service. Claims included in the analysis were limited to those for which the date of service fell between January 1, 2013, and December 31, 2014. Each claim contained the month and year that an individual's Medicaid eligibility began and ended. Because the dataset was pulled for analysis in May 2015, eligibility end dates were as late as May 2015. However, some eligibility start dates were also listed in the first five months of 2015, such that the claim made prior to the end of 2014 did not fall within the individual's dates of eligibility. Additionally, claims for individuals who were deemed eligible due to Medicaid expansion were aligned with service dates in 2013, prior to an individual's eligibility for Medicaid expansion. Information technology personnel at Passport Health Plan reported these issues were due to coding errors, and the claims were eliminated from the dataset.

The data were then sorted to exclude claims from individuals who do not meet eligibility criteria, including:

- 18-64 years of age;

- Residence in Jefferson County; and

- Beneficiary of Medicaid as a primary insurance carrier. 
Medicaid expansion is only available to individuals aged 18 through 64; therefore, data for individuals outside that age range were excluded from this analysis. The retained observations were then mapped by member longitude and latitude using ArcGIS 10.1 (Esri, 2012) to ensure residence within Jefferson County, since four zip codes are distributed across county lines. Data for individuals residing outside of Jefferson County were excluded from analysis. Additionally, claims were excluded for individuals who were noted as dually eligible and benefit from Medicare as primary insurance coverage, since the regulations for service provision to recipients of the federally-governed Medicare program differ from those of Kentucky Medicaid.

Once sorted, data were then recoded for all independent variables, dependent variables, and covariates (see Table 2). Data were divided into two contiguous years, 2013, prior to the implementation of Medicaid expansion, and 2014, the first year of Medicaid expansion. Service year was recoded to differentiate 2013 from 2014.

Individuals in this dataset could qualify for Medicaid through several eligibility categories: receipt of Supplemental Security Income (SSI) or Temporary Assistance for Needy Families (TANF), aging out of foster care, or Medicaid expansion. Medicaid eligibility type was recoded to differentiate the expansion population from individuals on traditional Medicaid eligibility types who would have qualified for benefits prior to ACA implementation. Additionally, individuals who received benefits due to traditional eligibility status for one period and then through Medicaid expansion for a second period were coded as individuals who had churned, differentiating them from individuals who had only one eligibility status throughout the study period. This change in eligibility status was most likely due to a change in income. This grouping meant that when 
comparing utilization between service years, some individuals were represented in both 2013 and 2014. Although the group benefitted from Medicaid expansion, they were an inherently different population from those new to Medicaid in 2014 through expansion, since they had used Medicaid benefits in the past year.

Geography was recoded using the geographic boundaries of West Louisville as defined by the 22 Census Tracts. All claims were again mapped by individual longitude and latitude using ArcGIS 10.1 (Esri, 2012), and individuals were identified as West Louisville residents or as individuals living elsewhere in Louisville Metro.

As suggested by the literature, mental health services were categorized into three different classifications for distinct dependent variables: ambulatory care appointments for mental health evaluation, treatment, or medication management; outpatient counseling or psychotherapy; and psychotropic medication use (Clemans-Cope et al., 2013; Eisenberg et al., 2011; Golberstein \& Gonzales, 2015). This study measured utilization through counts of these variables per enrolled individual. This study did not examine inpatient admissions or services, since the criteria for using inpatient services for mental health are distinctly different from the criteria for using outpatient services (Kentucky Cabinet for Health and Family Services, 2015), and individuals in inpatient care may be receiving care involuntarily ("Kentucky Mental Health Hospitalization Act," 1982).

Passport Health Plan provided schema crosswalks for claims that they identify as those within the realm of behavioral health services. Ambulatory care visits and counseling sessions were identified in the dataset using Current Procedure Terminology (CPT) and Healthcare Common Procedure Coding System (HCPCS) codes. In addition to 
the CPT and HCPCS behavioral health codes provided, three depression screening codes, administered in primary care settings, were included as claims within ambulatory care (CMS, 2012, 2013). Office visit codes labeled for mental health service use were limited to those provided by a behavioral health subcontractor, since all physician specialty types utilize the same codes, regardless of the care provided during the visit. Psychotropic medications were identified using 32,427 Generic Code Numbers (GCNs). HCPCS codes for the injection of four psychotropic medications were designated as medication use; there were coinciding codes for the office visit in which the injection occurred, which were classified into ambulatory care.

Covariates were identified as predisposing demographic and social factors (Andersen \& Newman, 1973). Individual demographics included in the dataset were gender, age at service, and race. Individual age was coded categorically according to ranges presented in kynect enrollment data (KOHBHIE, 2016) to maintain consistency with Federal and state entities tasked with implementation and monitoring of the ACA. For individuals displaying multiple encounters over time, the age at first service was retained. This study coded race/ethnicity categorically as defined by the U.S. Census. However, within the original dataset, the category termed "Other" was undifferentiated from individuals whose race/ethnicity was unknown; there were no missing data in this field. The majority of claims, 62.4 percent, fell into this category.

Because the indicated primary diagnosis serves as the clinical reason for treatment, diagnoses served as a proxy for illness severity. Diagnoses are classified following the International Statistical Classification of Diseases and Related Health Problems (ICD) codes. This dataset included codes from both the ICD, 9th revision, 
clinical modification (ICD-9-CM), which lists mental disorders, and the ICD, $10^{\text {th }}$ revision (ICD-10), which lists mental and behavioral disorders. Illness severity was coded for a mental illness listed as the primary diagnosis, a mental illness listed as the secondary diagnosis, a mental illness listed as both primary and secondary diagnoses, or no mental illness associated with the claim. Diagnoses were excluded from classification of mental illness according to the operational definition of AMI for this study. However, conduct disorder and oppositional defiant disorder were retained because the criteria for both diagnoses in the DSM, Fourth Edition, Text Revision (DSM-IV-TR) ${ }^{1}$ included individuals 18 and older when the criteria for antisocial personality disorder were not met (American Psychological Association, 2000). The ICD-9 codes for attention deficit disorder were also included, because there are no coinciding ICD-9 codes for adult diagnoses. Any individuals who had neither primary nor secondary diagnoses assigned to any claim were excluded from analysis.

Each claim also included the individual's dates of eligibility, allowing for calculation of the duration of enrollment. Although eligibility was provided by exact dates, Medicaid covers an individual the entirety of each month of enrollment, never partial months (907 KAR 205: 005). Eligibility dates were converted to reflect this regulation. Enrollment duration was then calculated and converted to person-months, divided between the two service years to control for the time period in which any one individual could have received services paid for by the MCO.

\footnotetext{
${ }^{1}$ The DSM-V was published in May 2013. Data in this study used both DSM-IV-TR and DSM-V diagnoses in alignment with ICD-9 and ICD-10 codes.
} 


\section{Quantitative Data Analysis}

Understanding how Medicaid expansion impacts utilization of mental health services for the West Louisville population required the investigation of differences between use of mental health services over time, by Medicaid eligibility segments, and across geography. Following data cleaning and variable recoding, the dataset had retained $1,738,625$ claims in $1,104,917$ encounters by 9,270 unique individuals. West Louisville residents comprised 23.7 percent of the total Louisville Metro sample, with 2,199 individuals having received health care services reimbursed by Passport Health Plan in 2013 and 2014. Use of each of the three mental health services was counted for each West Louisville resident by service year, for each West Louisville resident by Medicaid eligibility for 2014, and for all individuals over the course of 2014.

Quantitative data analysis was completed in IBM SPSS Statistics for Windows, Version 22.0 (IBM Corp., 2013), wherein $\alpha$ was set to 0.05 for determining statistical significance. Initial statistical analyses provided descriptive statistics of the sample, comparing the populations included in each separate analysis. To understand generalizability, these descriptive statistics were compared for the pre-ACA (2013) versus the post-ACA (2014) population of West Louisville; the 2014 West Louisville population with traditional Medicaid eligibility versus those members qualifying for Medicaid expansion; and the residents of West Louisville versus the residents of Louisville Metro who live elsewhere within city boundaries with 2014 claims. Chi-square analysis was used for between-group comparisons.

Statistical analysis was initially performed using a generalized linear model (GLM) with a Poisson link, which is appropriate for count data and has been used in 
previous studies of utilization changes after Medicaid expansion (Gold et al., 2014). However, goodness of fit statistics revealed over-dispersion, and analysis was then performed using a negative binomial regression model (Hilbe, 2011). A Bonferroni correction was used to control for multiple comparisons (Field, 2009). Analysis for each of the three outcome variables controlled for individual characteristics (age, race, gender), severity of illness, and duration of enrollment. For each model, Incidence Rate Ratios (IRR), defined as the rate of utilization based on the number of claims per person per service; 95 percent confidence intervals; and p-values are reported. Statistical significance was determined at the alpha 0.05 level. All independent variables, dependent variables, covariates, and statistical coding are listed in Table 2. 
Table 2

Independent variables, dependent variables, and covariates

\begin{tabular}{ll}
\hline \multicolumn{1}{c}{ Independent Variables } & \multicolumn{1}{c}{ Coding Scheme } \\
Service year & $0=2013$ (pre-Expansion) \\
& $1=2014$ (post-Expansion) \\
Medicaid Eligibility Type & $\begin{array}{l}0=\text { non-Expansion } \\
1\end{array}=$ Expansion \\
2 & $=$ Churn (Both Expansion and non-Expansion within the \\
study period) & \\
& $0=$ Louisville Metro resident (outside of West Louisville) \\
& $1=$ West Louisville resident
\end{tabular}

\begin{tabular}{ll}
\hline \multicolumn{1}{c}{ Dependent Variables } & \multicolumn{1}{c}{ Coding Scheme } \\
Ambulatory mental health appointment & Count of frequency across enrollment period \\
Counseling session & Count of frequency across enrollment period \\
Medication use & Count of frequency across enrollment period
\end{tabular}

\begin{tabular}{|c|c|}
\hline Covariates & Coding Scheme \\
\hline Race/ethnicity & $\begin{array}{l}0=\text { White } \\
1=\text { Black } \\
2=\text { Hispanic } \\
3=\text { Asian } \\
4=\text { American Indian or Alaska Native } \\
5=\text { Other }\end{array}$ \\
\hline Gender & $\begin{array}{l}0=\text { Male } \\
1=\text { Female }\end{array}$ \\
\hline Age at service & $\begin{array}{l}0=18-25 \text { years } \\
1=26-34 \text { years } \\
2=35-44 \text { years } \\
3=45-54 \text { years } \\
4=55-64 \text { years }\end{array}$ \\
\hline $\begin{array}{l}\text { Illness severity: Mental health } \\
\text { diagnosis }\end{array}$ & $\begin{array}{l}0=\text { Physical health diagnoses } \\
1=\text { Primary psychiatric diagnosis } \\
2=\text { Secondary psychiatric diagnosis } \\
3=\text { Dual psych diagnoses }\end{array}$ \\
\hline Length of enrollment & Continuous, measured in months \\
\hline
\end{tabular}


Each hypothesis requires three models to address each outcome measure, as described below.

$\mathrm{H}_{1}$ : The likelihood of mental health service utilization among West Louisville residents is different pre-ACA implementation from post-ACA implementation.

$$
Y=\beta_{0}+T_{x}+X_{1}+X_{2}+X_{3}+\varepsilon
$$

where $\mathrm{Y}=$ ambulatory mental health appointments

$\mathrm{T}_{\mathrm{x}}=$ service year $(2013$ or 2014$)$

$\mathrm{X}_{1}=\mathrm{a}$ vector of individual characteristics including race and gender

$\mathrm{X}_{2}=$ individual age at initial service

$\mathrm{X}_{3}=$ total length of enrollment

$$
Y=\beta_{0}+T_{x}+X_{1}+X_{2}+X_{3}+\varepsilon
$$

where $\mathrm{Y}=$ counseling sessions

$\mathrm{T}_{\mathrm{x}}=$ service year $(2013$ or 2014$)$

$\mathrm{X}_{1}=\mathrm{a}$ vector of individual characteristics including race and gender

$\mathrm{X}_{2}=$ individual age at initial service

$\mathrm{X}_{3}=$ total length of enrollment

$$
Y=\beta_{0}+T_{x}+X_{1}+X_{2}+X_{3}+\varepsilon
$$

where $\mathrm{Y}=$ medication use

$\mathrm{T}_{\mathrm{x}}=$ service year $(2013$ or 2014$)$

$\mathrm{X}_{1}=\mathrm{a}$ vector of individual characteristics including race and gender

$\mathrm{X}_{2}=$ individual age at initial service

$\mathrm{X}_{3}=$ total length of enrollment 
$\mathrm{H}_{2}$ : The likelihood of mental health service utilization among West Louisville residents is different among the Medicaid expansion population compared to the traditional Medicaid population, but still varies by group.

$$
Y=\beta_{0}+M_{x}+X_{1}+X_{2}+X_{3}+\varepsilon
$$

where $\mathrm{Y}=$ ambulatory mental health visits

$\mathrm{M}_{\mathrm{x}}=$ Medicaid type (traditional or expansion)

$\mathrm{X}_{1}=\mathrm{a}$ vector of individual characteristics including race and gender

$\mathrm{X}_{2}=$ individual age at initial service

$\mathrm{X}_{3}=$ total length of enrollment

$$
Y=\beta_{0}+M_{x}+X_{1}+X_{2}+X_{3}+\varepsilon
$$

where $\mathrm{Y}=$ counseling sessions

$\mathrm{M}_{\mathrm{x}}=$ Medicaid type (traditional or expansion)

$\mathrm{X}_{1}=\mathrm{a}$ vector of individual characteristics including race and gender

$\mathrm{X}_{2}=$ individual age at initial service

$\mathrm{X}_{3}=$ total length of enrollment

$$
Y=\beta_{0}+M_{x}+X_{1}+X_{2}+X_{3}+\varepsilon
$$

where $\mathrm{Y}=$ medication use

$\mathrm{M}_{\mathrm{x}}=$ Medicaid type (traditional or expansion)

$\mathrm{X}_{1}=\mathrm{a}$ vector of individual characteristics including race and gender

$\mathrm{X}_{2}=$ individual age at initial service

$\mathrm{X}_{3}=$ total length of enrollment 
$\mathrm{H}_{3}$ : The likelihood of mental health service utilization among Medicaid-enrolled West Louisville residents is different from that of the Medicaid-enrolled population who reside elsewhere in Louisville Metro.

$$
Y=\beta_{0}+G_{x}+X_{1}+X_{2}+X_{3}+\varepsilon
$$

where $\mathrm{Y}=$ ambulatory mental health visits

$\mathrm{G}_{\mathrm{x}}=$ geographic residence (West Louisville or elsewhere in Louisville Metro)

$\mathrm{X}_{1}=\mathrm{a}$ vector of individual characteristics including race and gender

$\mathrm{X}_{2}=$ individual age at initial service

$\mathrm{X}_{3}=$ total length of enrollment

$$
Y=\beta_{0}+G_{x}+X_{1}+X_{2}+X_{3}+\varepsilon
$$

where $\mathrm{Y}=$ counseling sessions

$\mathrm{G}_{\mathrm{x}}=$ geographic residence (West Louisville or elsewhere in Louisville Metro)

$\mathrm{X}_{1}=\mathrm{a}$ vector of individual characteristics including race and gender

$\mathrm{X}_{2}=$ individual age at initial service

$\mathrm{X}_{3}=$ total length of enrollment

$$
Y=\beta_{0}+G_{x}+X_{1}+X_{2}+X_{3}+\varepsilon
$$

where $\mathrm{Y}=$ medication use

$\mathrm{G}_{\mathrm{x}}=$ geographic residence (West Louisville or elsewhere in Louisville Metro)

$\mathrm{X}_{1}=\mathrm{a}$ vector of individual characteristics including race and gender

$\mathrm{X}_{2}=$ individual age at initial service

$\mathrm{X}_{3}=$ total length of enrollment 


\section{Qualitative Methods}

The purpose of qualitative data collection was to understand the factors that influence utilization of mental health services other than health insurance. Although research indicates that health insurance increases access to care by removing cost as a barrier, other studies have concluded that there are additional barriers to mental health care, particularly in disparate populations. Because the West Louisville community is unique within the contexts of both Louisville and Kentucky, the facilitators and barriers to health care encountered by West Louisville residents are also unique.

\section{Sample}

\section{Sampling strategy}

Qualitative research methods suggest that it is most important to reach a point of saturation in data collection (Creswell, Hanson, Clark Plano, \& Morales, 2007), rather than to pre-determine a finite number of participants. This study conducted qualitative interviews with 20 health care consumers who have been referred to or are currently utilizing mental health services and six mental health service professionals who have observed systemic issues impacting service provision and the experiences of the population studied. Data collection ceased when new information gathered reinforced data previously collected and no longer contributed new concepts or themes for analysis. Consulting with both health care consumers and professionals provides multiple perspectives on the factors that influence utilization of mental health services in West Louisville. 
This study used strategic and purposive sampling to include adult residents of West Louisville who might use mental health services and the professionals who serve this population.

Inclusion criteria

In order to participate in the study, consumers must:

- Have insurance coverage through Medicaid expansion;

- Reside in one of the identified nine West Louisville neighborhoods;

- Have been professionally referred for mental health services;

- Speak English; and

- Be 18 through 64 years of age.

In order to participate in the study, health professionals must work in primary care or mental health care, serving in either an administrative or direct service capacity to residents of West Louisville.

\section{Exclusion Criteria}

Individuals who meet inclusion criteria were additionally screened for comprehension of the informed consent provided verbally and in written format (as verified through the informed consent process). None of the initially recruited participants were excluded from the study for this purpose.

\section{Recruitment}

Two local federally qualified health centers (FQHCs), served as centers for recruiting participants. In each $\mathrm{FQHC}$, staff extended invitations to health care consumers who had been referred mental health services by providing the study recruitment flyer. This referral served as a proxy for need for mental health care. Consumers independently 
contacted the researcher, who screened the caller for inclusion criteria, then scheduled an appointment to meet at a location convenient to the consumer. The FQHCs also both permitted the researcher to conduct interviews on site, so that consumers were able to meet with the researcher as they were at the $\mathrm{FQHC}$ for a scheduled health appointment. Participants were provided with $\$ 50.00$ cash to compensate for their time.

Six community-based mental health providers were invited via phone contact and/or email to participate in individual interviews. Invited professionals included individuals who provide services through the FHQCs, individuals who provide services at West Louisville sites for the Community Mental Health Center (CMHC), an individual who provides counseling services in private practice, and an individual who serves as a mental health clinic director in West Louisville. Invited professionals were included because they provide mental health services to adult residents of West Louisville neighborhoods. Professionals who volunteered to participate in this study did not receive compensation.

\section{Instrument}

Interviews were conducted using a semi-structured interview guide (see Appendices A and B), which were developed based on a review of the literature, Andersen and Newman's (1973) conceptual framework for health care utilization, and the guidance of local professionals who have previously conducted health research within the West Louisville community.

In an effort to understand consumers' perceptions of facilitators and barriers to using mental health services, interviews were designed to collect data about consumers' definitions of mental health, their knowledge of the mental health care system, and their 
understanding of insurance benefits. Using the findings of prior studies, questions and probes addressed consumers' perceptions of their need for mental health care (Abrams et al., 2009), the stigma of mental illness (Byers et al., 2012), and their use of mental health treatment (Bryant et al., 2013; Lucca et al., 2015). Additional questions were asked to understand the population's health systems literacy (Mojtabai et al., 2014; SAMHSA, 2014a) and health insurance literacy (Mesidor et al., 2011). Prior to formal use, interview questions were posed to a mental health professional familiar with the West Louisville community and culture during a cognitive interview process in order to refine the interview questions (Collins, 2003; Turner, 2010).

Professional interviews included questions regarding observed changes in mental health care since the implementation of ACA and Medicaid expansion. Questions were designed to understand the current landscape of mental health services in West Louisville, systemic and service delivery issues (Chung et al., 2012; Mesidor et al., 2011), and local workforce availability (Thomas et al., 2009). Additional questions probed for providers' perceptions of consumers' attitudes toward mental health services, as well as observed facilitators and barriers to consumer engagement in mental health services.

\section{Interviews}

Interviews took place at private rooms within community buildings that were familiar and accessible to participants, such as the FQHCs, the Louisville Central Community Center, or the professional's office. Individual appointments were set with participants at their convenience. Each interview began with a description of the purpose of the study, with the emphasis that participation is both confidential and voluntary. 
Participants were provided with the opportunity to ask clarifying questions. This process included a request for permission to record the interview so that interviews could be transcribed. Written informed consent for participation was obtained for each participant.

\section{Qualitative Data Analysis Plan}

Following the interviews, recordings were transcribed by a contracted transcription agency. Interview transcripts were reviewed by the investigator for accuracy, and de-identified where necessary. The investigator then reviewed the transcripts a second time to understand the scope and contexts of the dataset.

The investigator then extracted relevant data segments from the transcripts. With the assistance of a second investigator, these segments were organized according to their meaning during an initial coding process, which identified participants' thoughts that are similar in nature in effort to establish repetitions within the dataset (Bradley, Curry, \& Devers, 2007; Miles, Huberman, \& Saldana, 2014). The two investigators continued to engage in inductive thematic analysis through manual coding and organization to identify key concepts and observe emergent patterns, or themes. In the initial round of coding, any data segments that were not coded identically by the two coders were set aside. After completing the entire first round, the two coders revisited the data segments in question and discussed the extent to which each one fit into existing themes, reaching agreement on how to code each one. For several data segments, the ideas overlapped into two different codes, and thus were duplicated and assigned to both.

During the coding process, provider data were color-coded separately from consumer data in order to observe any differences in response patterns. Thematic analysis was an iterative and reflexive process, as the investigators reviewed data line-by-line to 
compare text segments for recurring sentiments and similar concepts, in order to accurately interpret the raw data. The data were continuously revisited for new insights and connections between the research question and the data. This process continued to theoretical saturation. This process used descriptive, values, evaluation, and causation coding methods (Miles et al., 2014). Codes were revised throughout the coding process as necessary, and were defined following the inclusion of all relevant data. The framework of themes developed through analysis was applied back to the raw data to ensure it captured the intent of the original interviews (Bradley et al., 2007), validated by a qualitative researcher external to the study, and reviewed by a member of the West Louisville community. The external researcher also reviewed the original data segments to ensure the final codes were interpreted correctly. 


\section{CHAPTER IV}

\section{RESULTS}

This study employed a mixed methods design to determine the impact of Medicaid expansion on the use of mental health services by West Louisville residents, as well as factors other than insurance coverage that influence the population's use of mental health services. Results in this chapter are organized by research question. A discussion of the results and their implications for public health policy and practice are presented in Chapter V.

\section{Quantitative Results}

Research Question 1: How does Medicaid expansion through ACA impact utilization of mental health services for residents of West Louisville neighborhoods? Hypothesis 1: The likelihood of mental health service utilization among West Louisville residents is different pre-ACA implementation from post-ACA implementation.

\section{West Louisville Resident Pre- and Post-Medicaid Expansion Sample Demographics}

Health care claims by West Louisville residents in one $\mathrm{MCO}$ reflected that Medicaid expansion covered 39.3 percent of the total population for that MCO in 2014 . Chi square and t-test analyses reflected that the 2013 population was dissimilar from the 2014 population not only in Medicaid eligibility type, but also in terms of gender, race, illness severity, and length of enrollment. These differences are to be expected, since the 
Medicaid expansion population was added to the sample in 2014. The change in eligibility requirements opens Medicaid enrollment to middle-aged men and women without dependent children or disabilities. This non-equivalence is important as each of these characteristics serves as a covariate in the regression models examining differences between utilization patterns between the two groups. Table 3 displays demographic characteristics of West Louisville residents in the sample for these two years and provides p-values to demonstrate differences in the two groups included in the analyses. 
Table 3

Descriptive Statistics for West Louisville Residents Who Made Claims to Passport Health Plan in 2013 and 2014

\begin{tabular}{|c|c|c|c|}
\hline & $\begin{array}{c}\mathbf{2 0 1 3} \\
(n=1,397)\end{array}$ & $\begin{array}{c}\mathbf{2 0 1 4} \\
(n=2,199)\end{array}$ & $p$-value \\
\hline \multicolumn{4}{|l|}{ Medicaid Eligibility Type (frequency (\%)) } \\
\hline Traditional & $1,222(87.5 \%)$ & $1,334(60.7 \%)$ & \multirow[t]{3}{*}{$p<0.001$} \\
\hline Expansion & 0 & $640(29.1 \%)$ & \\
\hline Churn & $175(12.5 \%)$ & $225(10.2 \%)$ & \\
\hline \multicolumn{4}{|l|}{ Gender (frequency $(\%)$ ) } \\
\hline Male & $302(21.6 \%)$ & $663(30.2 \%)$ & \multirow[t]{2}{*}{$p<0.001$} \\
\hline Female & $1,095(78.4 \%)$ & $1,536(69.8 \%)$ & \\
\hline \multicolumn{4}{|l|}{ Race/Ethnicity (frequency (\%)) } \\
\hline White & $181(13.0 \%)$ & $185(8.4 \%)$ & \multirow[t]{6}{*}{$p<0.001$} \\
\hline Black & $481(34.4 \%)$ & $468(21.3 \%)$ & \\
\hline Hispanic & 0 & 0 & \\
\hline Asian & $1(0.1 \%)$ & $1(<0.1 \%)$ & \\
\hline American Indian or Alaska Native & $2(0.1 \%)$ & $2(<0.1 \%)$ & \\
\hline Other & $732(52.4 \%)$ & $1,543(70.2 \%)$ & \\
\hline \multicolumn{4}{|l|}{ Age (frequency $(\%)$ ) } \\
\hline $18-25$ & $392(28.1 \%)$ & $555(25.2 \%)$ & \multirow[t]{5}{*}{$p<0.05$} \\
\hline $26-34$ & $348(24.9 \%)$ & $531(24.1 \%)$ & \\
\hline $35-44$ & $256(18.3 \%)$ & $477(21.7 \%)$ & \\
\hline $45-54$ & $235(16.8 \%)$ & $405(18.4 \%)$ & \\
\hline $55-64$ & $166(11.9 \%)$ & $231(10.6 \%)$ & \\
\hline \multicolumn{4}{|l|}{ Illness Severity (frequency (\%)) } \\
\hline Physical Health Diagnosis & $285(20.4 \%)$ & $419(19.1 \%)$ & \multirow[t]{4}{*}{$p<0.001$} \\
\hline Primary Psychiatric Diagnosis & $763(54.6 \%)$ & $1,050(47.7 \%)$ & \\
\hline Secondary Psychiatric Diagnosis & $183(13.1 \%)$ & $320(14.6 \%)$ & \\
\hline Dual Psych Diagnosis & $166(11.9 \%)$ & $410(18.6 \%)$ & \\
\hline \multicolumn{4}{|l|}{ Length of Enrollment (mean (range)) } \\
\hline Months & $6.8(1-12)$ & $7.3(1-12)$ & $p<0.001$ \\
\hline
\end{tabular}




\section{Likelihood of Mental Health Service Utilization Pre- and Post-Medicaid Expansion}

The total number of individuals with mental health claims increased from 2013 to 2014. But the statistical models show that the rate at which West Louisville residents made mental health-related ambulatory care visits $(\mathrm{IRR}=0.931, p=0.203)$, attended counseling sessions $(\mathrm{IRR}=0.866, p=0.073)$, and used psychotropic medications $(\mathrm{IRR}=0.937, p=0.206)$ pre-ACA implementation did not significantly differ from the rate by which they used these services post-ACA implementation, when controlling for Medicaid eligibility type, demographics, illness severity, and length of enrollment. Therefore, the null hypothesis was not rejected for this hypothesis.

When controlling for the timing of the policy change, the rates by which West Louisville residents used all three modes of service were significantly different between the Medicaid expansion population and the traditional Medicaid population, with the rate of utilization being lower in the expansion population. In all three service categories, the rate of service use increased with age, although rates for counseling use was highest for individuals age 45 through 54 . Females used significantly less ambulatory care services than males, although this trend was not true for counseling nor medication use. Length of enrollment was significantly associated with ambulatory care visits and medication use; the rate of service use increased the longer individuals had health coverage. Having a mental illness listed as any diagnosis was associated with a higher rate for all outcome variables. Due to high rate of cases in which race was listed Other and the small sample sizes of Asians and American Indians or Alaskan Natives, differences in race/ethnicity were largely inconclusive. However, it was noted that Blacks used medications at a rate 
$27 \%$ lower than Whites (IRR $=0.730, p<0.001)$. The results for each of the three models are presented in Table 4, Table 5, and Table 6.

Table 4

Results of Negative Binomial Regression Analysis, Likelihood of Ambulatory Care Service Use by Service Year

\begin{tabular}{|c|c|c|c|c|}
\hline \multirow[b]{2}{*}{ Variable } & \multirow[b]{2}{*}{ IRR } & \multirow[b]{2}{*}{$p$-value } & \multicolumn{2}{|c|}{ 95\% Wald CI for IRR } \\
\hline & & & Lower & Upper \\
\hline \multicolumn{5}{|l|}{ Service year (referent is 2013) } \\
\hline 2014 & .931 & .203 & .833 & 1.040 \\
\hline \multicolumn{5}{|c|}{ Medicaid Eligibility (referent is non-Expansion) } \\
\hline Churn & .835 & .050 & .698 & 1.000 \\
\hline Expansion & .669 & $<.001$ & .571 & .784 \\
\hline \multicolumn{5}{|l|}{ Gender (referent is Male) } \\
\hline Female & .827 & .001 & .740 & .924 \\
\hline \multicolumn{5}{|l|}{ Race/Ethnicity (referent is White) } \\
\hline Other & .666 & $<0.001$ & .557 & .795 \\
\hline American Indian or Alaska Native & 5.595 & .006 & 1.645 & 19.025 \\
\hline Asian & 142 & .148 & .010 & 1.999 \\
\hline Black & 955 & .597 & .806 & 1.132 \\
\hline \multicolumn{5}{|l|}{ Age Group (referent is 18-25) } \\
\hline $55-64$ & 2.492 & $<0.001$ & 2.089 & 2.974 \\
\hline 45-54 & 2.376 & $<0.001$ & 2.029 & 2.782 \\
\hline $35-44$ & 2.079 & $<0.001$ & 1.787 & 2.420 \\
\hline 26-34 & 1.571 & $<0.001$ & 1.358 & 1.818 \\
\hline \multicolumn{5}{|c|}{ Illness severity (referent is Physical health diagnosis) } \\
\hline Dual psychiatric diagnosis & 83.705 & $<0.001$ & 59.719 & 117.326 \\
\hline Secondary psychiatric diagnosis & 67.297 & $<0.001$ & 47.874 & 94.601 \\
\hline Primary psychiatric diagnosis & 56.481 & $<0.001$ & 40.782 & 78.224 \\
\hline Length of enrollment & 1.023 & $<0.001$ & 1.010 & 1.037 \\
\hline
\end{tabular}


Table 5

Results of Negative Binomial Regression Analysis, Likelihood of Counseling Use by Service Year

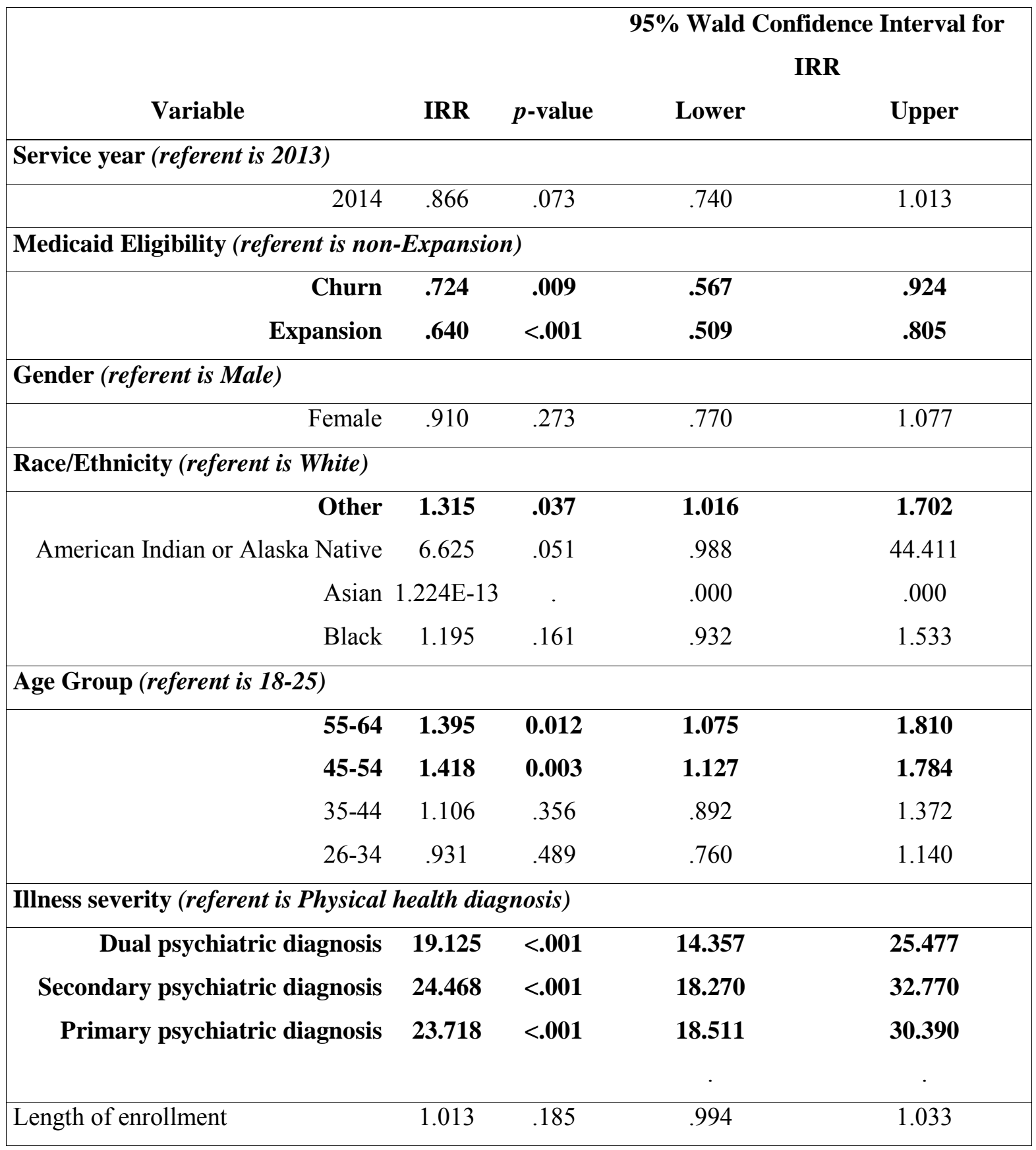


Table 6

Results of Negative Binomial Regression Analysis, Likelihood of Medication Use by

Service Year

\begin{tabular}{|c|c|c|c|c|}
\hline \multirow[b]{2}{*}{ Variable } & \multirow[b]{2}{*}{ IRR } & \multirow[b]{2}{*}{$p$-value } & \multicolumn{2}{|c|}{$\begin{array}{l}\text { 95\% Wald Confidence Interval for } \\
\text { IRR }\end{array}$} \\
\hline & & & Lower & Upper \\
\hline \multicolumn{5}{|l|}{ Service year (referent is 2013) } \\
\hline 2014 & .937 & .206 & .847 & 1.036 \\
\hline \multicolumn{5}{|c|}{ Medicaid Eligibility (referent is non-Expansion) } \\
\hline Churn & .875 & .100 & .746 & 1.026 \\
\hline Expansion & .733 & $<0.001$ & .635 & .846 \\
\hline \multicolumn{5}{|l|}{ Gender (referent is Male) } \\
\hline Female & .917 & .101 & .826 & 1.017 \\
\hline \multicolumn{5}{|l|}{ Race/Ethnicity (referent is White) } \\
\hline Other & .657 & $<0.001$ & .559 & .771 \\
\hline American Indian or Alaska Native & 2.509 & .150 & .717 & 8.779 \\
\hline Asian & 1.358 & .744 & .216 & 8.550 \\
\hline Black & .730 & $<0.001$ & .622 & .857 \\
\hline \multicolumn{5}{|l|}{ Age Group (referent is 18-25) } \\
\hline $55-64$ & 4.044 & $<0.001$ & 3.426 & 4.772 \\
\hline 45-54 & 3.887 & $<0.001$ & 3.361 & 4.495 \\
\hline $35-44$ & 3.473 & $<0.001$ & 3.029 & 3.981 \\
\hline 26-34 & 2.154 & $<0.001$ & 1.887 & 2.458 \\
\hline \multicolumn{5}{|c|}{ Illness severity (referent is Physical health diagnosis) } \\
\hline Dual psychiatric diagnosis & 11.910 & $<0.001$ & 10.128 & 14.005 \\
\hline Secondary psychiatric diagnosis & 7.402 & $<0.001$ & 6.264 & 8.745 \\
\hline Primary psychiatric diagnosis & 5.222 & $<0.001$ & 4.559 & 5.981 \\
\hline Length of enrollment & 1.035 & $<0.001$ & 1.022 & 1.048 \\
\hline
\end{tabular}


Hypothesis 2: The likelihood of mental health service utilization among West Louisville residents is different among the Medicaid expansion population compared to the traditional Medicaid population, but still varies by group.

\section{West Louisville Resident 2014 Medicaid Eligibility Type Sample Demographics}

A total of 2,199 West Louisville residents made claims to MCO in 2014.

Medicaid eligibility groups among this population were dissimilar in terms of gender, race/ethnicity, age, illness severity, and length of enrollment. Again, this dissimilarity is to be expected, and these five items serve as covariates in the analysis of the influence of Medicaid eligibility type on mental health service use. Table 7 presents the demographics of individuals who accessed health care while enrolled in traditional Medicaid and expanded Medicaid, as well as those currently enrolled in expanded Medicaid although having been eligible for traditional Medicaid coverage in the past. 
Table 7

Descriptive Statistics for West Louisville Residents Who Made Claims to Passport Health Plan in 2014, by Medicaid Eligibility Type

\begin{tabular}{|lcccc|}
\hline & $\begin{array}{c}\text { Traditional } \\
\text { Medicaid } \\
(\mathrm{n}=1,334)\end{array}$ & $\begin{array}{c}\text { Medicaid } \\
\text { Expansion } \\
(\mathrm{n}=640)\end{array}$ & $\begin{array}{c}\text { Churn } \\
\text { Population } \\
(\mathrm{n}=225)\end{array}$ & $\boldsymbol{p}$-value \\
Gender (frequency (\%)) & & & & \\
\hline Male & $321(24.1 \%)$ & $311(48.6 \%)$ & $31(13.8 \%)$ & $p<0.01$ \\
Female & $1,013(75.9 \%)$ & $329(51.4 \%)$ & $194(86.2 \%)$ & \\
Race/Ethnicity (frequency (\%)) & & & & \\
\hline White & $181(13.6 \%)$ & $1(0.2 \%)$ & $3(1.3 \%)$ & $p<0.01$ \\
Black & $457(34.3 \%)$ & $3(0.5 \%)$ & $8(3.6 \%)$ & \\
Hispanic & 0 & 0 & 0 & \\
Asian & $1(0.1 \%)$ & 0 & 0 & \\
American Indian or Alaska Native & $2(0.1 \%)$ & 0 & 0 & \\
Other & $693(51.9 \%)$ & $636(99.3 \%)$ & $214(95.1 \%)$ & \\
Age (frequency (\%)) & & & & \\
\hline 18-25 & $391(29.3 \%)$ & $99(15.5 \%)$ & $65(28.9 \%)$ & $p<.001$ \\
26-34 & $304(22.8 \%)$ & $155(24.2 \%)$ & $72(32.0 \%)$ & \\
35-44 & $245(18.3 \%)$ & $182(28.4 \%)$ & $50(22.2 \%)$ & \\
45-54 & $225(16.9 \%)$ & $155(24.2 \%)$ & $25(11.1 \%)$ & \\
55-64 & $169(12.7 \%)$ & $49(7.7 \%)$ & $13(5.8 \%)$ & \\
Illness Severity (frequency (\%)) & & & & \\
\hline Physical Health Diagnosis & $277(0.3 \%)$ & $78(12.2 \%)$ & $64(28.5 \%)$ & $p<.001$ \\
Primary Psychiatric Diagnosis & $649(2.1 \%)$ & $316(49.4 \%)$ & $85(37.8 \%)$ & \\
Secondary Psychiatric Diagnosis & $188(0.15 \%)$ & $102(15.9 \%)$ & $30(13.3 \%)$ & \\
Dual Psych Diagnosis & $220(0.15 \%)$ & $144(22.5 \%)$ & $46(20.4 \%)$ & \\
Length of Enrollment (mean (range)) & & & & \\
\hline Months & $8.0(1-12)$ & $6.9(1-12)$ & $5.1(1-12)$ & $p<.001$ \\
\hline
\end{tabular}

\section{Likelihood of Mental Health Service Utilization by Medicaid Eligibility Type}

Examination of the use of services by Medicaid eligibility type resulted in rejection of the null hypothesis, suggesting that utilization of mental health services is different by coverage type. The rate at which West Louisville residents in the Medicaid 
expansion population made mental health-related ambulatory care visits $(\mathrm{IRR}=0.670$, $p<0.001$ ), attended counseling sessions ( $\mathrm{IRR}=0.666, p=0.001)$, and used psychotropic medications ( $\mathrm{IRR}=0.751, p<0.001)$ in 2014 was significantly less than the rate at which residents enrolled in traditional Medicaid used those services, when controlling for demographics, illness severity, and length of enrollment. Individuals who churned from traditional Medicaid eligibility to Medicaid expansion in 2014 used mental health services at similar rates to those on traditional Medicaid. Individuals ages 45 through 54 used services at higher rates than other age groups: they used ambulatory care services 206 percent more than referent group of youngest adults ( $\mathrm{IRR}=2.057, p<0.001$ ), counseling services 146 percent more (IRR $=1.461, p=0.012$ ), and psychotropic medications over 400 percent more (IRR=4.036, $p<0.001)$. All age groups varied in their use of ambulatory care visits and medications. This model appeared to reinforce that Blacks utilized psychotropic medications less than Whites ( $\mathrm{IRR}=0.747, p=0.013)$, but results for race/ethnicity may be skewed due to the sample size in each category. Again, for all outcomes, length of enrollment positively associated with increased rates of utilization, with the rates of service use increasing with each additional month of enrollment. These results for each of the three models are presented in Table 8, Table 9, and Table 10. 
Table 8

Results of Negative Binomial Regression Analysis, Likelihood of Ambulatory Care Service Use by Medicaid Eligibility Type

\begin{tabular}{|c|c|c|c|c|}
\hline \multirow{2}{*}{ Variable } & \multirow{2}{*}{ IRR } & \multirow{2}{*}{$p$ value } & \multicolumn{2}{|c|}{ 95\% Wald Confidence Interval } \\
\hline & & & Lower & Upper \\
\hline \multicolumn{5}{|c|}{ Medicaid Eligibility (referent is non-Expansion) } \\
\hline Churn & .814 & .070 & .652 & 1.017 \\
\hline Expansion & .670 & $<0.001$ & .571 & .786 \\
\hline \multicolumn{5}{|l|}{ Gender (referent is Male) } \\
\hline Female & .843 & .010 & .740 & .959 \\
\hline \multicolumn{5}{|l|}{ Race/Ethnicity (referent is White) } \\
\hline \multirow{2}{*}{$\begin{array}{r}\text { Other } \\
\text { American Indian or Alaska Native }\end{array}$} & .639 & $<0.001$ & .510 & .802 \\
\hline & 3.628 & .118 & .722 & 18.226 \\
\hline Asian & $1.475 \mathrm{E}-13$ & 1.000 & .000 & . \\
\hline Black & .919 & .456 & .737 & 1.147 \\
\hline \multicolumn{5}{|l|}{ Age Group (referent is $18-25$ ) } \\
\hline $55-64$ & 1.863 & $<0.001$ & 1.492 & 2.325 \\
\hline $45-54$ & 2.057 & $<0.001$ & 1.702 & 2.486 \\
\hline $35-44$ & 1.780 & $<0.001$ & 1.486 & 2.131 \\
\hline 26-34 & 1.557 & $<0.001$ & 1.304 & 1.859 \\
\hline \multicolumn{5}{|c|}{ Illness severity (referent is Physical health diagnosis) } \\
\hline Dual psychiatric diagnosis & 59.105 & $<0.001$ & 40.869 & 85.478 \\
\hline Secondary psychiatric diagnosis & 47.787 & $<0.001$ & 32.816 & 69.588 \\
\hline Primary psychiatric diagnosis & 35.394 & $<0.001$ & 24.762 & 50.590 \\
\hline Length of enrollment & 1.038 & $<0.001$ & 1.021 & 1.055 \\
\hline
\end{tabular}


Table 9

Results of Negative Binomial Regression Analysis, Likelihood of Counseling Use by Medicaid Eligibility Type

\begin{tabular}{|c|c|c|c|c|}
\hline \multirow[b]{2}{*}{ Variable } & \multirow[b]{2}{*}{ IRR } & \multirow[b]{2}{*}{$p$-value } & \multicolumn{2}{|c|}{ 95\% Wald Confidence Interval } \\
\hline & & & Lower & Upper \\
\hline \multicolumn{5}{|c|}{ Medicaid Eligibility (referent is non-Expansion) } \\
\hline Churn & .850 & .321 & .616 & 1.173 \\
\hline Expansion & .666 & .001 & .522 & .851 \\
\hline \multicolumn{5}{|l|}{ Gender (referent is Male) } \\
\hline Female & .954 & .665 & .772 & 1.180 \\
\hline \multicolumn{5}{|l|}{ Race/Ethnicity (referent is White) } \\
\hline \multirow{2}{*}{$\begin{array}{r}\text { Other } \\
\text { American Indian or Alaska Native }\end{array}$} & 1.211 & .289 & .850 & 1.726 \\
\hline & 2.173 & .574 & .145 & 32.632 \\
\hline Asian & $2.029 \mathrm{E}-13$ & . & .000 & .000 \\
\hline Black & 1.075 & .686 & .758 & 1.524 \\
\hline \multicolumn{5}{|l|}{ Age Group (referent is 18-25) } \\
\hline $55-64$ & 1.237 & .235 & .871 & 1.758 \\
\hline $45-54$ & 1.461 & 0.012 & 1.086 & 1.964 \\
\hline $35-44$ & .975 & .892 & .743 & 1.281 \\
\hline $26-34$ & .982 & .205 & .757 & 1.274 \\
\hline \multicolumn{5}{|c|}{ Illness severity (referent is Physical health diagnosis) } \\
\hline Dual psychiatric diagnosis & 16.819 & $<.001$ & 11.746 & 24.082 \\
\hline Secondary psychiatric diagnosis & 20.366 & $<.001$ & 14.106 & 29.404 \\
\hline Primary psychiatric diagnosis & 18.757 & $<.001$ & 13.690 & 25.699 \\
\hline Length of enrollment & 1.040 & .002 & 1.014 & 1.067 \\
\hline
\end{tabular}


Table 10

Results of Negative Binomial Regression Analysis, Likelihood of Medication Use by Medicaid Eligibility Type

\begin{tabular}{|c|c|c|c|c|}
\hline \multirow{2}{*}{ Variable } & \multirow[b]{2}{*}{ IRR } & \multirow[b]{2}{*}{$p$-value } & \multicolumn{2}{|c|}{ 95\% Wald Confidence Interval } \\
\hline & & & Lower & Upper \\
\hline \multicolumn{5}{|c|}{ Medicaid Eligibility (referent is non-Expansion) } \\
\hline Churn & 1.016 & .887 & .821 & 1.256 \\
\hline Expansion & .751 & $<0.001$ & .641 & .878 \\
\hline \multicolumn{5}{|l|}{ Gender (referent is Male) } \\
\hline Female & .947 & .416 & .831 & 1.080 \\
\hline \multicolumn{5}{|l|}{ Race/Ethnicity (referent is White) } \\
\hline \multirow{2}{*}{$\begin{array}{r}\text { Other } \\
\text { American Indian or Alaska Native }\end{array}$} & .626 & $<0.001$ & .498 & .786 \\
\hline & 2.087 & .424 & .343 & 12.699 \\
\hline Asian & .841 & .896 & .062 & 11.341 \\
\hline Black & .747 & 0.013 & .594 & .940 \\
\hline \multicolumn{5}{|l|}{ Age Group (referent is 18-25) } \\
\hline $55-64$ & 3.975 & $<0.001$ & 3.187 & 4.959 \\
\hline $45-54$ & 4.036 & $<0.001$ & 3.343 & 4.873 \\
\hline $35-44$ & 3.446 & $<0.001$ & 2.891 & 4.109 \\
\hline 26-34 & 2.192 & $<0.001$ & 1.842 & 2.609 \\
\hline \multicolumn{5}{|c|}{ Illness severity (referent is Physical health diagnosis) } \\
\hline Dual psychiatric diagnosis & 12.117 & $<0.001$ & 9.883 & 14.856 \\
\hline Secondary psychiatric diagnosis & 6.324 & $<0.001$ & 5.097 & 7.846 \\
\hline Primary psychiatric diagnosis & 5.019 & $<0.001$ & 4.202 & 5.995 \\
\hline Length of enrollment & 1.027 & .001 & 1.010 & 1.043 \\
\hline
\end{tabular}


Hypothesis 3: The likelihood of mental health service utilization among Medicaid-enrolled West Louisville residents is different from that of the Medicaid-enrolled population who reside elsewhere in Louisville Metro.

\section{Louisville 2014 Medicaid Sample Demographics}

The group of 2,199 West Louisville residents who made claims to one MCO in 2014 were dissimilar from the 7,071 other Louisville residents in terms of Medicaid eligibility type, gender, race/ethnicity, illness severity, and length of enrollment. However, the groups were comparable in age. Table 11 presents the demographics of Louisville residents who utilized Medicaid coverage for health care in 2014. These demographics serve as covariates in the models that predict the effect of geography on service utilization. 
Table 11

Descriptive Statistics for Louisville Metro Residents Who Made Claims to Passport Health Plan in 2014, by Geography

\begin{tabular}{|c|c|c|c|}
\hline & $\begin{array}{c}\text { Louisville Metro } \\
\text { (Outside of West) } \\
(\mathrm{n}=7,071)\end{array}$ & $\begin{array}{c}\text { West Louisville } \\
(n=2,199)\end{array}$ & $p$-value \\
\hline \multicolumn{4}{|c|}{ Medicaid Eligibility Type (frequency (\%)) } \\
\hline Traditional & $3,924(55.5 \%)$ & $1,334(60.7 \%)$ & \multirow[t]{3}{*}{$p<0.001$} \\
\hline Expansion & $2,349(33.2 \%)$ & $640(29.1 \%)$ & \\
\hline Churn & $798(11.3 \%)$ & $225(10.2 \%)$ & \\
\hline \multicolumn{4}{|l|}{ Gender (frequency (\%)) } \\
\hline Male & $2,310(32.7 \%)$ & $663(30.2 \%)$ & \multirow[t]{2}{*}{$p<0.05$} \\
\hline Female & $4,761(67.3 \%)$ & $1,536(69.8 \%)$ & \\
\hline \multicolumn{4}{|l|}{ Race (frequency $(\%)$ ) } \\
\hline White & $1,133(16.0 \%)$ & $185(8.4 \%)$ & \multirow[t]{6}{*}{$p<0.001$} \\
\hline Black & $589(8.3 \%)$ & $468(21.3 \%)$ & \\
\hline Hispanic & $2(<0.1 \%)$ & 0 & \\
\hline Asian & $17(.2 \%)$ & $1(<0.1 \%)$ & \\
\hline American Indian or Alaska Native & $8(0.1 \%)$ & $2(<0.1 \%)$ & \\
\hline Other & $5,322(75.3 \%)$ & $1,543(70.2 \%)$ & \\
\hline \multicolumn{4}{|l|}{ Age (frequency $(\%)$ ) } \\
\hline $18-25$ & $1,777(25.1 \%)$ & $555(25.2 \%)$ & \multirow[t]{5}{*}{$p=.759$} \\
\hline $26-34$ & $1,758(24.9 \%)$ & $531(24.1 \%)$ & \\
\hline $35-44$ & $1,445(20.4 \%)$ & $477(21.7 \%)$ & \\
\hline $45-54$ & $1,333(18.9 \%)$ & $405(18.4 \%)$ & \\
\hline $55-64$ & $758(10.7 \%)$ & $231(10.6 \%)$ & \\
\hline \multicolumn{4}{|l|}{ Illness Severity (frequency $(\%)$ ) } \\
\hline Physical Health Diagnosis & $1,239(17.5 \%)$ & $419(19.1 \%)$ & \multirow[t]{4}{*}{$p<0.001$} \\
\hline Primary Psychiatric Diagnosis & $2,997(42.4 \%)$ & $1,050(47.7 \%)$ & \\
\hline Secondary Psychiatric Diagnosis & $1,260(17.8 \%)$ & $320(14.6 \%)$ & \\
\hline Dual Psych Diagnosis & $1,575(22.3 \%)$ & $410(18.6 \%)$ & \\
\hline \multicolumn{4}{|l|}{ Length of Enrollment (mean (range)) } \\
\hline Months & $7.0(1-12)$ & $7.3(1-12)$ & $p<0.001$ \\
\hline
\end{tabular}




\section{Likelihood of Mental Health Service Utilization by Louisville Geography}

Louisville residents who live in West Louisville use mental health ambulatory care services ( $I R R=0.908, p=0.007)$ and medications $(I R R=0.753, p<0.001)$ less than individuals residing outside of West Louisville when Medicaid eligibility, demographics, illness severity, and length of enrollment are held constant. The null hypothesis that residents West Louisville use mental health services at similar rates to other residents of Louisville is thus rejected for ambulatory care visits and medication use. However, the two groups are similar in their rates of use attending counseling sessions (IRR $=0.925$, $\mathrm{p}=0.162$ ). In each of the three outcome variables, the Medicaid expansion population used services less than individuals who met traditional eligibility terms. There were significant differences between rates of all service use between age groups, and service use generally increased with age. As in other analyses, a primary and/or secondary diagnosis of mental illness was significantly associated with mental health service use. This model also reflected that Blacks use medications at a lower rate than Whites, even when geography is held constant (IRR $=0.631, \mathrm{p}<0.001)$. Length of enrollment was significantly associated with all outcome variables, with individuals using mental health services at higher rates the longer they had health coverage. These results of the three models for use of ambulatory care services, counseling, and medication are presented in Table 12, Table 13, and Table 14. 
Table 12

Results of Negative Binomial Regression Analysis, Likelihood of Ambulatory Care Service Use by Geography

\begin{tabular}{|c|c|c|c|c|}
\hline \multirow[b]{2}{*}{ Variable } & \multirow[b]{2}{*}{ IRR } & \multirow[b]{2}{*}{$p$-value } & \multicolumn{2}{|c|}{ 95\% Wald Confidence Interval } \\
\hline & & & Lower & Upper \\
\hline \multicolumn{5}{|c|}{ Geography (referent is Louisville Metro outside of West Louisville) } \\
\hline West Louisville & .908 & .007 & .847 & .974 \\
\hline \multicolumn{5}{|c|}{ Medicaid Eligibility (referent is non-Expansion) } \\
\hline Churn & .939 & .242 & .845 & 1.044 \\
\hline Expansion & .835 & $<0.001$ & .772 & .903 \\
\hline \multicolumn{5}{|l|}{ Gender (referent is Male) } \\
\hline Female & .863 & $<0.001$ & .809 & .922 \\
\hline \multicolumn{5}{|l|}{ Race/Ethnicity (referent is White) } \\
\hline \multirow{2}{*}{$\begin{array}{r}\text { Other } \\
\text { American Indian or Alaska Native }\end{array}$} & .685 & $<0.001$ & .622 & .754 \\
\hline & 1.301 & .526 & .577 & 2.937 \\
\hline Asian & 1.237 & .497 & .669 & 2.287 \\
\hline Hispanic & $1.009 \mathrm{E}-12$ & . & .000 & .000 \\
\hline Black & 1.052 & .375 & .941 & 1.177 \\
\hline \multicolumn{5}{|c|}{ Age Group (referent is 18-25) } \\
\hline $55-64$ & 1.791 & $<0.001$ & 1.601 & 2.004 \\
\hline $45-54$ & 1.859 & $<0.001$ & 1.690 & 2.044 \\
\hline $35-44$ & 1.615 & $<0.001$ & 1.472 & 1.771 \\
\hline 26-34 & 1.586 & $<0.001$ & 1.452 & 1.732 \\
\hline \multicolumn{5}{|c|}{ Illness severity (referent is Physical health diagnosis) } \\
\hline Dual psychiatric diagnosis & 14.291 & $<0.001$ & 12.671 & 16.118 \\
\hline Secondary psychiatric diagnosis & 9.684 & $<0.001$ & 8.544 & 10.977 \\
\hline Primary psychiatric diagnosis & 8.636 & $<0.001$ & 7.708 & 9.676 \\
\hline Length of enrollment & 1.043 & $<0.001$ & 1.035 & 1.051 \\
\hline
\end{tabular}


Table 13

Results of Negative Binomial Regression Analysis, Likelihood of Counseling Use by Geography

\begin{tabular}{|c|c|c|c|c|}
\hline Variable & IRR & $p$-value & \multicolumn{2}{|c|}{ 95\% Wald Confidence Interval } \\
\hline \multicolumn{5}{|c|}{ Geography (referent is Louisville Metro outside of West Louisville) } \\
\hline West Louisville & .925 & .162 & .828 & 1.032 \\
\hline \multicolumn{5}{|c|}{ Medicaid Eligibility (referent is non-Expansion) } \\
\hline Churn & 1.045 & .587 & .892 & 1.224 \\
\hline Expansion & .866 & .023 & .764 & .981 \\
\hline \multicolumn{5}{|l|}{ Gender (referent is Male) } \\
\hline Female & .967 & .523 & .871 & 1.073 \\
\hline \multicolumn{5}{|l|}{ Race/Ethnicity (referent is White) } \\
\hline \multirow{2}{*}{$\begin{array}{r}\text { Other } \\
\text { American Indian or Alaska Native }\end{array}$} & .924 & .312 & .792 & 1.077 \\
\hline & .682 & .577 & .178 & 2.612 \\
\hline Asian & 1.877 & .212 & .698 & 5.048 \\
\hline Hispanic & 2.824 & .529 & .111 & 71.706 \\
\hline Black & .943 & .523 & .787 & 1.129 \\
\hline \multicolumn{5}{|l|}{ Age Group (referent is 18-25) } \\
\hline $55-64$ & 1.415 & $<0.001$ & 1.185 & 1.690 \\
\hline $45-54$ & 1.661 & $<0.001$ & 1.429 & 1.931 \\
\hline $35-44$ & 1.362 & $<0.001$ & 1.181 & 1.572 \\
\hline 26-34 & 1.359 & $<0.001$ & 1.188 & 1.554 \\
\hline \multicolumn{5}{|c|}{ Illness severity (referent is Physical health diagnosis) } \\
\hline Dual psychiatric diagnosis & 10.795 & $<0.001$ & 9.138 & 12.751 \\
\hline Secondary psychiatric diagnosis & 11.132 & $<0.001$ & 9.353 & 13.249 \\
\hline Primary psychiatric diagnosis & 11.899 & $<0.001$ & 10.213 & 13.862 \\
\hline Length of enrollment & 1.047 & $<0.001$ & 1.034 & 1.060 \\
\hline
\end{tabular}


Table 14

Results of Negative Binomial Regression Analysis, Likelihood of Medication Use by

Service Year

\begin{tabular}{|c|c|c|c|c|}
\hline & & & \% Wald & ce Interval \\
\hline Variable & IRR & $p$-value & Lower & Upper \\
\hline Geography (referent is Louisville 1 & Ietro outsid & f West L & & \\
\hline West Louisville & .753 & $<0.001$ & .705 & .805 \\
\hline Medicaid Eligibility (referent & is non-Expc & sion) & & \\
\hline Churn & 1.092 & .071 & .993 & 1.201 \\
\hline Expansion & .801 & $<0.001$ & .746 & .860 \\
\hline Gender (referent is Male) & 1 & & ${ }^{\circ}$ & e \\
\hline Female & .995 & .873 & .937 & 1.057 \\
\hline Race/Ethnicity (referent is White) & & & & \\
\hline Other & .659 & $<0.001$ & .603 & .721 \\
\hline American Indian or Alaska Native & 1.353 & .454 & .614 & 2.983 \\
\hline Asian & .685 & .215 & .377 & 1.246 \\
\hline Hispanic & $2.207 \mathrm{E}-13$ & & .000 & .000 \\
\hline Black & 631 & $<0.001$ & .566 & .704 \\
\hline Age Group (referent is 18 - & & & & \\
\hline $55-64$ & 2.918 & $<0.001$ & 2.632 & 3.234 \\
\hline 45-54 & 2.853 & $<0.001$ & 2.616 & 3.112 \\
\hline $35-44$ & 2.475 & $<0.001$ & 2.277 & 2.689 \\
\hline 26-34 & 1.764 & $<0.001$ & 1.628 & 1.911 \\
\hline Illness severity (referent is Physica & health diag & osis) & & \\
\hline Dual psychiatric diagnosis & 8.356 & $<0.001$ & 7.621 & 9.162 \\
\hline Secondary psychiatric diagnosis & 5.437 & $<0.001$ & 4.936 & 5.990 \\
\hline Primary psychiatric diagnosis & 3.937 & $<0.001$ & 3.624 & 4.278 \\
\hline Length of enrollment & 1.042 & $<0.001$ & $\mathbf{1 . 0 3 5}$ & 1.050 \\
\hline
\end{tabular}




\section{Qualitative Results}

Research Question 2: What factors besides health insurance impact utilization of mental health care by West Louisville residents?

Interviews were conducted with six health care professionals and 20 consumers.

Of the professionals, five were licensed clinical social workers and one was a licensed psychologist; two worked at FQHCs, two practiced for the local CMHC, and one had an established private practice; two provided clinic oversight; four were female and two were male. Each of the professionals had provided services to West Louisville residents for at least two years, although three professionals stated they had been in the community as long as 20 years.

The majority of the consumers interviewed were Black females. They represented six of the nine neighborhoods of West Louisville and all age groups. One fourth of the consumers did not complete twelfth grade, and another one fourth of consumers had graduated from high school or earned a GED ${ }^{\circledR}$. Although nine of the consumers interviewed had some college education, no one had completed a bachelor's degree. Of the consumers interviewed, 18 reported enrollment in Medicaid expansion. It was discovered through the course of the interviews that one consumer was eligible for Medicaid due to disability, but had enrolled since ACA implementation, and a second was eligible for Medicaid as a parent of small children. Seventeen consumers reported having been uninsured prior to their recent enrollment in Medicaid, and twelve of those reported having been uninsured for longer than one year. The demographics of the 20 consumers are displayed in Table 15. 
Table 15

Demographics of Consumer Interview Participants

\begin{tabular}{|c|c|c|c|}
\hline $\mathrm{N}=20$ & & Frequency & Percent \\
\hline \multirow[t]{9}{*}{ Neighborhood } & Algonquin & 1 & $5 \%$ \\
\hline & California & 0 & $0 \%$ \\
\hline & Chickasaw & 1 & $5 \%$ \\
\hline & Park DuValle & 0 & $0 \%$ \\
\hline & Park Hill & 0 & $0 \%$ \\
\hline & Parkland & 2 & $10 \%$ \\
\hline & Portland & 2 & $10 \%$ \\
\hline & Russell & 8 & $40 \%$ \\
\hline & Shawnee & 6 & $30 \%$ \\
\hline \multirow[t]{2}{*}{ Gender } & Male & 4 & $20 \%$ \\
\hline & Female & 16 & $80 \%$ \\
\hline \multirow[t]{5}{*}{ Age Group } & $18-25$ & 2 & $10 \%$ \\
\hline & $26-34$ & 4 & $20 \%$ \\
\hline & $35-44$ & 6 & $30 \%$ \\
\hline & $45-54$ & 4 & $20 \%$ \\
\hline & $55-64$ & 4 & $20 \%$ \\
\hline \multirow[t]{2}{*}{ Race/Ethnicity } & Black or African American & 19 & $95 \%$ \\
\hline & Native Hawaiian & 1 & $5 \%$ \\
\hline \multirow[t]{5}{*}{ Education } & 12th grade or less (no diploma) & 5 & $25 \%$ \\
\hline & High school/ GED & 5 & $25 \%$ \\
\hline & Some college, no degree & 6 & $30 \%$ \\
\hline & Associate or technical degree & 3 & $15 \%$ \\
\hline & Unknown & 1 & $5 \%$ \\
\hline \multirow[t]{2}{*}{ Prior Insurance Status } & Yes & 3 & $15 \%$ \\
\hline & No & 17 & $85 \%$ \\
\hline \multirow[t]{5}{*}{ Self-reported Health Status } & Excellent & 2 & $10 \%$ \\
\hline & Very good & 3 & $15 \%$ \\
\hline & Good & 4 & $20 \%$ \\
\hline & Fair & 7 & $35 \%$ \\
\hline & Poor & 4 & $20 \%$ \\
\hline
\end{tabular}


Initial coding of the raw data resulted in 118 first round codes. These were grouped into 50 second round codes. One first round code, Professional referral sources for mental health providers include primary care providers, hospitals, and schools, was not integrated into other iterations of coding due to dissimilarity from other identified codes. Thirteen third round codes were then grouped into six themes, while another five themes emerged during third round coding. The grouping process and emerging 11 themes are presented in Tables 16 through 26. Resultant themes described the need for mental health services among West Louisville residents, facilitators of use of mental health services, barriers to mental health services, and other influential factors that play a role in mental health service utilization. 
Table 16

Theme 1: Need for Mental Health Services

\begin{tabular}{|c|c|c|c|}
\hline Theme & Third Round Codes & Second Round Codes & First Round Codes \\
\hline \multirow{7}{*}{$\begin{array}{l}\text { West } \\
\text { Louisville } \\
\text { residents need } \\
\text { mental health } \\
\text { services }\end{array}$} & \multirow{3}{*}{$\begin{array}{l}\text { Consumers } \\
\text { experience toxic } \\
\text { stress from living in } \\
\text { West Louisville }\end{array}$} & $\begin{array}{l}\text { Poverty plays a role in } \\
\text { community mental health }\end{array}$ & $\begin{array}{l}\text { - The poor socioeconomic status } \\
\text { of the West Louisville } \\
\text { environment is stressful }\end{array}$ \\
\hline & & $\begin{array}{l}\text { Violence plays a role in } \\
\text { community mental health }\end{array}$ & $\begin{array}{l}\text { - Consumers have experienced } \\
\text { domestic violence and child } \\
\text { abuse } \\
\text { - Consumers report violence in } \\
\text { the West Louisville community } \\
\text { - Members of the community are } \\
\text { scared }\end{array}$ \\
\hline & & $\begin{array}{l}\text { Substance abuse plays a } \\
\text { role in community mental } \\
\text { heath }\end{array}$ & $\begin{array}{l}\text { - Substance abuse is a challenge } \\
\text { for the community } \\
\text { - Consumers have utilized } \\
\text { substances to escape symptoms } \\
\text { of mental illness }\end{array}$ \\
\hline & \multirow[t]{2}{*}{$\begin{array}{l}\text { Residents of West } \\
\text { Louisville see mental } \\
\text { illness in their } \\
\text { community }\end{array}$} & $\begin{array}{l}\text { Consumers in West } \\
\text { Louisville report } \\
\text { experiencing symptoms } \\
\text { of mental illness }\end{array}$ & $\begin{array}{l}\text { - Many consumers report grief } \\
\text { from losing a loved one } \\
\text { - Consumers in West Louisville } \\
\text { experience anxiety or worry } \\
\text { - Consumers in West Louisville } \\
\text { report feeling overwhelmed or } \\
\text { stressed } \\
\text { - Consumers in West Louisville } \\
\text { experience depression } \\
\text { - Consumers in West Louisville } \\
\text { report feelings of hopelessness }\end{array}$ \\
\hline & & $\begin{array}{l}\text { Consumers report mental } \\
\text { health symptoms in } \\
\text { others }\end{array}$ & $\begin{array}{l}\text { - Other people in my family have } \\
\text { mental health issues }\end{array}$ \\
\hline & \multirow[t]{2}{*}{$\begin{array}{l}\text { Residents of West } \\
\text { Louisville recognize } \\
\text { that mental health } \\
\text { plays a role in doing } \\
\text { what they want to do } \\
\text { and need to do }\end{array}$} & $\begin{array}{l}\text { Consumers are aware that } \\
\text { mental health is a part of } \\
\text { overall health }\end{array}$ & $\begin{array}{l}\text { - Physical health impacts mental } \\
\text { health when you can't do what } \\
\text { you want and need to do } \\
\text { - Mental health impacts physical } \\
\text { health } \\
\text { - There is a relationship between } \\
\text { depression and pain }\end{array}$ \\
\hline & & $\begin{array}{l}\text { Consumers report that } \\
\text { mental health impacts } \\
\text { function }\end{array}$ & $\begin{array}{l}\text { - Poor mental health results in } \\
\text { anger } \\
\text { - Poor mental health results in } \\
\text { poor engagement in daily tasks } \\
\text { - Poor mental health results in } \\
\text { isolation } \\
\text { - Mental health symptoms result } \\
\text { in sleep problems }\end{array}$ \\
\hline
\end{tabular}




\section{Table 17}

\section{Theme 2: ACA has Positively Influenced Access}

\begin{tabular}{|c|c|c|}
\hline Theme & Second Round Codes & First Round Codes \\
\hline \multirow[t]{2}{*}{$\begin{array}{l}\text { ACA has } \\
\text { positively } \\
\text { influenced } \\
\text { access to } \\
\text { mental health } \\
\text { services for } \\
\text { Medicaid } \\
\text { consumers }\end{array}$} & $\begin{array}{l}\text { ACA has expanded } \\
\text { access to mental health } \\
\text { services }\end{array}$ & $\begin{array}{l}\text { - ACA is allowing for expansion of } \\
\text { provider capacity } \\
\text { - Consumers have more choice of where } \\
\text { to receive care } \\
\text { - Medicaid expansion has increased } \\
\text { access to care for consumers } \\
\text { - Medicaid has eliminated or } \\
\text { significantly reduced the cost of } \\
\text { services for consumers }\end{array}$ \\
\hline & $\begin{array}{l}\text { The consumer population } \\
\text { has changed since the } \\
\text { implementation of ACA }\end{array}$ & $\begin{array}{l}\text { - Providers recognize increasing } \\
\text { diversity in their patient population } \\
\text { - Providers have experienced an influx } \\
\text { of new groups of patients who have not } \\
\text { received mental health care previously }\end{array}$ \\
\hline
\end{tabular}

\section{Table 18}

\section{Theme 3: Bureaucracy is a Barrier to Utilization}

\begin{tabular}{|c|c|c|}
\hline Theme & Second Round Codes & First Round Codes \\
\hline \multirow[t]{2}{*}{$\begin{array}{l}\text { Bureaucracy } \\
\text { surrounding } \\
\text { mental health } \\
\text { care is a } \\
\text { barrier to } \\
\text { utilization }\end{array}$} & $\begin{array}{l}\text { Cost of services is a } \\
\text { barrier for both providers } \\
\text { and consumers }\end{array}$ & $\begin{array}{l}\text { - Providers have had to identify } \\
\text { alternative funding sources to meet } \\
\text { consumers' needs } \\
\text { - Without insurance, the out-of-pocket } \\
\text { costs kept people from getting services } \\
\text { - For some, co-pays force a choice } \\
\text { between care and basic needs }\end{array}$ \\
\hline & $\begin{array}{l}\text { Medicaid/MCOs present } \\
\text { barriers to providing and } \\
\text { accessing services }\end{array}$ & $\begin{array}{l}\text { - The administrative burden of working } \\
\text { with MCOs discourages providers from } \\
\text { accepting Medicaid } \\
\text { - The time it takes to complete } \\
\text { administrative tasks detracts time from } \\
\text { provider capacity } \\
\text { - Access to medications can be } \\
\text { complicated by MCO regulations } \\
\text { - Navigating the MCOs is difficult and } \\
\text { frustrating for consumers who are } \\
\text { attempting to get care }\end{array}$ \\
\hline
\end{tabular}


Table 19

Theme 4: Lack of Provider Availability is a Barrier to Access and Use

\begin{tabular}{|c|c|c|c|}
\hline Theme & Third Round Codes & Second Round Codes & First Round Codes \\
\hline \multirow[t]{5}{*}{$\begin{array}{l}\text { Lack of } \\
\text { adequate } \\
\text { provider } \\
\text { availability in } \\
\text { West } \\
\text { Louisville is a } \\
\text { barrier to } \\
\text { access and use } \\
\text { of mental } \\
\text { health services }\end{array}$} & \multirow[t]{3}{*}{$\begin{array}{l}\text { Access to mental } \\
\text { health providers for } \\
\text { the West Louisville } \\
\text { community remains } \\
\text { difficult }\end{array}$} & $\begin{array}{l}\text { Access is impacted by } \\
\text { provider availability }\end{array}$ & $\begin{array}{l}\text { - Lack of providers in } \\
\text { Louisville } \\
\text { - Lack of providers who take } \\
\text { Medicaid } \\
\text { - Lack of provider capacity to } \\
\text { see clients at the time that they } \\
\text { need services (Provider } \\
\text { perception) } \\
\text { - Because of the lack of mental } \\
\text { health providers in the local } \\
\text { community who accept } \\
\text { Medicaid, consumers } \\
\text { practically do not have } \\
\text { choices in providers }\end{array}$ \\
\hline & & $\begin{array}{l}\text { The West Louisville } \\
\text { community has limited } \\
\text { access to providers in } \\
\text { proximity and to } \\
\text { providers whose diversity } \\
\text { reflects that of the } \\
\text { population }\end{array}$ & $\begin{array}{l}\text { - There is a lack of African } \\
\text { American providers in } \\
\text { Louisville } \\
\text { - The availability of providers } \\
\text { in West Louisville is different } \\
\text { from that in East Louisville }\end{array}$ \\
\hline & & $\begin{array}{l}\text { Many providers have no } \\
\text { incentive to establish a } \\
\text { practice in West } \\
\text { Louisville }\end{array}$ & $\begin{array}{l}\text { - Staff turnover results from } \\
\text { working in a high stress } \\
\text { environment for low wages } \\
\text { Employers prefer staff } \\
\text { commitment to the population } \\
\text { to reduce turnover and meet } \\
\text { consumer needs } \\
\text { - Because of the context of } \\
\text { West Louisville, providers do } \\
\text { not want to practice there, and } \\
\text { they don't have to in order to } \\
\text { sustain their business }\end{array}$ \\
\hline & \multirow[t]{2}{*}{$\begin{array}{l}\text { Access to local } \\
\text { mental health } \\
\text { providers is a factor in } \\
\text { utilization }\end{array}$} & $\begin{array}{l}\text { Consumers do not have } \\
\text { flexibility in } \\
\text { transportation }\end{array}$ & $\begin{array}{l}\text { - Consumers use public } \\
\text { transportation to get to } \\
\text { appointments } \\
\text { - Use of public transportation is } \\
\text { a barrier to accessing services } \\
\text { - Consumers rely on family and } \\
\text { friends for rides } \\
\text { - Consumers walk to } \\
\text { appointments }\end{array}$ \\
\hline & & $\begin{array}{l}\text { Location is a factor in } \\
\text { using services }\end{array}$ & $\begin{array}{l}\text { Location of services is } \\
\text { important in terms of } \\
\text { proximity and bus routes }\end{array}$ \\
\hline
\end{tabular}


Table 20

Theme 5: Stigma Persists in the West Louisville Community

\begin{tabular}{|c|c|c|}
\hline Theme & Second Round Codes & First Round Codes \\
\hline \multirow{3}{*}{$\begin{array}{l}\text { The stigma of } \\
\text { using mental } \\
\text { health services } \\
\text { persists in the } \\
\text { West } \\
\text { Louisville } \\
\text { community }\end{array}$} & $\begin{array}{l}\text { Culture influences the } \\
\text { acceptability of } \\
\text { discussing mental health }\end{array}$ & $\begin{array}{l}\text { - Black people don't talk about mental } \\
\text { health } \\
\text { - Stigma is magnified in some cultures or } \\
\text { populations }\end{array}$ \\
\hline & $\begin{array}{l}\text { Consumers have negative } \\
\text { beliefs about using } \\
\text { mental health services }\end{array}$ & $\begin{array}{l}\text { - Consumers are afraid of what they } \\
\text { think mental health care entails } \\
\text { - Consumers are ashamed or } \\
\text { embarrassed to acknowledge they have } \\
\text { mental health needs }\end{array}$ \\
\hline & $\begin{array}{l}\text { The community hears } \\
\text { negative beliefs about } \\
\text { mental illness }\end{array}$ & $\begin{array}{l}\text { - People joke or use derogatory } \\
\text { terminology about mental health that } \\
\text { increase the shame and embarrassment } \\
\text { - The environment of a provider can } \\
\text { reinforce the perceptions of stigma }\end{array}$ \\
\hline
\end{tabular}




\section{Table 21}

Theme 6: Poor Health Literacy is a Barrier to Utilization

\begin{tabular}{|c|c|c|c|}
\hline Theme & Third Round Codes & Second Round Codes & First Round Codes \\
\hline \multirow[t]{5}{*}{$\begin{array}{l}\text { Poor health } \\
\text { literacy is a } \\
\text { barrier to use } \\
\text { of mental } \\
\text { health services }\end{array}$} & \multirow[t]{2}{*}{$\begin{array}{l}\text { Social constraints } \\
\text { influence knowledge }\end{array}$} & $\begin{array}{l}\text { The population has } \\
\text { difficulty defining mental } \\
\text { health, and the } \\
\text { perspectives vary widely }\end{array}$ & $\begin{array}{l}\text { - People define mental health in } \\
\text { terms of mental illness or } \\
\text { "unhealthy" } \\
\text { - People define mental health as } \\
\text { functionality } \\
\text { - People recognize that mental } \\
\text { health problems are not } \\
\text { always visible to others }\end{array}$ \\
\hline & & $\begin{array}{l}\text { Consumers learn about } \\
\text { resources through their } \\
\text { social networks }\end{array}$ & $\begin{array}{l}\text { - Consumers rely on friends and } \\
\text { family to learn where services } \\
\text { are and what resources are } \\
\text { trusted }\end{array}$ \\
\hline & \multirow[t]{3}{*}{$\begin{array}{l}\text { Consumers present } \\
\text { with poor health } \\
\text { literacy }\end{array}$} & $\begin{array}{l}\text { Consumers do not know } \\
\text { their options for mental } \\
\text { health services }\end{array}$ & $\begin{array}{l}\text { - Seven Counties is an } \\
\text { established and well-known } \\
\text { entity in the community; some } \\
\text { consumers think they are the } \\
\text { only provider } \\
\text { - Consumers do not know } \\
\text { where services are offered }\end{array}$ \\
\hline & & $\begin{array}{l}\text { Consumers present with } \\
\text { poor mental health } \\
\text { literacy }\end{array}$ & $\begin{array}{l}\text { - Consumers lack basic mental } \\
\text { health literacy } \\
\text { - Some consumers do not } \\
\text { connect mental health to } \\
\text { overall health }\end{array}$ \\
\hline & & $\begin{array}{l}\text { Consumers present with } \\
\text { poor health insurance } \\
\text { literacy }\end{array}$ & $\begin{array}{l}\text { - Consumers don't know their } \\
\text { insurance benefits }\end{array}$ \\
\hline
\end{tabular}


Table 22

Theme 7: Community Resources impact Utilization

\begin{tabular}{|c|c|c|c|}
\hline Theme & Third Round Codes & Second Round Codes & First Round Codes \\
\hline \multirow[t]{6}{*}{$\begin{array}{l}\text { Community } \\
\text { resources } \\
\text { impact use of } \\
\text { mental health } \\
\text { services }\end{array}$} & \multirow[t]{4}{*}{$\begin{array}{l}\text { Logistics influence } \\
\text { the use of mental } \\
\text { health services }\end{array}$} & $\begin{array}{l}\text { Housing impacts mental } \\
\text { health }\end{array}$ & $\begin{array}{l}\text { - Instability in housing is a } \\
\text { barrier to treatment } \\
\text { - Instability in housing is a } \\
\text { stressor }\end{array}$ \\
\hline & & $\begin{array}{l}\text { Child care impacts use of } \\
\text { services }\end{array}$ & $\begin{array}{l}\text { - Lack of child care is a barrier } \\
\text { to utilizing mental health } \\
\text { services }\end{array}$ \\
\hline & & $\begin{array}{l}\text { Scheduling impacts use } \\
\text { of services }\end{array}$ & $\begin{array}{l}\text { - Lack of capacity results in } \\
\text { long waits for appointments } \\
\text { - Many consumers work and } \\
\text { need appointment times that } \\
\text { allow them to maintain } \\
\text { employment }\end{array}$ \\
\hline & & $\begin{array}{l}\text { Consumers do not have } \\
\text { flexibility in } \\
\text { transportation }\end{array}$ & $\begin{array}{l}\text { - Consumers use public } \\
\text { transportation to get to } \\
\text { appointments } \\
\text { - Use of public transportation is } \\
\text { a barrier to accessing services } \\
\text { - Consumers rely on family and } \\
\text { friends for rides } \\
\text { - Consumers walk to } \\
\text { appointments } \\
\end{array}$ \\
\hline & \multirow[t]{2}{*}{$\begin{array}{l}\text { Socio-economic } \\
\text { factors of the West } \\
\text { Louisville community } \\
\text { influence consistent } \\
\text { use of mental health } \\
\text { services }\end{array}$} & $\begin{array}{l}\text { Consumers need } \\
\text { community supports }\end{array}$ & $\begin{array}{l}\text { - Consumers identify a need for } \\
\text { resources } \\
\text { - There is a need for services } \\
\text { beyond the medical model } \\
\text { (provider perception) }\end{array}$ \\
\hline & & $\begin{array}{l}\text { Providers are aware of } \\
\text { social factors that } \\
\text { influence use of services }\end{array}$ & $\begin{array}{l}\text { Providers acknowledge that } \\
\text { some of the no-shows are } \\
\text { based on factors in } \\
\text { consumers' lives } \\
\text { - Some providers are } \\
\text { implementing strategies to } \\
\text { accommodate consumers' } \\
\text { scheduling needs }\end{array}$ \\
\hline
\end{tabular}


Table 23

Theme 8: Support Systems Influence Utilization

\begin{tabular}{|c|c|c|c|}
\hline Theme & Third Round Codes & Second Round Codes & First Round Codes \\
\hline \multirow[t]{7}{*}{$\begin{array}{l}\text { Support } \\
\text { systems have a } \\
\text { strong } \\
\text { influence on } \\
\text { use of mental } \\
\text { health services }\end{array}$} & \multirow[t]{4}{*}{$\begin{array}{l}\text { Social relationships } \\
\text { can facilitate use of } \\
\text { mental health service }\end{array}$} & $\begin{array}{l}\text { Family supports mental } \\
\text { health promotion }\end{array}$ & $\begin{array}{l}\text { - Family inspires someone to } \\
\text { take initiative towards health } \\
\text { - Family directs someone to } \\
\text { seek help } \\
\text { - Family is generally supportive } \\
\text { of using mental health } \\
\text { services } \\
\text { - I can talk to a family member } \\
\text { about my stressors }\end{array}$ \\
\hline & & $\begin{array}{l}\text { Community networks } \\
\text { support mental health } \\
\text { promotion }\end{array}$ & $\begin{array}{l}\text { - I use a friend for emotional } \\
\text { support } \\
\text { - Consumers rely on friends and } \\
\text { family to learn where services } \\
\text { are and what resources are } \\
\text { trusted } \\
\text { - Living in a homeless shelter } \\
\text { facilitates receipt of mental } \\
\text { health treatment } \\
\end{array}$ \\
\hline & & $\begin{array}{l}\text { Faith and religion play a } \\
\text { role in mental health } \\
\text { promotion }\end{array}$ & $\begin{array}{l}\text { - Consumers have used pastoral } \\
\text { counseling } \\
\text { - Consumers practice } \\
\text { expressions of faith as a } \\
\text { positive alternative strategy }\end{array}$ \\
\hline & & $\begin{array}{l}\text { Consumers value } \\
\text { knowing they are not } \\
\text { alone }\end{array}$ & $\begin{array}{l}\text { Consumers report group } \\
\text { therapy enables a connection } \\
\text { with other people who have } \\
\text { similar problems }\end{array}$ \\
\hline & \multirow[t]{3}{*}{$\begin{array}{l}\text { The social } \\
\text { environment can be a } \\
\text { barrier to use of } \\
\text { mental health services }\end{array}$} & $\begin{array}{l}\text { Family and friends may } \\
\text { not positively influence } \\
\text { use of mental health } \\
\text { services }\end{array}$ & $\begin{array}{l}\text { - Family doesn't think that I } \\
\text { should need mental health } \\
\text { services } \\
\text { - Family is judgmental of me } \\
\text { - Family does not discuss } \\
\text { mental health } \\
\text { - Lack of a support system is a } \\
\text { barrier to using mental health } \\
\text { services }\end{array}$ \\
\hline & & $\begin{array}{l}\text { The social environment } \\
\text { plays a role in the success } \\
\text { of treatment }\end{array}$ & $\begin{array}{l}\text { Some consumers recognize } \\
\text { that once the counseling } \\
\text { session is over, they have to } \\
\text { return to the toxic stress of the } \\
\text { environment, and therefore it } \\
\text { is not helpful }\end{array}$ \\
\hline & & $\begin{array}{l}\text { The stigma of using } \\
\text { mental health services is } \\
\text { a barrier to use of mental } \\
\text { health services }\end{array}$ & $\begin{array}{l}\text { - Family and friends joke or use } \\
\text { derogatory terminology about } \\
\text { mental health that increase the } \\
\text { shame and embarrassment } \\
\text { - Stigma is magnified in some } \\
\text { cultures or populations }\end{array}$ \\
\hline
\end{tabular}


Table 24

\section{Theme 9: Consumers in West Louisville Use Mental Health Services}

\begin{tabular}{|c|c|c|c|}
\hline Theme & Third Round Codes & Second Round Codes & First Round Codes \\
\hline \multirow[t]{6}{*}{$\begin{array}{l}\text { Some } \\
\text { consumers in } \\
\text { West } \\
\text { Louisville will } \\
\text { use mental } \\
\text { health services }\end{array}$} & \multirow[t]{3}{*}{$\begin{array}{l}\text { Consumers } \\
\text { acknowledge the } \\
\text { benefits of mental } \\
\text { health treatment }\end{array}$} & $\begin{array}{l}\text { Some consumers will } \\
\text { use medications for } \\
\text { treatment }\end{array}$ & $\begin{array}{l}\text { - Consumers want a quick } \\
\text { resolution to their problems by } \\
\text { using medication only (provider } \\
\text { perception) } \\
\text { - A medical provider } \\
\text { recommended medications } \\
\text { - Medications can be effective for } \\
\text { symptom management } \\
\text { - Consumers bring their } \\
\text { medication concerns to their } \\
\text { provider }\end{array}$ \\
\hline & & $\begin{array}{l}\text { Consumers report } \\
\text { positive results of } \\
\text { mental health treatment }\end{array}$ & $\begin{array}{l}\text { - Consumers report that } \\
\text { counseling helps } \\
\text { - Results of counseling include a } \\
\text { change in thinking } \\
\text { - Results of counseling include a } \\
\text { change in behavior } \\
\text { - Results of counseling include a } \\
\text { change in self-concept } \\
\text { - Consumers engage in activities } \\
\text { as positive strategies to improve } \\
\text { mental health }\end{array}$ \\
\hline & & $\begin{array}{l}\text { Consumer attitudes } \\
\text { toward mental health } \\
\text { treatment evolve }\end{array}$ & $\begin{array}{l}\text { - Consumers appear to be wary of } \\
\text { mental health treatment until } \\
\text { they try it } \\
\text { - Providers perceive an increasing } \\
\text { open-mindedness toward mental } \\
\text { health treatment } \\
\text { - The younger generation presents } \\
\text { with less reservation about using } \\
\text { mental health services }\end{array}$ \\
\hline & \multirow[t]{3}{*}{$\begin{array}{l}\text { Consumers are } \\
\text { currently using } \\
\text { mental health } \\
\text { services }\end{array}$} & $\begin{array}{l}\text { Some consumers can } \\
\text { access outpatient } \\
\text { mental health services }\end{array}$ & $\begin{array}{l}\text { - A minority of consumers drive a } \\
\text { personal vehicle to appointments } \\
\text { - Some consumers can make } \\
\text { appointments as they need to }\end{array}$ \\
\hline & & $\begin{array}{l}\text { Some consumers have } \\
\text { accessed inpatient } \\
\text { services }\end{array}$ & $\begin{array}{l}\text { - Consumers have been } \\
\text { hospitalized for mental illness }\end{array}$ \\
\hline & & $\begin{array}{l}\text { Consumers will } \\
\text { independently initiate } \\
\text { use of mental health } \\
\text { services }\end{array}$ & $\begin{array}{l}\text { Some consumers recognized a } \\
\text { need for treatment and decided } \\
\text { to do something good for } \\
\text { themselves by actively seeking } \\
\text { help } \\
\text { - Some consumers were motivated } \\
\text { by wanting something better for } \\
\text { their lives }\end{array}$ \\
\hline
\end{tabular}


Table 25

Theme 10: Importance of the Therapeutic Relationship

\begin{tabular}{|c|c|c|}
\hline Theme & Second Round Codes & First Round Codes \\
\hline \multirow[t]{4}{*}{$\begin{array}{l}\text { Importance of } \\
\text { relationship } \\
\text { between } \\
\text { providers and } \\
\text { consumers in } \\
\text { mental health } \\
\text { treatment }\end{array}$} & $\begin{array}{l}\text { Consumers appreciate } \\
\text { having a professional to } \\
\text { whom they can talk } \\
\text { without judgment }\end{array}$ & $\begin{array}{l}\text { - Consumers in West Louisville } \\
\text { expressed a need for an outlet to which } \\
\text { they can vent } \\
\text { - Some people would rather talk to a } \\
\text { mental health professional than a friend } \\
\text { because they know a professional } \\
\text { won't judge them }\end{array}$ \\
\hline & $\begin{array}{l}\text { Consumers want } \\
\text { empathy and respect } \\
\text { from providers }\end{array}$ & $\begin{array}{l}\text { - Consumers do not like counseling } \\
\text { when they feel the counselor is not } \\
\text { engaged } \\
\text { - Consumers are perceptive to the ability } \\
\text { of a provider to listen with genuine } \\
\text { concern and provide person-centered } \\
\text { services } \\
\text { - People want to feel respected }\end{array}$ \\
\hline & $\begin{array}{l}\text { Trust is important for } \\
\text { facilitating use of } \\
\text { mental health services }\end{array}$ & $\begin{array}{l}\text { - Trust is an important factor for the } \\
\text { West Louisville population } \\
\text { - Consumers are more open to treatment } \\
\text { if they develop a trusting relationship } \\
\text { with their provider } \\
\text { - Consumers do not want to attend group } \\
\text { therapy because they are not } \\
\text { comfortable disclosing personal } \\
\text { information to that many people they } \\
\text { don't know and don't trust }\end{array}$ \\
\hline & $\begin{array}{l}\text { Providers reflect on the } \\
\text { influence they have on } \\
\text { consumers' comfort } \\
\text { with participation in } \\
\text { treatment }\end{array}$ & $\begin{array}{l}\text { - Providers acknowledge that trust is } \\
\text { imperative in a therapeutic relationship } \\
\text { - Providers are sensitive to the effect of } \\
\text { turnover on consumers, but consumers } \\
\text { did not mention this } \\
\text { - Providers perceive that having } \\
\text { providers who looks like the patient } \\
\text { population is important (provider } \\
\text { perception) }\end{array}$ \\
\hline
\end{tabular}


Table 26

Theme 11: Resistance to Mental Health Treatment

\begin{tabular}{|l|l|l|}
\hline \multicolumn{1}{|c|}{ Theme } & Second Round Codes & \multicolumn{1}{c|}{ First Round Codes } \\
\hline $\begin{array}{l}\text { Some } \\
\text { consumers are } \\
\text { resistant to } \\
\text { mental health } \\
\text { treatment }\end{array}$ & $\begin{array}{l}\text { Some consumers do not } \\
\text { initiate treatment, } \\
\text { despite referral }\end{array}$ & $\begin{array}{l}\text { - Some consumers were referred to } \\
\text { treatment, but didn't follow through } \\
\text { because they didn't think they needed } \\
\text { it, didn't think it would work, or didn't } \\
\text { want to go }\end{array}$ \\
\cline { 2 - 3 } & $\begin{array}{l}\text { Some consumers } \\
\text { disengage from } \\
\text { treatment for various } \\
\text { reasons }\end{array}$ & $\begin{array}{l}\text { - Providers express concern regarding } \\
\text { consumer commitment and consistency } \\
\text { in treatment } \\
\text { - When people start to feel better, they } \\
\text { no longer perceive a need for treatment }\end{array}$ \\
\cline { 2 - 4 } & $\begin{array}{l}\text { Some consumers do not } \\
\text { want to take } \\
\text { medications for mental } \\
\text { health }\end{array}$ & $\begin{array}{l}\text { Consumers do not consistently take } \\
\text { medications as prescribed (without } \\
\text { provider consultation) } \\
\text { - Consumers experience side effects of } \\
\text { psychotropic medication } \\
\text { - Consumers know someone who has } \\
\text { experienced negative side effects from } \\
\text { medication } \\
\text { - Consumers do not perceive they need } \\
\text { medication }\end{array}$ \\
& &
\end{tabular}

\section{Need for Mental Health Services}

\section{West Louisville residents need mental health services}

Consumers and providers both spoke about the environment of West Louisville and the toxic stress that residents endure. While an alarming proportion of consumers mentioned that a family member or friend had been murdered, others referred to the trauma they had experienced, or simply the stress of living in a "bad neighborhood." One consumer summed up the status of West Louisville:

We have a lot of problems down here... We're living in poverty down here and depression is so bad that you don't even want to come out your door because you livin' in a war zone. Usually you run into people that's usin' or sellin' or out just, you know, that they don't have nothin' in the world.

Consumers recognized signs of mental illness in others around them and spoke of their own feelings of anxiety, depression, and hopelessness. As they described their symptoms 
of poor mental health, they reported anger and isolation, with difficulty sleeping, or engaging in daily activities. One consumer described her battle with depression:

I didn't want to clean up. I didn't want to be bothered with nobody. I'm like, "I don't remember the last...I haven't been out of the house for over a week." I just didn't even want to step on the porch and check my mail. I was just in a bad place.

Additionally, consumers linked their mental health to overall health, which more than half described as fair or poor.

\section{Facilitators of Use of Mental Health Services}

\section{ACA has positively influenced access to mental health services for Medicaid consumers}

Both providers and consumers reported that the implementation of the ACA has had positive results for access to mental health treatment. Providers recognized systemic changes, such as the ability of private practitioners to accept Medicaid and the theoretical increase of consumer choice that would result. They also noted more diversity in their caseloads as more consumers who are new to counseling have sought services. After telling stories about the inability to get care without insurance, consumers reported that the majority of costs associated with mental health treatment had been eliminated. One consumer reported:

I was going through depression...I just never go nowhere because if they required [MCO] or some kind of medical insurance... As the years went on, it got worse. My mind's got worse and it got worse...Now, by me having [Medicaid expansion] I'm able to really get the proper care that I need, my medicine. As far as the counseling, and the little guidance that you get from your therapist at [CMHC].

\section{Barriers to Using Mental Health Services}

Despite ACA, both consumers and providers described ongoing barriers to using mental health services. 


\section{Bureaucracy surrounding mental health care is a barrier to utilization}

Although ACA has eliminated many costs associated with using health care, both providers and consumers mentioned that there are continued copays for some services. Providers shared that they had applied for grants and external funding to ensure they could provide needed services as no cost or minimal cost to the consumer. Furthermore, both providers and consumers reported that accepting Medicaid is an administrative burden that consumes their time, especially to request prior authorizations for counseling or prescriptions. When consumers mentioned interactions with MCOs, they described their attempts at navigating insurance as frustrating.

\section{Lack of provider availability in West Louisville is a barrier to access and utilization}

When asked about other providers in West Louisville, providers repeatedly noted the same few. Not only did they mention that it is more difficult to identify providers in the West End than in other areas of town, they also reinforced that the majority of providers in all of Louisville do not take Medicaid. One provider stated:

All those people, overnight, got mental health coverage. We had no more mental health providers the day after ACA went into effect than we did the day before.

Providers additionally reported that other providers may not be willing to practice there because of the high stress demands of the job in the environment of West Louisville.

Although only a few consumers directly recognized limited provider availability, more spoke about not knowing their options, other than the well-established CMHC. In relationship to their need for providers to be located nearby, however, nearly 75 percent of consumers reported they rely on public transportation, ask for rides from family and friends, or walk when they have appointments. They stressed that the proximity of health 
care in relationship to their homes was important due to a lack of flexibility in transportation.

\section{Stigma persists in the West Louisville community}

The concept of stigma was reiterated through consumers' discussion about how friends and family perceived mental health and use of mental health services, and reinforced by providers' perceptions of attitudes toward mental health in the community. Consumers referred to the culture of their community, stating that "Black people are too proud" to use mental health services or that their friends and family do not talk about mental health. Consumers spoke about the negative connotation associated with mental illness. One consumer stated:

People don't talk about stuff, they make jokes out of it. As far as, "Oh, you're bipolar, " or "You're crazy." People just take words and don't know what they really mean.

A second consumer referred specifically to the stigma of mental illness:

It's like, I don't know why people be putting like a stigma on it that it's not good to see somebody. I met people throughout my lifetime where they don't want to go because it makes you crazy and stuff.

Consumers' statements provided evidence that they felt judged and embarrassed by using mental health services.

\section{Poor Health Literacy is Barrier to Utilization}

Consumers' health literacy can be viewed in terms of their understanding of mental health, their knowledge of health insurance benefits, and their familiarity with the local health care system. This sample presented with low education levels and general literacy levels, with half the sample ceasing to pursue education prior to or at the end of high school. Mental health literacy was reflected in consumers' language about mental 
health and their perceptions about the purpose of mental health services. Definitions of mental health varied widely; in general, however, the definitions presented described the behaviors or symptoms of someone who is mentally unhealthy. They shared their beliefs

about the mental health care system, but they mentioned that they rely on their family and friends or the media for health information.

\section{Other Factors That Influence Mental Health Service Utilization}

\section{Community resources impact use of mental health services}

Both consumers and providers spoke of the low socio-economic status of the West Louisville community and the complicated logistics of seeking care. They referred to difficulty with housing, child care, and transportation, and the impact that has on scheduling and keeping a health care appointment. Consumers reported that they found it helpful when providers pointed them toward resources available outside their appointments. Providers perceived that consumers require community supports beyond the medical model to improve mental health, such as peer supports and case management to aid individuals in following through with tasks at home. A provider from an $\mathrm{FQHC}$ stated:

If we have someone who we would really like to refer and say, get them connected with [CMHC]. The prospect of going through that all by themselves is overwhelming. I can help them schedule the first time appointment.

Providers also reported that they have implemented strategies to accommodate consumers' needs, such as open clinic hours for flexible scheduling and seeking to provide services in locations to which consumers already go. 


\section{Support Systems Influence Utilization}

The data reflect that support systems can be either a facilitator or barrier to use of mental health services. Consumers reported that they initiated seeking help because of their children or had been instructed by a friend or relative to get care. One provider noticed that the older generation facilitates mental health care utilization:

What I'm finding is that grandparents in particular have a great influence on young adults and children seeking and continuing to get help that wouldn't continue with us otherwise.

However, consumers were equally as likely to state their children were the instigators of using mental health services. One consumer stated that his son had told him to go to counseling:

You know what [my son] said to me? He said, "What's wrong with you?" He said, "You need to go get help," and I went. He gave me \$20, dude. My 16 year old kid gave me \$20 and put me in a cab.

Other consumers went to friends for advice or had support systems outside of therapy that motivated them to participate in mental health promotion strategies. Consumers who appreciated group therapy sessions stated that they appreciated knowing they were not alone and that other people were in similar stressful situations. Some consumers also found support in their faith and religious communities, reporting that they had asked a pastor for counsel.

Conversely, lack of social support can negatively influence use of mental health services. Some consumers were hesitant to participate in treatment due to the judgment of family and friends or the reports of others who had tried treatment, especially regarding medications. One provider mentioned that the symptoms of mental illness can overwhelm 
a person's ability to cognitively process the steps toward seeking treatment without a support system.

\section{Use of Mental Health Services}

Many of the consumers interviewed had used or were currently using mental health services. They reported the results of treatment and what they liked or disliked about providers they had encountered. A few consumers had reported trying mental health services but not currently using them. Only one consumer in this sample had never used mental health services despite a referral in the past.

\section{Consumers in West Louisville Use Mental Health Services}

Consumers interviewed had used the entire continuum of care from inpatient to outpatient services. Some reported that transportation and scheduling did not hold them back from getting to appointments. Those who reported appreciating counseling described positive changes in their thinking, behaviors, self-concept, and use of alternative strategies to improve their mental health outside of counseling sessions. Two consumers described the good feelings they experienced from counseling:

It's good, it makes me feel good. It makes me feel like I'm doing something for myself, number one. It makes me feel like I'm digging through dirt, trying to get to the root of the problem. It makes me feel like I'm advocating for myself, which I never really do.

At first I was like...I mean, really for real, to be honest, I really had no selfrespect for myself because people make me feel like that... She tells me, thank God, she tells me that she sees good in me...It makes me feel good, that somebody does.

A third consumer reported that despite the toxic environment of West Louisville, counseling had taught him to employ positive strategies to release tension:

You've got fights going on and you got weapons pulled, but me, I'm going to dance my ass off. 
Providers had noticed that the attitudes toward use of mental health services had begun to change in the community. Providers also reported their perception that consumers often seek care and want a quick resolution to their symptoms by taking medication and not wanting to participate in counseling. However, there was no supportive evidence of this in the sample of consumers.

\section{Importance of the therapeutic relationship}

The concept of trust was repeated throughout the interviews. Both consumers and providers were sensitive to the therapeutic relationship. Consumers often spoke about the need to have an outlet for venting their stress, and their preference to speak to someone who would listen to them without judgment. Although providers perceived that consumers might prefer a provider population that reflects the diversity of the community, consumer interviews did not substantiate this. Consumers placed importance on the quality of the provider's ability to listen with empathy and treat them with respect.

\section{Resistance to mental health treatment}

Regardless of need, the idea that some consumers will not use mental health treatment emerged. Some consumers admitted they did not follow through with a provider's recommendation to pursue treatment, either due to lack of motivation or because they did not feel they needed it. Providers expressed concern that some consumers stopped participating in treatment when they felt better, and only returned when they experienced another crisis. Many consumers spoke specifically about their

dislike for medications, either because they had experienced side effects or because they 
had witnessed others' experiences of side effects. One consumer described the effect:

I hated it. It made me tired all the time...I don't take that anymore. It just...I didn't like how it made you feel...I felt spaced out.

Another consumer explained why counseling was not effective for her:

It didn't help. 'Cause the problem was still there when I got up and left. You know, I was still depressed and just like, it didn't help at all.

The experiences of these consumers inhibited their desire to continue with mental health treatment.

This study investigated changes in the rates of utilization of mental health care by a largely segregated urban population following the implementation of health care reform policies that include increased access to health care coverage and mental health parity. The results of this study demonstrate that Medicaid expansion has not impacted overall rates of utilization of mental health services by West Louisville residents but the Medicaid expansion population uses mental health services at a lower rate than other beneficiaries of Medicaid. Qualitative results provide evidence that factors other than health insurance that influence use of mental health services in the West Louisville community include the number of providers, bureaucracy, stigma, health literacy, and social relationships. Despite limitations of this study, these results can be applicable to local policy, public health practice, and future research. 


\section{CHAPTER V \\ DISCUSSION AND CONCLUSIONS}

A publication from the Kentucky Governor's Office reports that Medicaid claims data reflect a 68 percent increase in use of mental health services by Kentucky adults between 2013 and 2014 (2015). This study highlighted a small part of that increase by focusing on the utilization patterns of designated mental health services by one specific population within the state that has consistently experienced poor access to services and health disparities over time. The results of this study have implications for public health policy and practice to continue to improve the health of Kentuckians.

\section{The Impact of Medicaid Expansion on Utilization of Mental Health Services for Residents of West Louisville Neighborhoods}

Quantitative results of this study reflected that although the overall use of mental health services by West Louisville residents increased in 2014, the rate of utilization based on the number of Medicaid beneficiaries did not significantly change with the implementation of ACA. However, results of analysis indicated that there were differences in rates of utilization of all mental health services between Medicaid eligibility groups. The expansion population in West Louisville used ambulatory care services, counseling, and psychotropic medications at lower rates than the traditional Medicaid population, who may have had coverage Medicaid in years prior. Additionally, the traditional Medicaid population includes adults with serious and persistent mental 
illness who qualify for disability and may use services at a greater rate than the general population.

Finally, results indicated that even with Medicaid expansion, the West Louisville population utilizes ambulatory care and psychotropic medication at a lower rate than other residents of Louisville Metro. These results may be linked; claims for mental health ambulatory care visits are most often psychiatry visits for medication management. Qualitative results of this study indicate limitations in provider availability in West Louisville, especially psychiatrists, and resultant long wait times for receipt of psychiatric care. Thus, even if a new enrollee who lived in West Louisville attempted to make an appointment with a psychiatrist, this service may not have been immediately available. Of note, the results of this study may represent conservative estimates because this study was unable to capture the encounters in which a primary care provider prescribes psychotropic medications. Because office visits and prescription fills were not linked, there was no indication that an office visit to a primary care provider addressed any mental health needs. Primary care providers are a substantial contributor to medication oversight (Olfson, Kroenke, Wang, \& Blanco, 2014), especially when a consumer does not want simultaneous counseling (Brody, Khaliq, \& Thompson, 1997).

Consumers' race/ethnicity was largely undefined in the dataset. Analysis of mental health service use by race/ethnicity therefore may not be meaningful in this analysis. However, for each hypothesis, of those whose race/ethnicity was identified, Blacks used medication at a significantly lower rate than Whites. This is consistent with findings in the literature, which have identified that Blacks use psychotropic medications 
at lower rates than Whites and would prefer counseling to medication (Brody et al., 1997; Diaz et al., 2005; Gonzalez et al., 2008).

A notable trend throughout the analyses was the impact of age on service use. In every model, individuals ages 45 through 54 in all racial and ethnic groups used services at a significantly higher rate than the younger adult referent group, and often at higher rates than all other age groups. During qualitative interviews, one provider observed a need for support of older adults in the community, citing the added stressors of grandparents raising their grandchildren while remaining in the workforce.

Due to the large size of this dataset, analysis was able to detect small differences between groups. This was the case with length of enrollment: length of enrollment appeared to have statistical significance as a predictor of differences in services use in some models. However, when examined more closely, the length of enrollment was not practically significant in any event.

\section{Factors Other Than Health Insurance That Impact Utilization of Mental Health Services}

Despite 11 distinct emergent themes in the qualitative data, the raw data and the results presented with interconnected concepts. The culture and socioeconomic environment of West Louisville has not only influenced consumers' need for mental health services, but also the availability of community resources that might enhance mental health promotion and the use and success of therapeutic services. The toxic stress of the community both increases the potential demand for services and serves as a barrier to the establishment of an adequate supply of service providers. Furthermore, the chaos of living in an environment of toxic stress can result in difficulty with negotiating the 
logistics to attend an appointment (i.e., scheduling, childcare, and transportation) with existing providers.

Although the quantitative results of this study demonstrate mixed results regarding the impact of Medicaid expansion on use of mental health services, qualitative results indicate that there has been a recognized need for mental health care in the West Louisville community and that individuals who have enrolled in Medicaid through the expansion have utilized services. For those West Louisville residents who have pursued mental health treatment using their new Medicaid benefits, the ACA has been successful. Consumers repeatedly reported that they had needed treatment prior to the implementation of Medicaid expansion, but were unable to seek care without insurance. Without the barrier of cost, consumers have discovered that both counseling and medication use have aided them to relieve anxiety, gain coping skills, and generally feel better.

However, the success of the ACA has been constrained in the West End. The implementation of the ACA has increased the potential for more individuals to use services and consumers to have more choice of service providers, but this potential has thus far been unrealized. Without new providers moving into the West Louisville community, service use continues to be limited by a defined provider capacity, regardless of how many individuals hold a Medicaid card. Providers find the bureaucracy of becoming a Medicaid provider burdensome and the West Louisville population inconsistent in appointment attendance, and can establish a thriving and lucrative practice in other areas of town without needing to accept Medicaid. 
Health literacy and stigma are somewhat intertwined as both are influenced by one's social community; preconceived and negative judgments regarding mental illness result in rumors and misinterpretations of symptoms of mental health and the purpose of services in addition to an individual's feelings of embarrassment and shame for having a mental health condition. Defined as the skills to read and understand information in order to make decisions about one's health (Nielsen-Bohlman, Panzer, \& King, 2004), health literacy is influenced by education and general literacy. Poor health literacy is aligned with low education rates for the West Louisville community. With low health literacy rates, this population is less likely to successfully navigate the challenges presented by the bureaucracy of Medicaid and MCOs.

Stigma can also limit one's social support system for utilizing mental health care. Although individuals may reach out to family and friends for recommendations for health care providers, this may not be the case for mental health care due to stigma. A culture of not talking about mental health additionally yields poor literacy regarding mental health issues, available services, and what types of treatment may be beneficial. When people do ask for the trusted opinions of others, they are limited to the knowledge of that social circle.

Generally, the literature emphasizes a lack of trust in medical providers among the Black population (Bailey et al., 2011). The qualitative results of this study demonstrate that trust is important to the West Louisville population, and imperative for a therapeutic relationship. The strength of the therapeutic relationship influences the outcome of the intervention, whether that is counseling or medication. Individuals who reported that they trusted their providers also reported they found value in counseling and 
were likely to accept a provider's recommendations to try medications. However, with limited choices in providers, residents of West Louisville may be less likely to identify a provider with whom they feel comfortable.

Consumers' descriptions of their symptoms of mental illness reflect grief, anger, hopelessness, and apathy. Experiencing these symptoms without intervention can play a role in the community's ongoing violence and poverty. One consumer summarized the fact that anger causes problems in her community:

When a person's mad and very upset, they don't think, people don't think. They going to do the first that come to they head. They ain't thinking about no consequences or nothing. I was there.

Such emotions interrupt education and productivity, which in turn can result in poor literacy rates, unemployment, crime, and substance abuse. Thus, the cycle of toxic stress persists (Shern, Blanch, \& Steverman, 2016). After completing a needs assessment in West Louisville, one provider reflected that the community is seeking mental health promotion:

The community is saying, "We have mental health needs that are unmet and they hold the community back from being socially and economically strong and vibrant."

Strengthening the conditions and socioeconomic environment of West Louisville depends on the mental health of its residents.

The current study began to answer research questions regarding the impact of Medicaid expansion on mental health service utilization within a low-socioeconomic status minority population that has historically suffered significant barriers to care and subsequent health disparities. Perhaps more importantly, the study raised additional ideas and questions that highlight the complexity of mental health within this population. 
Although Medicaid expansion and the parity of ACA have impacted use of mental health services, the new law has not eliminated mental health disparities. Some of the very things that cause poor mental health within a community can also pose as barriers to that community's access to care.

\section{Public Health Policy Implications}

The ACA, with its provisions for Medicaid expansion and mental health parity, was designed to offer financial protection through insurance coverage to increase access to services. However, Medicaid expansion was ruled by the Supreme Court as an option for state implementation ("National Federation of Independent Business (NFIB) v. Sebelius, 567 U. S. __, 2012). Consequently, the poorest residents of states that did not adopt Medicaid expansion have been caught in a coverage gap, still unable to access affordable health insurance or preventive care (Han, Nguyen, Drope, \& Jemal, 2015). Benitez, Creel, and Jennings (2016) confirmed that the ACA is in fact benefitting Kentuckians in the lowest income bracket by removing financial barriers to accessing health care, unlike neighboring states that did not adopt Medicaid expansion.

Quantitative results offer evidence that there was a rise in use of mental health services with the implementation of Medicaid expansion, but that it may not have been significant due to the lack of an increase in provider capacity between years. These results suggest the importance of creating a workforce development plan and fostering a workforce pipeline, especially for underserved areas. Qualitative results of this study reinforce that some of the individuals in the West Louisville community did not use mental health care services prior to receiving insurance coverage due to their inability to pay out of pocket for care; these needs went unmet. Thus the law has provided an initial 
step toward improving the dismal health outcomes that have persisted in the state. Consequently, changes to reduce the benefits of Kentucky's Medicaid expansion policy would negatively affect mental health care for residents of West Louisville and other Kentuckians who live in poverty.

The Office of the Assistant Secretary for Planning and Evaluation (ASPE) in the U.S. Department of Health and Human Services published an issue brief in March 2016 regarding the benefits of Medicaid expansion for behavioral health (Dey et al., 2016). The report concluded that individuals who qualify for Medicaid expansion have behavioral health needs, access to treatment results in improved health outcomes, and there are economic benefits to the state in which Medicaid is expanded as a result of addressing the population's behavioral health needs. Health and the economy are intimately linked (Bloom \& Canning, 2008), and there is evidence that economic recessions are associated with a rise in mental illness (Hodgkin \& Karpman, 2010). The current poor mental health status of Kentuckians results in lower workforce participation rate and low productivity (Childress, \& Sharpe, 2015). The majority of adults who can benefit from Medicaid expansion in Kentucky are working in low-wage jobs as contributing members of Kentucky's economy (Bailey, 2015). State policies that promote access to health care, such as Medicaid expansion, will support economic growth for the state.

Medicaid expansion alone has not removed all barriers to care for some populations. Other barriers, such as provider availability and stigma, require health system transformation to align clinical and economic incentives with mental health care. Medicaid must incentivize providers to establish practices that expand access and choice 
for populations that face health disparities. This includes holding MCOs accountable for mental health parity in terms of coverage, reimbursement, and provider network adequacy. Kentucky Medicaid and MCOs should also be held accountable for compliance with race and ethnicity reporting requirements issued by the CMS so that accurate data can be available for analysis of ongoing disparities (CMS, 2014).

The health system can also incentivize integrated care models, which promote holistic care and attend to consumers' socioeconomic position as it impacts medical needs and adherence to care recommendations. This may include the co-location of health services, a medical-legal partnership, and Medicaid coverage of home and community-based supports that reduce institutionalization. Integrated care can increase effective and appropriate service utilization by using the trust gained by one provider to reduce stigma. This also increases consumer and engagement and improves adherence for the individuals served (Kuramoto, 2014). Ultimately, integrated care and attention to the social determinants of health can improve health outcomes while lowering costs for both payers and consumers.

Beyond the ACA and health care policy, Louisville Metro policies can significantly reduce barriers presented by the West Louisville environment. The city's decision-making process can promote health equity by the active implementation of its Health in All Policies perspective, which addresses the community's health through the consideration of health determinants across sectors, such as economic development, transportation, environmental protections, education, and safety (Puska, 2007). Louisville Metro leadership and Louisville Metro Public Health and Wellness have an opportunity to foster a culture of health. In West Louisville, this includes investment in community 
development, which can have significant effects on mental health by reducing toxic stress.

\section{Public Health Practice Implications}

WHO notes that mental health is more than the absence of mental illness (2004b). Considering mental health promotion in public health practice requires a substantial culture change that might begin with accurate and timely data collection. As noted in Chapter II, surveillance of mental health conditions occurs through a myriad of surveys, each with differing operational definitions of mental illness. Furthermore, many epidemiologic studies were completed using data from the National Comorbidity Survey Replication (NCS-R), which was executed more than a decade ago (Kessler et al., 2004). The examination of disease prevalence and the effects they have on sub-populations can assist in planning interventions and assessing outcomes (Freeman et al., 2010).

Secondly, mental health must be a national public health priority that is translated to the health care community. The U.S. Preventive Services Task Force recommends screening for depression in adolescents and adults, and depression screens are an essential benefit all health insurance plans (U.S. Department of Health and Human Services, 2010; U.S. Preventive Services Task Force, 2016). The recommendation of the Task Force not only draws attention to a need for primary care practitioners to consider the mental health of their patients, but also for the health care community to ensure the ability to care for individuals with a positive depression screening. However, in a culture

of mental health promotion, the recommendation for mental health promotion should not merely include depression screening, but also the number of other mental health diagnoses that can impact a person's overall wellbeing. 
Finally, mental health must be a local public health priority. Interventions should be designed to reduce stigma, such that it is acceptable to talk about mental health and strategies for mental health promotion. For the West Louisville population, this also includes mental health literacy and education regarding symptoms of mental illness, the assistance that mental health services might provide, and choices in local service providers. Results of the study provide evidence that the Medicaid expansion population use services at a lower rate than those on traditional Medicaid and younger adults use services at a lower rate than older adults. Specific outreach and education efforts should target populations who may be new to health insurance and the health care system. These interventions should be made in the context of the social environment, with the understanding that one's social network can influence mental health and use of mental health services (Primm et al., 2010).

Since the toxic stress of West Louisville plays such a significant role in the mental health of that community, public health interventions must also target reducing institutional and socioeconomic stressors and the impact they have on individuals. Louisville Metro Public Health and Wellness must play a role in the development of an infrastructure that addresses the social determinants of health. Other interventions can be designed to minimize the impact of toxic stress by improving the resilience of West Louisville residents (Bonanno, 2004; Diehl, Hay, \& Chui, 2012).

\section{Study Limitations}

The limitations of the MCO dataset impacted the results of this study, specifically the limited number of assigned diagnoses and the number of cases whose race/ethnicity was labeled as other. The inability to link primary care visits to psychotropic medication 
management may have underrepresented the true results for both ambulatory care visits and medication use. Without the ability to identify site of service, data analysis could not investigate the proximity of a consumer to a provider or other provider-level associations with service utilization.

This study was limited in its consideration of time, as claims data were available for only one year post-expansion. This provided a limited time to allow for new Medicaid beneficiaries to learn about services available to them and for providers to expand their capacity to meet the demands of growing covered population needing services. The one year pre-post design limited the ability to capture any changes throughout the first year of the new policy. Observing smaller intervals in time, such as quarters, would have enabled a closer look at any changes in service utilization as more individuals enrolled throughout the year.

The specific culture of Louisville Metro may limit the generalizability of the findings to other communities or even neighborhoods. Although the dynamics surrounding race and residential segregation are not necessarily unique to Louisville, the local history and subsequent intergenerational socialization of the city's residents is undoubtedly unique. Within the culture of Louisville Metro, there may be a difference between individuals who choose Passport Health Plan over other MCOs, thus creating a sample bias within quantitative methodology using only the one Medicaid plan.

The qualitative methods of this study attempted to describe the entirety of the population living in West Louisville. However, there may be cultural or access differences between the nine neighborhoods, particularly those in which an FQHC is located. The participants in this study were not representative of the diversity of the West 
Louisville population. Also, within any community, there is a wide range of opinions and experiences with mental health issues. One provider observed, "We can pick 10 patients just at random. You could talk to each one of them and all 10 of them will tell you something different."

Additionally, the majority of participants in this study reported they were currently engaged in mental health treatment or had used services in the past. This population is inherently different from those who experience symptoms of mental illness but do not use treatment, either because they do not recognize the need or otherwise choose not to seek help. Barriers to utilizing services may be different for individuals who do seek care than for those who do not. Selection bias may have also influenced the data collected, because individuals who were willing to participate in a study may also be more willing to participate in counseling sessions than someone who chooses to not discuss his or her mental health. Because the racial and ethnic demographics of the qualitative sample did not reflect the overall demographics of the West Louisville community, White residents of West Louisville may not experience the same influences on their use of mental health services.

\section{Future Research}

The results of this study provide numerous implications for future research. Quantitative methodology would benefit from use of a larger, more comprehensive dataset, such as all Medicaid claims for Jefferson County over a longer span of time, with data to compare Louisville to other similar communities with differing characteristics in their delivery system. It would also be valuable to examine all payer claims data to compare differences between use of mental health services by Medicaid beneficiaries and 
by individuals covered by private insurance plans. This would enable analysis of trends in utilization and enable comparisons to establish best practice. Additionally, Medicaid enrollment data that provides a more complete picture of consumer demographics would allow for analysis of the association between consumer characteristics and use of mental health services, such as differences between racial and ethnic groups and the utilization of services associated with an individual's primary diagnosis. This larger dataset would also enable a closer look at the population of individuals who churned from traditional Medicaid eligibility to eligibility through Medicaid expansion to investigate how churning might be associated with differences in care-seeking behaviors.

A number of provider-level studies should also be pursued, as this study clearly associated the disparity in the availability of local providers to consumers' use of services and there is value in examining clinic- and provider-level fixed effects. Future research should examine the population of consumers who are prescribed medication by a primary care provider and the relationship of service utilization to provider type. Additional research should also continue to delve into the differences between the West Louisville community and others in Louisville Metro by exploring use of inpatient care and differences in the rate of time between inpatient and outpatient follow up.

The addition of depression screens as an essential health benefit should increase the incidence that this tool is used in primary care practice. The number of claims for depression screens by primary care providers was limited in this MCO dataset and could not be isolated for meaningful analysis. Future research should investigate both the use of depression screening and the follow up on positive screens. 
Coverage of services for substance abuse were also added to Medicaid plans with the ACA. Qualitative results of this study highlighted that substance abuse serves as a contributor to toxic stress as well as a coping strategy for mental illness. Future research should not only further explore these qualitative findings, but also investigate use of substance abuse services and their impact on community health and economic outcomes.

Finally, the study of mental health should not take place in a vacuum, recognizing interconnectedness of social and health issues and environment. This includes measuring the long-term impact of utilization of mental health services on overall health and socioeconomic outcomes. The community needs to understand mechanisms that work to address the system in its entirety to be able to adequately create and sustain an environment where everyone has the opportunity to be healthy. 


\section{REFERENCES}

Abrams, L. S., Dornig, K., \& Curran, L. (2009). Barriers to service use for postpartum depression symptoms among low-income ethnic minority mothers in the United States. Qualitative Health Research, 19, 535-551. doi:10.1177/1049732309332794

Agency for Healthcare Research and Quality. (2014). 2013 National Healthcare Disparities Report (14-0006). Retrieved from the AHRQ website: www.ahrq.gov/research/findings/nhqrdr/index.html

Agency for Healthcare Research and Quality. (2016). Medical Expenditure Panel Survey Retrieved from the AHRQ website: http://meps.ahrq.gov/mepsweb/

Alegria, M., Chatterji, P., Wells, K., Cao, Z., Chen, C. N., Takeuchi, D., . . Meng, X. L. (2008). Disparity in depression treatment among racial and ethnic minority populations in the United States. Psychiatric Service, 59, 1264-1272. doi:10.1176/appi.ps.59.11.1264

Alegria, M., Fortuna, L. R., Lin, J. Y., Norris, F. H., Gao, S., Takeuchi, D. T., . . Valentine, A. (2013). Prevalence, risk, and correlates of posttraumatic stress disorder across ethnic and racial minority groups in the United States. Medical Care, 51, 1114-1123. doi:10.1097/mlr.0000000000000007

Allen, H., Baicker, K., Finkelstein, A., Taubman, S., \& Wright, B. J. (2010). What the Oregon health study can tell us about expanding Medicaid. Health Affairs, 29, 1498-1506. doi:10.1377/hlthaff.2010.0191

American Psychological Association. (2000). Diagnostic and statistical manual of mental disorders (4th ed., text rev. ed.). Washington, DC: Author.

Amri, R., Stronks, K., Bordeianou, L. G., Sylla, P., \& Berger, D. L. (2014). Gender and ethnic disparities in colon cancer presentation and outcomes in a US universal health care setting. Journal of Surgical Oncology, 109, 645-651. doi:10.1002/jso. 23567

Andersen, R., \& Newman, J. F. (1973). Societal and individual determinants of medical care utilization in the United States. Milbank Quarterly, 51, 95-124. 
Anesetti-Rothermel, A., \& Sambamoorthi, U. (2011). Physical and mental illness burden: Disability days among working adults. Population Health Management, 14, 223 230. doi:10.1089/pop.2010.0049

Asnaani, A., Richey, J. A., Dimaite, R., Hinton, D. E., \& Hofmann, S. G. (2010). A cross-ethnic comparison of lifetime prevalence rates of anxiety disorders. Journal of Nervous and Mental Disease, 198, 551-555. doi:10.1097/NMD.0b013e3181ea169f

Bagalman , E., \& Napili, A. (2014). Prevalence of mental illness in the United States: Data sources and estimates. Retrieved from the Federation of American Scientists website: https://www.fas.org/sgp/crs/misc/R43047.pdf

Baicker, K., Taubman, S. L., Allen, H. L., Bernstein, M., Gruber, J. H., Newhouse, J. P., . . . Smith, J. (2013). The Oregon experiment--Effects of Medicaid on clinical outcomes. New England Journal of Medicine, 368, 1713-1722. doi:10.1056/NEJMsa1212321

Bailey, J. (2015). Many Kentucky Workers Have Gained Insurance through the Medicaid Expansion, Are at Risk If Program Is Scaled Back [blog]. Retrieved from the Kentucky Center for Economic Policy website: http://kypolicy.org/manykentucky-workers-have-gained-insurance-through-the-medicaid-expansion-are-atrisk-if-program-is-scaled-back/

Bailey, R. K., Patel, M., Barker, N. C., Ali, S., \& Jabeen, S. (2011). Major depressive disorder in the African American population. Journal of National Medical Association, 103, 548-557.

Barrett, B., Fogel, S., Garrett, J., \& Young, M. S. (2011). Assessing health care needs among street homeless and transitionally housed adults. Journal of Social Service Research, 37, 338-350. doi:10.1080/01488376.2011.564073

Barry, C. L. (2004). Trends in mental health care [issue brief]. Washington, DC: The Commonwealth Fund.

Barry, C. L., Huskamp, H. A., \& Goldman, H. H. (2010). A political history of federal mental health and addiction insurance parity. Milbank Quarterly, 88, 404-433. doi:10.1111/j.1468-0009.2010.00605.x

Bazelon Center for Mental Health Law. (2014). Medicaid: Lifeline for children and adults with serious mental illnesses. Retrieved from the Bazelon Center website: http://www.bazelon.org/LinkClick.aspx?fileticket=ARq331Ujs3Q\%3D\&tabid=40

Beardsley, R. S., Gardocki, G. J., Larson, D. B., \& Hidalgo, J. (1988). Prescribing of psychotropic medication by primary care physicians and psychiatrists. Archives of General Psychiatry, 45, 1117-1119. 
Benitez, J. A., Creel, L., \& Jennings, J. (2016). Kentucky's Medicaid Expansion Showing Early Promise On Coverage And Access To Care. Health Affairs, 35, 528-534. doi:10.1377/hlthaff.2015.1294

Berdahl, T. A., Friedman, B. S., McCormick, M. C., \& Simpson, L. (2013). Annual report on health care for children and youth in the United States: Trends in racial/ethnic, income, and insurance disparities over time, 2002-2009. Academic Pediatrics, 13, 191-203. doi:10.1016/j.acap.2013.02.003

Bernstein, J., Chollet, D., \& Peterson, S. (2010). How Does Insurance Coverage Improve Health Outcomes? [issue brief]. Princeton, NJ: Mathematica Policy Research, Inc.

Bigelow, D. A., McFarland, B. H., MCCamant, L. E., Deck, D. D., \& Gabriel, R. M. (2004). Effect of managed care on access to mental health services among medicaid enrollees receiving substance treatment. Psychiatric Services, 55, 775779 .

Bloom, D. E., \& Canning, D. (2008). Population Health and Economic Growth. Washington, DC: The International Bank for Reconstruction and Development and The World Bank on behalf of the Commission on Growth and Development.

Bonanno, G. A. (2004). Loss, trauma, and human resilience: Have we underestimated the human capacity to thrive after extremely aversive events? American Psychologist, 59(1), 20-28. doi:10.1037/0003-066X.59.1.20

Bradley, E. H., Curry, L. A., \& Devers, K. J. (2007). Qualitative data analysis for health services research: Developing taxonomy, themes, and theory. Health Service Research, 42, 1758-1772. doi:10.1111/j.1475-6773.2006.00684.x

Breslau, J., Aguilar-Gaxiola, S., Kendler, K. S., Su, M., Williams, D., \& Kessler, R. C. (2006). Specifying race-ethnic differences in risk for psychiatric disorder in a USA national sample. Psychological Medicine, 36, 57-68. doi:10.1017/S0033291705006161

Breslau, J., Kendler, K. S., Su, M., Gaxiola-Aguilar, S., \& Kessler, R. C. (2005). Lifetime risk and persistence of psychiatric disorders across ethnic groups in the United States. Psychological Medicine, 35, 317-327.

Brody, D. S., Khaliq, A. A., \& Thompson, T. L. (1997). Patients' perspecitves on the management of emotional distress in primary care settings. Journal of General Internal Medicine, 12, 403-406.

Brown, C., Schulberg, H. C., \& Madonia, M. J. (1996). Clinical presentations of major depression by African Americans and whites in primary medical care practice. Journal of Affective Disorders, 41, 181-191. 
Bruce, M. L., Takeuchi, D. T., \& Leaf, P. J. (1991). Poverty and psychiatric status. Longitudinal evidence from the New Haven Epidemiologic Catchment Area study. Archives of General Psychiatry, 48, 470-474.

Bryant, K., Greer-Williams, N., Willis, N., \& Hartwig, M. (2013). Barriers to diagnosis and treatment of depression: Voices from a rural African-American faith community. Journal of the National Black Nurses Association, 24(1), 31-38.

Buchmueller, T. C., Grumbach, K., Kronick, R., \& Kahn, J. G. (2005). The effect of health insurance on medical care utilization and implications for insurance expansion: A review of the literature. Medical Care Research and Review, 62(1), 3-30. doi:10.1177/1077558704271718

Byers, A. L., Arean, P. A., \& Yaffe, K. (2012). Low use of mental health services among older Americans with mood and anxiety disorders. Psychiatric Services, 63, 6672.

Call, K. T., McAlpine, D. D., Garcia, C. M., Shippee, N., Beebe, T., Adeniyi, T. C., \& Shippee, T. (2014). Barriers to care in an ethnically diverse publicly insured population: Is health care reform enough? Medical Care, 52, 720-727. doi:10.1097/mlr.0000000000000172

Center for Behavioral Health Statistics and Quality. (2014). The N-MHSS Report: Introduction to the National Mental Health Services Survey, 2010. Retrieved from the SAMHSA website: http://www.samhsa.gov/data/sites/default/files/NMHSSSR178-Intro-2014/NMHSS-SR178-Intro-2014.pdf

Center for Behavioral Health Statistics and Quality. (2015). Behavioral Health Trends in the United States: Results from the 2014 National Survey on Drug Use and Health. Retrieved from the SAMHSA website: http://www.samhsa.gov/data/sites/default/files/NSDUH-FRR1-2014/NSDUHFRR1-2014.pdf

Centers for Disease Control and Prevention. (2011, October 4, 2013). Non-specific psychological distress. Retrieved from http://www.cdc.gov/mentalhealth/data_stats/nspd.htm

Centers for Disease Control and Prevention. (2012). Suicide: Facts at a glance. Atlanta, GA: Centers for Disease Control and Prevention.

Centers for Disease Control and Prevention. (2016a). Behavioral Risk Factor Surveillance System. Retrieved from http://www.cdc.gov/brfss/

Centers for Disease Control and Prevention. (2016b). National Health and Nutrition Examination Survey. Retrieved from http://www.cdc.gov/nchs/nhanes.htm 
Centers for Disease Control and Prevention. (2016c). National Health Interview Survey. Retrieved from http://www.cdc.gov/nchs/nhis.htm

Centers for Medicare and Medicaid Services. (2012). Screening for Depression in Adults. Retrieved from the CMS website: https://www.cms.gov/Outreach-andEducation/Medicare-Learning-NetworkMLN/MLNMattersArticles/downloads/MM7637.pdf

Centers for Medicare and Medicaid Services. (2013). Measure 6: Screening for Clinical Depression and Follow-up Plan. Retrieved from the CMS website: https://www.medicaid.gov/Medicaid-CHIP-Program-Information/ByTopics/Quality-of-Care/Downloads/Medicaid-Adult-Core-Set-ManualDepression-Screening-Revised.pdf

Centers for Medicare and Medicaid Services. (2014). Eligible professional meaningful use core measures: Measure 7 of 13. Retrieved from the CMS website: https://www.cms.gov/Regulations-andGuidance/Legislation/EHRIncentivePrograms/downloads/7_Record_Demographi cs.pdf

Centers for Medicare and Medicaid Services. (2015). Medicaid.gov: Behavioral Health Services. Retrieved from http://www.medicaid.gov/Medicaid-CHIP-ProgramInformation/By-Topics/Benefits/Mental-Health-Services.html

Chen, J., \& Rizzo, J. (2010). Racial and Ethnic Disparities in Use of Psychotherapy: Evidence From U.S. National Survey Data. Psychiatric Services, 61, 364-372.

Childress, M. T. (2012). A Profile of Kentucky Medicaid Mental Health Diagnoses 20002010. Retrieved from http://uknowledge.uky.edu/cber_researchreports/2/

Childress, M. T., \& Sharpe, J. M. (Eds.). (2015). Kentucky Annual Economic Report 2015. Retrieved from the Center for Business and Economic Research website: http://cber.uky.edu/Downloads/CBER_2015_AnnualReport.pdf

Chou, C. H., Tulolo, A., Raver, E. W., Hsu, C. H., \& Young, G. (2013). Effect of race and health insurance on health disparities: Results from the National Health Interview Survey 2010. Journal of Health Care for the Poor and Underserved, 24, 1353-1363. doi:10.1353/hpu.2013.0131

Chung, J. Y., Frank, L., Subramanian, A., Galen, S., Leonhard, S., \& Green, B. L. (2012). A qualitative evaluation of barriers to care for trauma-related mental health problems among low-income minorities in primary care. Journal of Nervous and Mental Disease, 200, 438-443. doi:10.1097/NMD.0b013e31825322b3 
Clark, C. R., Soukup, J., Govindarajulu, U., Riden, H. E., Tovar, D. A., \& Johnson, P. A. (2011). Lack of access due to costs remains a problem for some in Massachusetts despite the state's health reforms. Health Affairs, 30, 247-255.

doi:10.1377/hlthaff.2010.0319

Clemans-Cope, L., Long, S. K., Coughlin, T. A., Yemane, A., \& Resnick, D. (2013). The expansion of Medicaid coverage under the ACA: Implications for health care access, use, and spending for vulnerable low-income adults. Inquiry, 50, 135-149. doi: $10.1177 / 0046958013513675$

Collins, D. (2003). Pretesting survey instruments: An overview of cognitive methods. Quality of Life Research, 12, 229-238. doi:10.1023/A:1023254226592

Colton, C. W., \& Manderscheid, R. W. (2006). Congruencies in increased mortality rates, years of potential life lost, and causes of death among public mental health clients in eight states. Preventing Chronic Disease, 3(2), A42.

Cook, B. L., McGuire, T., \& Miranda, J. (2007). Measuring trends in mental health care disparities, 2000-2004. Psychiatric Services, 58, 1533-1540. doi:10.1176/appi.ps.58.12.1533

Corrigan, P. W., Druss, B. G., \& Perlick, D. A. (2014). The impact of mental illness stigma on seeking and participating in mental health care. Psychological Science in the Public Interest, 15(2), 37-70. doi:10.1177/1529100614531398

Courtemanche, C. J., \& Zapata, D. (2014). Does universal coverage improve health? The Massachusetts experience. Journal of Policy Anaysis andl Management, 33(1), 36-69. doi:10.1002/pam.21737

Creswell, J. W., Hanson, W. E., Clark Plano, V. L., \& Morales, A. (2007). Qualitative research designs: Selection and implementation. Counseling Psychologist, 35, 236-264. doi:10.1177/0011000006287390

Crutcher, D. (2013). The West End. Louisville Magazine, 24-29.

Dalton, A. R., Vamos, E. P., Harris, M. J., Netuveli, G., Wachter, R. M., Majeed, A., \& Millett, C. (2014). Impact of universal health insurance coverage on hypertension management: A cross-national study in the United States and England. PLOS One, 9(1), e83705. doi:10.1371/journal.pone.0083705

Davidson, S., Judd, F., Jolley, D., Hocking, B., \& Thompson, S. (2000). The general health status of people with mental illness. Australasian Psychiatry, 8, 31-35.

Dey, J., Rosenoff, E., West, K., Ali, M. M., Lynch, S., McClellan, C., . . Woodward, A. (2016). ASPE issue breif: Benefits of Medicaid expansion for behavioral health. Washington, DC: U.S. Department of Health and Human Services. 
Diaz, E., Woods, S. W., \& Rosenheck, R. A. (2005). Effects of ethnicity on psychotropic medications adherence. Community Mental Health Journal, 41, 521-537. doi:10.1007/s10597-005-6359-x

Diehl, M., Hay, E. L., \& Chui, H. (2012). Personal risk and resilience factors in the context of daily stress. Annual Review of Gerontology and Geriatrics, 32(1), 251274. doi:10.1891/0198-8794.32.251

Dixon, R. B., \& Hertelendy, A. J. (2014). Interrelation of preventive care benefits and shared costs under the Affordable Care Act (ACA). International Journal of Health Policy and Management, 3, 145-148. doi:10.15171/ijhpm.2014.76

Donohue, J., Garfield, R., \& Lave, J. (2010). The impact of expanded health insurance coverage on individuals with mental illnesses and substance use disorders. Retrieved from http://www.wchsa.org/vertical/sites/\%7BB5D9E240-2100-4AE1B9FD-C91DC7DBA2A5\%7D/uploads/\%7BEF33AA4A-558D-4D6D-9870EEFBC0B20FEA\%7D.PDF

Druss, B. G., Hwang, I., Petukhova, M., Sampson, N. A., Wang, P. S., \& Kessler, R. C. (2009). Impairment in role functioning in mental and chronic medical disorders in the United States: Results from the National Comorbidity Survey Replication. Molecular Psychiatry, 14, 728-737. doi:10.1038/mp.2008.13

Druss, B. G., Wang, P. S., Sampson, N. A., Olfson, M., Pincus, H. A., Wells, K. B., \& Kessler, R. C. (2007). Understanding mental health treatment in persons without mental diagnoses: Results from the National Comorbidity Survey Replication. Archives of General Psychiatry, 64, 1196-1203. doi:10.1001/archpsyc.64.10.1196

Eisenberg, D., Hunt, J., Speer, N., \& Zivin, K. (2011). Mental health service utilization among college students in the United States. Journal of Nervous and Mental Disease, 199, 301-308. doi:10.1097/NMD.0b013e3182175123

Esri. (2012). ArcGIS 10.1. Redlands, CA: Esri.

Everett, A., \& Lee, S. Y. (2012). Community and Public Mental Health Services in the United States: History and Programs. In W. W. Eaton (Ed.), Public Mental Health (pp. 396-414). New York, NY: Oxford University Press.

Fang, J., Yang, Q., Ayala, C., \& Loustalot, F. (2014). Disparities in access to care among US adults with self-reported hypertension. American Journal of Hypertension, 27, 1377-1386. doi:10.1093/ajh/hpu061

Farley, P. J. (1985). Who are the underinsured? Milbank Quarterly, 63, 476-503. 
Fayanju, O. M., Kraenzle, S., Drake, B. F., Oka, M., \& Goodman, M. S. (2014). Perceived barriers to mammography among underserved women in a Breast Health Center Outreach Program. American Journal of Surgery, 208, 425-434. doi:10.1016/j.amjsurg.2014.03.005

Field, A. (2009). Disocvering statistics using SPSS (3rd ed.). Los Angeles, CA: Sage.

Finkelstein, A., Taubman, S., Wright, B., Bernstein, M., Gruber, J., Newhouse, J. P., . . . Oregon Health Study, G. (2012). The Oregon Health Insurance Experiment: Evidence from the First Year. Quarterly Journal of Economics, 127, 1057-1106.

Fox, J. B., \& Shaw, F. E. (2014). Relationship of income and health care coverage to receipt of recommended clinical preventive services by adults: United States, 2011-2012. Morbidity and Mortality Weekly Report, 63, 666-670.

Frank, R. G., Beronio, K., \& Glied, S. A. (2014). Behavioral health parity and the Affordable Care Act. Journal of Social Work in Disability and Rehabilitation. doi:10.1080/1536710x.2013.870512

Frank, R. G., \& Glied, S. A. (2006). Better but not well: Mental health policy in the United States since 1950. Baltimore, MD: The John Hopkins University Press.

Franks, P., Muennig, P., Lubetkin, E., \& Jia, H. (2006). The burden of disease associated with being African-American in the United States and the contribution of socioeconomic status. Social Science and Medicine, 62, 2469-2478. doi:10.1016/j.socscimed.2005.10.035

Freeman, E. J., Colpe, L. J., Strine, T. W., Dhingra, S., McGuire, L. C., Elam-Evans, L. D., \& Perry, G. S. (2010). Public health surveillance for mental health. Preventing Chronic Disease, 7(1), A17.

Fuchs, V. R., \& Emanuel, E. J. (2005). Health care reform: Why? What? When? Health Affairs, 24, 1399-1414. doi:10.1377/hlthaff.24.6.1399

Garfield, R. L. (2011). Mental Health Financing in the United States: A Primer (8182). Retrieved from the Kaiser Family Foundation website: http://kaiserfamilyfoundation.files.wordpress.com/2013/01/8182.pdf

Garfield, R. L., Lave, J. R., \& Donohue, J. M. (2010). Health reform and the scope of benefits for mental health and substance use disorder services. Psychiatric Services, 61, 1081-1086. doi:10.1176/appi.ps.61.11.1081

Gelberg, L., Andersen, R. M., \& Leake, B. D. (2000). The Behavioral Model for Vulnerable Populations: Application to medical care use and outcomes for homeless people. Health Services Research, 34, 1273-1302. 
Gilmer, T. P., Dolder, C. R., Lacro, J. P., Folsom, D. P., Lindamer, L., Garcia, P., \& Jeste, D. V. (2004). Adherence to treatment with antipsychotic medication and health care costs among Medicaid beneficiaries with schizophrenia. American Journal of Psychiatry, 161, 692-699. doi:10.1176/appi.ajp.161.4.692

Glantz, M. D., Anthony, J. C., Berglund, P. A., Degenhardt, L., Dierker, L., Kalaydjian, A., ... Kessler, R. C. (2009). Mental disorders as risk factors for later substance dependence: Estimates of optimal prevention and treatment benefits. Psychological Medicine, 39, 1365-1377. doi:10.1017/s0033291708004510

Golberstein, E., \& Gonzales, G. (2015). The effects of Medicaid eligibility on mental health sevices and out-of-pocket spending for mental health services. Health Services Research. doi:10.1111/1475-6773.12399

Gold, R., Bailey, S. R., O'Malley, J. P., Hoopes, M. J., Cowburn, S., Marino, M., . . . DeVoe, J. E. (2014). Estimating demand for care after a Medicaid expansion: Lessons from Oregon. Journal of Ambulatory Care Management, 37, 282-292. doi:10.1097/JAC.0000000000000023

Gonzalez, H. M., Tarraf, W., Croghan, T., Taylor, R. J., West, B., Hinton, L., . . Jackson, J. (2008). Antidepressant use in Black and White populations in the United States. Psychiatric Services, 59, 1131-1138.

Grant, B. F., \& Dawson, D. A. (n. d.). National Institute on Alcohol Abuse and Alcoholism: Introduction to the National Epidemiologic Survey on Alcohol and Related Conditions. Retrieved from http://pubs.niaaa.nih.gov/publications/arh292/74-78.htm

Greater Louisville Project. (2013). Building a healthier Louisville. Retrieved from http://reglp.kbddev.com/wp-content/uploads/2013/11/GLP_HealthyLouisville1.pdf

Hadley, J. (2007). Insurance coverage, medical care use, and short-term health changes following an unintentional injury or the onset of a chronic condition. JAMA, 297, 1073-1084. doi:10.1001/jama.297.10.1073

Haggins, A., Patrick, S., Demonner, S., \& Davis, M. M. (2013). When coverage expands: Children's Health Insurance Program as a natural experiment in use of health care services. Academic Emergency Medicine, 20, 1026-1032. doi:10.1111/acem.12236

Han, X., Nguyen, B. T., Drope, J., \& Jemal, A. (2015). Health-Related outcomes among the poor: Medicaid Expansion vs. Non-Expansion States. PLoS One, 10(12), e0144429. doi:10.1371/journal.pone.0144429 
Harris, E. C., \& Barraclough, B. (1998). Excess mortality of mental disorder. British Journal of Psychiatry, 173, 11-53.

Hartman, M., Martin, A. B., Lassman, D., Catlin, A., \& the National Health Expenditure Accounts Team. (2015). National health spending in 2013: Growth slows, remains in step with the overall economy. Health Affairs, 34, 1-11. doi:10.1377/hlthaff.2014.1107

Hatzenbuehler, M. L., Phelan, J. C., \& Link, B. G. (2013). Stigma as a fundamental cause of population health inequalities. American Journal of Public Health, 103, 813821. doi:10.2105/AJPH.2012.301069

Henry J. Kaiser Family Foundation. (2015). Total monthly Medicaid and CHIP Enrollment. Retrieved from http://kff.org/health-reform/state-indicator/totalmonthly-medicaid-and-chip-enrollment/

Hilbe, J. M. (2011). Negative binomial regression (2nd ed.). New York, NY: Cambridge University Press.

Hodgkin, D., \& Karpman, H. E. (2010). Economic crises and public spending on mental health care. International Journal of Mental Health, 39, 91-106. doi:10.2753/imh0020-7411390205

Hodgkin, D., Volpe-Vartanian, J., \& Alegria, M. (2007). Discontinuation of antidepressant medication among Latinos in the USA. Journal of Behavioral Health Services Research, 34, 329-342. doi:10.1007/s11414-007-9070-6

Hofer, A. N., Abraham, J. M., \& Moscovice, I. (2011). Expansion of coverage under the Patient Protection and Affordable Care Act and primary care utilization. Milbank Quarterly, 89(1), 69-89. doi:10.1111/j.1468-0009.2011.00620.x

Horevitz, E., Organista, K. C., \& Arean, P. A. (2015). Depression treatment uptake in integrated primary care: How a "warm handoff" and other factors affect decision making by Latinos. Psychiatric Services, 66, 824-830.

doi:10.1176/appi.ps.201400085

Howell, E., Trenholm, C., Dubay, L., Hughes, D., \& Hill, I. (2010). The impact of new health insurance coverage on undocumented and other low-income children: Lessons from three California counties. Journal of Health Care for the Poor and Underserved, 21(2 Suppl), 109-124. doi:10.1353/hpu.0.0293

Hu, R., Shi, L., Rane, S., Zhu, J., \& Chen, C. C. (2014). Insurance, racial/ethnic, SESrelated disparities in quality of care among US adults with diabetes. Journal of Immigrant and Minority Health, 16, 565-575. doi:10.1007/s10903-013-9966-6 
Hudson, C. G. (2005). Socioeconomic status and mental illness: Tests of the social causation and selection hypotheses. American Journal of Orthopsychiatry, 75(1), 3-18. doi:10.1037/0002-9432.75.1.3

Hudson, J. I., Hiripi, E., Pope, H. G., Jr., \& Kessler, R. C. (2007). The prevalence and correlates of eating disorders in the National Comorbidity Survey Replication. Biological Psychiatry, 61, 348-358. doi:10.1016/j.biopsych.2006.03.040

IBM Corp. (2013). IBM SPSS Statistics for Windows, Version 22.0. Armonk, NY: IBM Corp.

Inter-university Consortium for Political and Social Research. (n. d.). Collaborative psychiatric epidemiology surveys: Background. Retrieved from Inter-university Consortium for Political and Social Research website: http://www.icpsr.umich.edu/icpsrweb/CPES/about_cpes/background.jsp

James, D. J., \& Glaze, L. E. (2006). Mental health problems of prison and jail inmates. Retrieved from the Bureau of Justice Statistics wesbsite: http://www.bjs.gov/content/pub/pdf/mhppji.pdf

Jones, P. B. (2013). Adult mental health disorders and their age at onset. British Journal of Psychiatry Supplement, 54, s5-10. doi:10.1192/bjp.bp.112.119164

Kaiser Commission on Medicaid and the Uninsured. (2013). The uninsured, a primer: Key facts about health Insurance on the eve of health reform. Retrieved from The Henry J. Kaiser Family Foundation wesbsite: http://kff.org/uninsured/report/theuninsured-a-primer-key-facts-about-health-insurance-and-the-uninsured-in-theera-of-health-reform/

Kapur, S., Phillips, A. G., \& Insel, T. R. (2012). Why has it taken so long for biological psychiatry to develop clinical tests and what to do about it? Molecular Psychiatry, 17, 1174-1179. doi:10.1038/mp.2012.105

Karlsen, S., \& Nazroo, J. Y. (2002). Relation between racial discrimination, social class, and health among ethnic minority groups. American Journal of Public Health, 92, 624-631.

Kenney, G. M., McMorrow, S., Zuckerman, S., \& Goin, D. E. (2012). A decade of health care access declines for adults holds implications for changes in the Affordable Care Act. Health Affairs, 31, 899-908. doi:10.1377/hlthaff.2012.0159

Kentucky Cabinet for Health and Family Services. 907 KAR 205:005. Medicaid technical eligibility requirements not related to a modified adjusted gross income standard or former foster care individuals. Retrieved from http://www.lrc.state.ky.us/kar/907/020/005.htm 
Kentucky Cabinet for Health and Family Services. (2015). Pyschiatric Inpatient Hospital Services. Retrieved from http://chfs.ky.gov/dms/mental+hospital.htm

Kentucky Cabinet for Health and Family Services. (2016). Department for Medicaid Services: Weekly membership counts by county. Retrieved from http://chfs.ky.gov/NR/rdonlyres/6FFD3BD9-151E-45EA-93CBDA95E5751811/0/KYDataWarehouseWeeklyMembershipCountsbyCountyJan20 14.pdf

Kentucky Department for Public Health. (2013). State health assessment: A compilation on health status. Retrieved from the Kentucky Department of Public Health website: http://chfs.ky.gov/nr/rdonlyres/cf31d71b-c7e3-4fa3-a8c7713bea63f833/0/2013kystatehealthassessmentfinal52913.pdf

Kentucky Governor's Office. (2015). kyhealthnow: Final Progress Report of the Beshear Administration. Retrieved from: http://chfs.ky.gov/NR/rdonlyres/D32B641AE004-43C4-8D0D-

DE456789539C/0/kyhealthnowFinalProgressReportoftheBeshearAdministrationN ov2015.pdf

Kentucky Mental Health Hospitalization Act, KRS, 202A Stat. (1982).

Kentucky Office of Health Benefit and Health Information Exchange (2016). Jefferson County, Kentucky, enrollment data.

Kessler, R. C. (2012). The costs of depression. Psychiatric Clinics of North America, 35(1), 1-14. doi:10.1016/j.psc.2011.11.005

Kessler, R. C., Adler, L., Barkley, R., Biederman, J., Conners, C. K., Demler, O., . . . Zaslavsky, A. M. (2006). The prevalence and correlates of adult ADHD in the United States: results from the National Comorbidity Survey Replication. American Journal of Psychiatry, 163, 716-723. doi:10.1176/ajp.2006.163.4.716

Kessler, R. C., Amminger, G. P., Aguilar-Gaxiola, S., Alonso, J., Lee, S., \& Ustun, T. B. (2007). Age of onset of mental disorders: A review of recent literature. Current Opinion in Psychiatry, 20, 359-364.

Kessler, R. C., Barker, P. R., Colpe, L. J., Epstein, J. F., Gfroerer, J. C., Hiripi, E., . . Zaslavsky, A. M. (2003). Screening for serious mental illness in the general population. Archives of General Psychiatry, 60, 184-189.

Kessler, R. C., Berglund, P., Chiu, W. T., Demler, O., Heeringa, S., Hiripi, E., .. . Zheng, H. (2004). The US National Comorbidity Survey Replication (NCS-R): design and field procedures. International Journal Methods in Psychiatr Research, 13(2), 69-92. 
Kessler, R. C., Berglund, P., Demler, O., Jin, R., Merikangas, K. R., \& Walters, E. E. (2005). Lifetime prevalence and age-of-onset distributions of DSM-IV disorders in the National Comorbidity Survey Replication. Archives of General Psychiatry, 62, 593-602. doi:10.1001/archpsyc.62.6.593

Kessler, R. C., Chiu, W. T., Demler, O., Merikangas, K. R., \& Walters, E. E. (2005). Prevalence, severity, and comorbidity of 12-month DSM-IV disorders in the National Comorbidity Survey Replication. Archives of General Psychiatry, 62, 617-627. doi:10.1001/archpsyc.62.6.617

Kessler, R. C., \& Neighbors, H. W. (1986). A New Perspective on the Relationships Among Race, Social Class, and Psychological Distress. Journal of Health and Social Behavior, 27, 107-115.

Kessler, R. C., Petukhova, M., Sampson, N. A., Zaslavsky, A. M., \& Wittchen, H. U. (2012). Twelve-month and lifetime prevalence and lifetime morbid risk of anxiety and mood disorders in the United States. International Journal of Methods in Psychiatr Research, 21, 169-184. doi:10.1002/mpr.1359

Kirby, J. B., Taliaferro, G., \& Zuvekas, S. H. (2006). Explaining racial and ethnic disparities in health care. Medical Care, 44(5 Suppl), I64-72. doi:10.1097/01.mlr.0000208195.83749.c3

Kroenke, K., Spitzer, R. L., \& Williams, J. B. W. (2001). The PHQ-9: Validity of a brief depression severity measure. Journal of General Internal Medicine, 16, 606-613.

Kuramoto, F. (2014). The Affordable Care Act and integrated care. Journal of Social Work and Disability Rehabilitation, 13(1-2), 44-86. doi:10.1080/1536710x.2013.870515

Laba, T. L., Essue, B., Kimman, M., \& Jan, S. (2015). Understanding patient preferences in medication nonadherence: A review of stated preference data. Patient, 8, 385395. doi:10.1007/s40271-014-0099-3

Le Cook, B., Manning, W., \& Alegria, M. (2013). Measuring disparities across the distribution of mental health care expenditures. Journal of Mental Health Policy and Economics, 16(1), 3-12.

LOJIC. (2015). 2010 Census Tracts with Urban Neighborhoods. Louisville, KY: LOGIC.

Long, S. K. (2013). Physicians may need more than higher reimbursements to expand Medicaid participation: Findings from Washington State. Health Affairs, 32, 1560-1567. doi:10.1377/hlthaff.2012.1010 
Lucca, J. M., Ramesh, M., Parthasarathi, G., \& Ram, D. (2015). Incidence and factors associated with medication nonadherence in patients with mental illness: A crosssectional study. Journal of Postgraduate Medicine, 61, 251-256.

doi:10.4103/0022-3859.166514

Mark, T. L., Levit, K. R., Vandivort-Warren, R., Buck, J. A., \& Coffey, R. M. (2011). Changes in US spending on mental health and substance abuse treatment, 19862005, and implications for policy. Health Affairs, 30, 284-292. doi: $10.1377 /$ hlthaff.2010.0765

Martin, L. A., Neighbors, H. W., \& Griffith, D. M. (2013). The experience of symptoms of depression in men vs women: Analysis of the National Comorbidity Survey Replication. JAMA Psychiatry, 70, 1100-1106. doi:10.1001/jamapsychiatry.2013.1985

Martins, S. S., Ko, J., Kuwabara, S., Clarke, D., Alexandre, P., Zandi, P., . . Eaton, W. W. (2012). The relationship of adult mental disorders to socioeconomic status, race/ethnicity, marital status, and urbanicity of residence. In W. W. Eaton (Ed.), Public Mental Health (pp. 151-197). New York, NY: Oxford University Press.

Maxwell, J., Cortes, D. E., Schneider, K. L., Graves, A., \& Rosman, B. (2011). Massachusetts' health care reform increased access to care for Hispanics, but disparities remain. Health Affairs, 30, 1451-1460. doi:10.1377/hlthaff.2011.0347

McAlpine, D. D., \& Mechanic, D. (2000). Utilization of specialty mental health care among persons with severe mental illness: The roles of demographics, need, insurance, and risk. Health Services Research, 35(1 Pt 2), 277-292.

McCarthy, D., How, S. K. H., Fryer, A. K., Radley, D. C., \& Schoen, C. (2011). Why not the best? Results from the National Scorecard on U.S. Health System

Performance, 2011. Retrieved from the Commonwealth Fund wesbsite: http://www.commonwealthfund.org/ /media/files/publications/fundreport/2011/oct/1500_wntb_natl_scorecard_2011_web_v2.pdf

McLean, C. P., Asnaani, A., Litz, B. T., \& Hofmann, S. G. (2011). Gender differences in anxiety disorders: Prevalence, course of illness, comorbidity and burden of illness. Journal of Psychiatric Research, 45, 1027-1035. doi:10.1016/j.jpsychires.2011.03.006

McWilliams, J. M., Zaslavsky, A. M., Meara, E., \& Ayanian, J. Z. (2003). Impact of Medicare coverage on basic clinical services for previously uninsured adults. JAMA, 290, 757-764. doi:10.1001/jama.290.6.757

Medical Assistance Act, Pub. L. No. KRS 205.520 (2005). 
Mesidor, M., Gidugu, V., Rogers, E. S., Kash-MacDonald, V. M., \& Boardman, J. B. (2011). A qualitative study: Barriers and facilitators to health care access for individuals with psychiatric disabilities. Psychiatric Rehabilitatioin Journal, 34, 285-294. doi:10.2975/34.4.2011.285.294

Miles, M. B., Huberman, A. M., \& Saldana, J. (2014). Qualitative data analysis: A methods sourcebook (3rd ed.). Thousand Oaks, CA: Sage Publications, Inc.

Miller, S. (2012). The effect of the Massachusetts reform on health care utilization. Inquiry, 49, 317-326.

Millman, M. E. (1993). Access to Health Care in America. Washington, D.C.: National Academies Press.

Mojtabai, R. (2011). National trends in mental health disability, 1997-2009. American Journal of Public Health, 101, 2156-2163. doi:10.2105/AJPH.2011.300258

Mojtabai, R., Chen, L. Y., Kaufmann, C. N., \& Crum, R. M. (2014). Comparing barriers to mental health treatment and substance use disorder treatment among individuals with comorbid major depression and substance use disorders. Journal of Substance Abuse Treatment, 46, 268-273. doi:10.1016/j.jsat.2013.07.012

Mojtabai, R., Olfson, M., Sampson, N. A., Jin, R., Druss, B., Wang, P. S., . . Kessler, R. C. (2011). Barriers to mental health treatment: Results from the National Comorbidity Survey Replication. Psycholical Medicine, 41, 1751-1761. doi:10.1017/S0033291710002291

Muennig, P., Franks, P., Jia, H., Lubetkin, E., \& Gold, M. R. (2005). The incomeassociated burden of disease in the United States. Social Science and Medicine, 61, 2018-2026. doi:10.1016/j.socscimed.2005.04.005

Mulcahy, A., Harris, K., Finegold, K., Kellermann, A., Edelman, L., \& Sommers, B. D. (2013). Insurance coverage of emergency care for young adults under health reform. New England Journal of Medicine, 368, 2105-2112. doi:10.1056/NEJMsa1212779

National Alliance on Mental Illness. (2014). Mental Illnesses. Retrieved from http://www.nami.org/Template.cfm?Section=By_Illness

National Alliance on Mental Illness. (2016). Mental Health Conditions. Retrieved from https://www.nami.org/Learn-More/Mental-Health-Conditions

National Alliance on Mental Illness Policy Research Institute. (2004). Spending money in all the wrong places: Jails and prisons. Retrieved from http://static1.1.sqspcdn.com/static/f/1176392/18407948/1337955233993/2007071 114374381.pdf?token=kPN05Mfrz1KLPN5eI7p14U6hdXI\%3D 
National Coalition for the Homeless. (2009). Mental illness and homelessness. Retrieved from http://www.nationalhomeless.org

National Federation of Independent Business (NFIB) v. Sebelius, 567 U. S. (2012).

Nguyen, T. (2014). Parity or Disparity: The State of Mental Health in America 2015. Retrieved from the Mental Health America website: http://www.mentalhealthamerica.net/sites/default/files/Parity\%20or\%20Disparity $\% 20$ Report\%20FINAL.pdf

Nielsen-Bohlman, L., Panzer, A. M., \& King, D. A. E. (2004). Health literacy: A prescription to end confusion. Washington, DC: Institute of Medicine, The National Academies Press.

Oberlander, J. (2012). Unfinished journey-A century of health care reform in the United States. New England Journal of Medicine, 367, 585-590.

doi:10.1056/NEJMp1202111

Office of National Drug Control Policy. (2016). Chapter 3. Integrate treatment for substance use disorders into mainstream health care and expand support for recovery. Retrieved from https://www.whitehouse.gov/ondcp/chapter-integratetreatment-for-substance-use-disorders

Olfson, M., Kroenke, K., Wang, S., \& Blanco, C. (2014). Trends in office-based mental health care provided by psychiatrists and primary care physicians. Journal of Clinical Psychiatry, 75, 247-253. doi:10.4088/JCP.13m08834

Olfson, M., Marcus, S. C., Tedeschi, M., \& Wan, G. J. (2006). Continuity of antidepressant treatment for adults with depression in the United States. American Journal of Psychiatry, 163(1), 101-108. doi:10.1176/appi.ajp.163.1.101

Parks, J., Svendsen, D., Singer, P., \& Foti, M. E. (2006). Morbidity and mortality in people with serious mental illness. Retrieved from http://www.nasmhpd.org/sites/default/files/Mortality\%20and\%20Morbidity\%20Fi nal\%20Report\%208.18.08.pdf

Perloff, J. D., Kletke, P., \& Fossett, J. W. (1995). Which physicians limit their Medicaid participation, and why. Health Services Research, 30(1), 7-26.

Perloff, J. D., Kletke, P. R., Fossett, J. W., \& Banks, S. (1997). Medicaid participation among urban primary care physicians. Medical Care, 35, 142-157.

Piatt, E. E., Munetz, M. R., \& Ritter, C. (2010). An examination of premature mortality among decedents with serious mental illness and those in the general population. Psychiatric Services, 61, 663-668. doi:10.1176/appi.ps.61.7.663 
A Place in time: The story of Louisville's neighborhoods. (1989). Louisville, KY: The Courier-Journal.

Porter, L. C. (2014). Incarceration and post-release health behavior. Journal of Health and Social Behavior, 55, 234-249. doi:10.1177/0022146514531438

Power, R., French, R., Connelly, J., George, S., Hawes, D., Hinton, T., .. . Warner, D. (1999). Health, health promotion, and homelessness. British Medical Journal, $318,590-592$.

Primm, A. B., Vasquez, M. J., Mays, R. A., Sammons-Posey, D., McKnight-Eily, L. R., Presley-Cantrell, L. R., . . Perry, G. S. (2010). The role of public health in addressing racial and ethnic disparities in mental health and mental illness. Preventing Chronic Disease, 7(1), A20.

Puska, P. (2007). Health in all policies. European Journal of Public Health, 17, 328. doi:10.1093/eurpub/ckm048

Radley, D. C., How, S. K. H., Fryer, A. K., McCarthy, D., \& Schoen, C. (2012). Rising to the challenge: Results from a scorecard on local health system performance, 2012. Retrieved from the Commonwealth Fund website: http://www.commonwealthfund.org/publications/fund-reports/2012/mar/localscorecard

Ramirez Garcia, J. I., Chang, C. L., Young, J. S., Lopez, S. R., \& Jenkins, J. H. (2006). Family support predicts psychiatric medication usage among Mexican American individuals with schizophrenia. Social Psychiatry and Psychiatric Epidemiology, 41, 624-631. doi:10.1007/s00127-006-0069-8

Reeves, W. C., Strine, T. W., Pratt, L. A., Thompson, W., Ahluwalia, I., Dhingra, S. S., ... Safran, M. A. (2011). Mental illness surveillance among adults in the United States. MMWR Surveill Summ, 60 Suppl 3, 1-29.

Roberts, A. L., Gilman, S. E., Breslau, J., Breslau, N., \& Koenen, K. C. (2011). Race/ethnic differences in exposure to traumatic events, development of posttraumatic stress disorder, and treatment-seeking for post-traumatic stress disorder in the United States. Psychological Medicine, 41(1), 71-83. doi:10.1017/S0033291710000401

Roll, J. M., Kennedy, J., Tran, M., \& Howell, D. (2013). Disparities in unmet need for mental health services in the United States, 1997-2010. Psychiatric Services, 64(1), 80-82. doi:10.1176/appi.ps.201200071

Rosenberg, A. R., Kroon, L., Chen, L., Li, C. I., \& Jones, B. (2015). Insurance status and risk of cancer mortality among adolescents and young adults. Cancer, 8, 12791286. doi:10.1002/cncr.29187 
Rowan, K., McAlpine, D. D., \& Blewett, L. A. (2013). Access and cost barriers to mental health care, by insurance status, 1999-2010. Health Affairs, 32, 1723-1730. doi:10.1377/hlthaff.2013.0133

Sareen, J., Jagdeo, A., Cox, B. J., Clara, I., ten Have, M., Belik, S. L., . . Stein, M. B. (2007). Perceived barriers to mental health service utilization in the United States, Ontario, and the Netherlands. Psychiatric Services, 58, 357-364.

Shern, D. L., Blanch, A. K., \& Steverman, S. M. (2016). Toxic stress, behavioral health, and the next major era in public health. American Journal of Orthopsychiatry, 86, 109-123. doi:10.1037/ort0000120

Social Security Administration. (2014a). Annual Report of the Supplemental Security Income Program. Retrieved from http://www.ssa.gov/oact/ssir/SSI14/index.html

Social Security Administration. (2014b). Annual Statistical Report on the Social Security Disability Insurance Program, 2013 (13-11826). Retrieved from http://www.ssa.gov/policy/docs/statcomps/di_asr/

Sommers, A., \& Cunningham, P. J. (2011). Medical bill problems steady for U.S. families, 2007-2010. Retrieved from the Robert Wood Johnson Foundation website:

http://www.rwjf.org/content/dam/farm/reports/surveys_and_polls/2011/rwjf72000

Sommers, B. D., Arntson, E., Kenney, G. M., \& Epstein, A. M. (2013). Lessons from early Medicaid expansions under health reform: Interviews with Medicaid officials. Medicare and Medicaid Research Review, 3(4). doi:10.5600/mmrr.003.04.a02

Sommers, B. D., Baicker, K., \& Epstein, A. M. (2012). Mortality and access to care among adults after state Medicaid expansions. New England Journal of Medicine, 367, 1025-1034. doi:10.1056/NEJMsa1202099

Sommers, B. D., Kenney, G. M., \& Epstein, A. M. (2014). New evidence on the Affordable Care Act: Coverage impacts of early Medicaid expansions. Health Affairs, 33, 78-87. doi:10.1377/hlthaff.2013.1087

Sommers, B. D., Long, S. K., \& Baicker, K. (2014). Changes in mortality after Massachusetts health care reform: A quasi-experimental study. Annals of Internal Medicine, 160, 585-593. doi:10.7326/m13-2275

Spaulding, A. C., Seals, R. M., McCallum, V. A., Perez, S. D., Brzozowski, A. K., \& Steenland, N. K. (2011). Prisoner survival inside and outside of the institution: Implications for health-care planning. American Journal of Epidemioogyl, 173, 479-487. doi:10.1093/aje/kwq422 
Stillman, M., \& Tailor, M. (2013). Dead Man Walking. New England Journal of Medicine, 369(20), 1880-1881. doi:10.1056/NEJMp1312793

Substance Abuse and Mental Health Services Administration. (2011). SAMHSA announces a working definition of "recovery" from mental disorders and substance use disorders. Retrieved from http://www.samhsa.gov/newsroom/pressannouncements/201112220300

Substance Abuse and Mental Health Services Administration. (2013). Behavioral Health, United States, 2012 (HHS Pub. No. (SMA) 13-4797). Retrieved from SAMHSA website: http://www.samhsa.gov/data/sites/default/files/2012-BHUS.pdf

Substance Abuse and Mental Health Services Administration. (2014a). Results from the 2013 National Survey on Drug Use and Health: Mental Health Findings (HHS Publication No. (SMA) 14-4887). Retrieved from SAMHSA website: http://www.samhsa.gov/data/sites/default/files/NSDUHmhfr2013/NSDUHmhfr20 13.pdf

Substance Abuse and Mental Health Services Administration. (2014). Substance Use and Mental Health Estimates from the 2013 National Survey on Drug Use and Health: Overview of Findings (HHS Publication No. (SMA) 14-4887). Retrieved from SAMHSA website:

http://www.samhsa.gov/data/sites/default/files/NSDUHmhfr2013/NSDUHmhfr20 13.pdf

Substance Abuse and Mental Health Services Administration. (2015). Racial/ethnic differences in mental health service use among adults. Retrieved from SAMHSA website:

http://www.samhsa.gov/data/sites/default/files/MHServicesUseAmongAdults/MH ServicesUseAmongAdults.pdf

Takayanagi, Y., Spira, A. P., Roth, K. B., Gallo, J. J., Eaton, W. W., \& Mojtabai, R. (2014). Accuracy of reports of lifetime mental and physical disorders: Results from the Baltimore Epidemiological Catchment Area study. JAMA Psychiatry, 7, 273-280. doi:10.1001/jamapsychiatry.2013.3579

Thomas, K. C., Ellis, A. R., Konrad, T. R., Holzer, C. E., \& Morrissey, J. P. (2009). County-level estimates of mental health professional shortage in the United States. Psychiatric Services, 60, 1323-1328. doi:10.1176/appi.ps.60.10.1323

Trivedi, J. K. (2006). Cognitive deficits in psychiatric disorders: Current status. Indian Journal of Psychiatry, 48(1), 10-20. doi:10.4103/0019-5545.31613

Turner, D. W. (2010). Qualitative interview design: A practical guide for novice investigators. The Qualitative Report, 15, 754-760. 
U. S. General Accounting Office. (2000). Mental Health Parity Act: Despite new Federal standards, mental health benefits remain limited. Retrieved from http://www.gao.gov/new.items/he00095.pdf

U.S. Department of Health and Human Services. (2010). Preventive services covered under the Affordable Care Act. Retrieved from

http://www.hhs.gov/healthcare/facts-and-features/fact-sheets/preventive-servicescovered-under-aca/index.html

U.S. National Library of Medicine. (2006). Diseases of the mind: Highlights of American psychiatry through 1900. Retrieved from http://www.nlm.nih.gov/hmd/diseases/early.html

U.S. Preventive Services Task Force. (2016, April 2016). Published Recommendations. Retrieved from http://www.uspreventiveservicestaskforce.org/BrowseRec/Index

United Health Foundation. (2014). America's health rankings. Retrieved from http://www.americashealthrankings.org/KY

United States Census Bureau. (2012). 2010 Census- Urbanized Area Reference Map: Louisville/Jefferson County, KY-IN. Retrieved from http://www2.census.gov/geo/maps/dc10map/UAUC_RefMap/ua/ua51755_louisvi lle_jefferson_county_ky--in/DC10UA51755.pdf.

Wheeler, K. J., Roberts, M. E., \& Neiheisel, M. B. (2014). Medication adherence part two: Predictors of nonadherence and adherence. Journal of the Amican Association of Nurse Practitioners, 26, 225-232. doi:10.1002/2327-6924.12105

Whitley, R., \& Lawson, W. B. (2010). The psychiatric rehabilitation of African Americans with severe mental illness. Psychiatric Services, 61, 508-511. doi:10.1176/appi.ps.61.5.508

Wilper, A. P., Woolhandler, S., Lasser, K. E., McCormick, D., Bor, D. H., \& Himmelstein, D. U. (2009). Health insurance and mortality in US adults. American Journal of Public Health, 99, 2289-2295. doi:10.2105/AJPH.2008.157685

World Health Organization. (1993). The ICD-10 Classification of mental and behavioural disorders: Diagnostic criteria for research. Retrieved from the WHO website: http://www.who.int/classifications/icd/en/GRNBOOK.pdf

World Health Organization. (2004a). Prevention of mental disorders: Effective interventions and policy options (summary report). Retrieved from the WHO website:

http://www.who.int/mental_health/evidence/en/prevention_of_mental_disorders_s r.pdf 
World Health Organization. (2004b). Promoting mental health: Concepts, emerging evidence, practice (summary report). Retrieved from the WHO website: http://www.who.int/mental_health/evidence/en/promoting_mhh.pdf

World Health Organization. (2011). Mental Health Atlas 2011. Retrieved from the WHO website:

http://www.who.int/mental_health/publications/mental_health_atlas_2011/en/

World Health Organization. (2012). Risks to Mental Health: An Overview of Vulnerabilities and Risk Factors. Retrieved from the WHO website: http://www.who.int/mental_health/mhgap/risks_to_mental_health_EN_27_08_12. pdf

World Health Organization. (2014). Mental health: Strengthening our response (Fact sheet No. 220). Retrieved from the WHO website: http://www.who.int/mediacentre/factsheets/fs220/en/

Zhu, J., Brawarsky, P., Lipsitz, S., Huskamp, H., \& Haas, J. S. (2010). Massachusetts health reform and disparities in coverage, access and health status. Journal of General Internal Medicine, 25, 1356-1362. doi:10.1007/s11606-010-1482-y

Zuvekas, S. H., \& Fleishman, J. A. (2008). Self-rated mental health and racial/ethnic disparities in mental health service use. Medical Care, 46, 915-923. doi:10.1097/MLR.0b013e31817919e5 


\section{APPENDICES}

Appendix A: Provider Interview Topic Guide

\section{Introductions and informed consent}

- Interviewer introduction

- Purpose of the study

- Informed consent document

Topic 1: Mental health care for West Louisville residents

- Describe the landscape of mental health services in West Louisville.

- Who is providing them?

$\circ$ Where are the providers?

- How do primary care physicians make referrals?

- How has mental health service provision changed in Louisville since ACA implementation in 2014 ?

- How has the number of providers changed?

- What changes have occurred in Medicaid billing procedures or reimbursement?

- How has the demand for services changed?

\section{Topic 2: Factors impacting the use of mental health care}

- What are the attitudes toward use of mental health services among consumers?

- What influences consumers' decision to see a counselor or use medication?

- How does insurance play a role in providing mental health services and consumer follow through with use of mental health service?

- How does your relationship and patient trust play a role in providing services and/or making referrals?

- What barriers persist to use of mental health services?

Wrap-up: Is there anything we have not talked about already that is relevant to the topic? 
Appendix B: Consumer Interview Guide

I am a doctoral student in the UofL School of Public Health and Information Sciences. I am researching how health care has changed in the past two years since the start of the Affordable Care Act, or Obamacare. I am talking to folks in West Louisville and looking to understand about the experience of having insurance and getting health care. A lot of research looks at physical health, but I'm interested in mental health since that affects a person's ability to do the things he or she wants or needs to do just as much as physical health does.

Before we begin, I would like to confirm that you have Medicaid.

\section{Which plan is your Medicaid through?}

1. Anthem Blue Cross and Blue Shield

2. CoventryCares

3. Humana Care Source

4. Passport

5. Wellcare of Kentucky

\section{What neighborhood do you live in?}

1. Algonquin

2. California

3. Chickasaw

4. Park DuValle

5. Park Hill

6. Parkland

7. Portland

8. Russell

9. Shawnee

\section{What is your zip code?}

1. 40203

2. 40208

3. 40210

4. 40211

5. 40212

Now I am going to ask for your signature that you are volunteering to be here today and that you understand how I will use the information you tell me. This is a copy of an Informed Consent document, and I would like to read that aloud now and give you time to ask questions about this research.

Read INFORMED CONSENT. 
What questions do you have?

Collect Informed Consent document.

What does being healthy mean to you?

How would you describe your health? If you rate your health, what word would you use?

1. Excellent

2. Very good

3. Good

4. Fair

5. Bad

6. Prefer not to say

Tell me about the last time you were sick and how you got help to feel better.

Do you have a regular health care provider whom you see? This could be a doctor, nurse practitioner, physician's assistant, or someone else.

\begin{tabular}{|r|r|}
\hline $\mathrm{Y}$ & $\mathrm{N}$ \\
\hline
\end{tabular}

How often do you see him or her? How many times did you go in the past year?

What other doctors or health care providers do you see?

How would you define mental health?

Tell me how you think mental health is related to overall health.

What do your friends and family think about mental health?

Who do you talk to when you feel nervous, stressed out, sad, or angry?

[incorporate the participant's definition of mental health into the remainder of questions]

- Have you ever gone to a pastor?

\begin{tabular}{|r|r|}
\hline $\mathrm{Y}$ & $\mathrm{N}$ \\
\hline
\end{tabular}

- Have you ever been to a support group or a self-help group?

\begin{tabular}{l|l|}
$\mathrm{Y}$ & $\mathrm{N}$ \\
\hline
\end{tabular}

- Have you ever used a friend or family member?

- Have you seen a mental health provider, such as a counselor, a social worker, a psychologist, or a psychiatrist?

\begin{tabular}{l|l|}
$\mathrm{Y}$ & $\mathrm{N}$ \\
\hline
\end{tabular}


- Have you ever taken medication because of emotional or mental health problems?

$$
\begin{array}{|l|l|}
\mathrm{Y} & \mathrm{N} \\
\hline
\end{array}
$$

- Have you ever gone to the emergency room because of emotional or mental health problems?

$\mathrm{Y} \quad \mathrm{N}$

- Have you ever stayed overnight in the hospital for emotional or mental health problems?

\begin{tabular}{|r|r|}
\hline $\mathrm{Y}$ & $\mathrm{N}$ \\
\hline
\end{tabular}

\section{If "Yes"}

Tell me about the experience of seeing a health care professional for mental health services.

- What or who influenced your decision to see a counselor or use medication?

- Tell me about how you chose to see the counselor that you do. How did you find out information about your choices for who to see?

- Does it help to go to counseling? How does it help? OR Why do you think it doesn't help?

- What are the effects of taking medications for emotional or mental health problems?

- What would you say to family and friends to get someone else to use mental health services?

- How do you get to appointments? How does the clinic's schedule impact your ability to see a provider when you want to?

\section{What has been your experience using [your MCO] for mental health services?}

- How much does it cost you to see a counselor or pick up medications?

- Have you ever gotten to an appointment and been surprised about what you have to pay because you have Medicaid?

- Have you ever been told you can't get the medicine you need or schedule an appointment? What did you do then?

Have you ever thought you needed help for emotional or mental health problems but got less help than you needed or there was a delay in getting care? What happened to cause that?

Have you ever been prescribed a medication and then didn't actually pick it up from the pharmacy or didn't use it once you had it at home? 


\section{If "No"}

Tell me about your reasons for not using professional mental health services.

- What are your insurance benefits for counseling? What is the copay?

- How much does it cost when you get a medication from the pharmacy?

- Where would someone who lives in West Louisville go for counseling?

- What do your friends and family think about using mental health services?

Was there ever a time when you felt that you might need to see a professional because of mental health problems but didn't go?

What happened to cause that?

Have you ever been prescribed a medication and then didn't actually pick it up from the pharmacy or didn't use it once you had it at home?

What happened to cause that?

What are some things that would help you decide to go to counseling?

Lastly, I would like to ask you a few questions about yourself so that I can describe the group of people I interview for this study.

How old are you?

What gender do you identify with?

1. Male

2. Female

3. Other:

What is your race or races do you identify with?

1. White

2. Black or African American

3. Hispanic

4. Asian

5. American Indian or Alaska Native

6. Native Hawaiian and Other Pacific Islander

What is the highest level of education you have completed?

1. $12^{\text {th }}$ grade or less (no diploma)

2. High School/ GED

3. Some college, no degree

4. Associate or technical degree

5. Bachelor's college degree

6. Graduate or Professional Degree 
When did you get Medicaid? (best guess of month, year)

Before you signed up for health insurance through Obamacare, did you have other health insurance?

1. Yes, I was insured

2. No, I did not have health insurance

If you were NOT insured, how long were you without insurance?

1. Less than 1 month

2. 1-3 months

3. 4-6 months

4. 7 months -1 year

5. longer than a year 


\section{CURRICULUM VITAE \\ SUSAN BUCHINO, PhD(c), MS, OTR/L}

Updated April 21, 2016

CONTACT

INFORMATION

EDUCATION
PROFESSIONAL EXPERIENCE
2025 Sherwood Avenue

Louisville, Kentucky 40205

(502) 509-5621

susan.buchino@louisville.edu

School of Public Health and Information Sciences

University of Louisville, Louisville, Kentucky

Ph.D. in Public Health, focus in Health Promotion and

Behavioral Sciences

Expected Graduation: May 2016

Dissertation Title: "The Impact of Medicaid Expansion of

Utilization of Mental Health Services in West Louisville,

Kentucky"

Advisor/Committee Chair: Monica L. Wendel, DrPH, MA

Auerbach School of Occupational Therapy

Spalding University, Louisville, Kentucky

Master of Science Degree in Occupational Therapy

Date of Graduation: August 2004

Masters Project: "Supporting Elderly in the Community"

University of Notre Dame, Notre Dame, Indiana

Bachelor of Arts Degree in Psychology

Date of Graduation: May 1997

Ballard High School, Louisville, Kentucky

High School Diploma: June 1993

University of Louisville, Louisville, Kentucky.

Senior Research Manager, Commonwealth Institute of

Kentucky at the School of Public Health and Information

Sciences: August 2015-Present.

- Project Manager for health care access and utilization research, including local ACA Evaluation and State Workforce Capacity. 
Research Assistant to the Louisville Metro Board of Health Affordable Care Act (ACA) Implementation Project:

March 2014-July 2015.

- Design outcome measures, direct evaluation, and report outcomes intended to assess coordinated efforts and inform the continued ACA implementation process in Jefferson County, Kentucky.

- Administrative Assistant to the Measurement and Outcomes Committee.

HMR Associates, Inc., Louisville, Kentucky.

Case Manager for the Supports for Community Living and Michelle P. Waivers: August 2013-November 2014.

- Service coordination and resource management for individuals with intellectual and developmental disabilities.

Auerbach School of Occupational Therapy, Spalding University, Louisville, Kentucky.

Instructor: August 2010_June 30, 2013.

Adjunct Faculty: Session 7, 2007; Session 7, 2010.

Aegis Therapies, Louisville, Kentucky.

Occupational Therapist: February 2007_-Present.

- Evaluation and intervention for individuals in nursing care.

Center for Comprehensive Services - Kentucky (As Christian Care Communities Stepping Stones until acquisition in August, 2009), Louisville, Kentucky. Occupational Therapist: November 2006-April 2010.

- Evaluation and community-based treatment for individuals with acquired brain injury.

- Service as primary therapist and treatment team leader responsible for guiding client-centered goals and practices and facilitating team communication.

- Development of structured, goal-directed group activities.

- Supervision of Certified Occupational Therapy Assistants.

- Supervision of occupational therapy students in their fieldwork experiences. 
Madison Center and Hospital, South Bend, Indiana.

Occupational Therapist/Case Manager: October 2004-

October 2006.

- Development of agency-wide outpatient occupational therapy services.

- Provision of community-based cognitive and home assessment as well as direct care to adults with chronic mental illness, teaching life skills in both group and individual sessions.

- Intervention for adults in day treatment program for substance abuse.

- Consultation to case managers.

- Supervision of occupational therapy students in their fieldwork experiences.

The Juilliard School, New York, New York. Opera Stage Manager: August 2000-May 2001.

- Management of rehearsals and performances.

- Supervision of interns.

- Coordination of scheduling and show production.

- Compilation of show documentation.

Stage Manager through The Professional Internship

Program: August 1999-May 2000.

- Service as assistant to production stage managers in drama, opera, and dance.

- Coordination of backstage activity during performances.

TEACHING

EXPERIENCE
Guest Lecture "Occupational Therapy in Community-based Practice: Issues, Resources, and Funding” in ALH 2490 Management, Scholarship, and Professional Responsibility at Brown Mackie College, Louisville, KY (T. Parr, MS, OTR/L, course director). September 21, 2015.

Guest Lecture "The Affordable Care Act" in PHUN-400 People, Policy, and the Environment at the University of Louisville, Louisville, KY (A. S. LaJoie, course director). October 2014. 
Auerbach School of Occupational Therapy, Spalding University, Louisville, Kentucky.

Instructor: August 2010_June 2013.

- HS 520 Physical Health and Wellness, HS 525

Psychosocial Wellness and Group Process, HS 550

Research Applications in Practice, OT 540

Evaluation/Intervention III (addressing psychosocial health conditions, community practice, and productive aging), OT 570 Ethical Decision Making in OT. Adjunct Faculty: Session 7, 2007; Session 7, 2010.

- HS 525 Psychosocial Health Conditions.

Guest Lecture "Occupational Therapy in Mental Health: Evaluation and Intervention" in OT 522 Occupational Performance I at the University of Indianapolis School of Occupational Therapy (Ann Chapleau, course director). November 6, 2006.

Guest Lecturer "Occupational Therapy in CommunityBased Mental Health" in OT 501 Fundamentals of Occupational Therapy at the Auerbach School of Occupational Therapy at Spalding University, (Jeffrey Lederer, course director). Spring 2007.

SCHOLARLY ACTIVITIES
Buchino, S. (2016, February 22). Consumer Perspectives on the Impact of Expanded Coverage. Research presented at the Kentucky Voices for Health Annual Meeting, Frankfort, KY.

Jones, A., Combs, R., Buchino, S. (2016). LGBTQ Health Equity \& Access Project: Final Report. Louisville, KY: Kentucky Voices for Health.

Buchino, S., Creel, L., Wendel, M. (2015). Kentucky SIM Design Grant: Consumer Engagement. Louisville, KY: Kentucky Office of Health Policy.

LaJoie, A. S., Buchino, S., Sentelik, M., Popich, B., \& Kothari, R. (2015, November). Decision Advocacy for Families of Infants with Hearing Loss. Poster presented at the $143^{\text {rd }}$ American Public Health Association Annual Meeting, Chicago, IL. 
Johnson, D. \& Buchino, S. (2015). Health in All Policies: A report to the Institute for Healthy Air, Water, and Soil. Louisville, KY: The Community Foundation of Louisville, Inc.

Wagner, W., \& Buchino, S. (2015, August 6). Local Implementation of the Affordable Care Act. Presented at the National Association of Local Boards of Health 2015 Annual Conference, Louisville, KY.

Buchino, S., Blakely, C., \& Altman, W. (2015, April 14). Local Implementation of the Affordable Care Act: Results of Collaboration in Jefferson County. Research presented at the Kentucky Public Health Association Conference, Owensboro, KY.

Buchino, S., \& Blakely, C. (2014, December). Evaluation of Affordable Care Act Implementation at the local level in Metro Louisville. Louisville, KY: Louisville Metro Board of Health.

Kentucky's State Integration \& Medicaid Health Homes Learning Community, sponsored by the National Council for Behavioral Health. Intern for The Foundation for a Healthy Kentucky. Contributed to and edited the Learning Community's report and policy recommendations, submitted to the Secretary of Kentucky's Cabinet for Health and Family Services: April 2013-September 2013.

Walsh, S. E., Gilderbloom, J., Buchino, S., \& LaJoie, A. S. (2013, November 3). Evaluating the built environment in senior-oriented spaces.

Poster presented at the $141^{\text {st }}$ American Public Health Association Annual Meeting, Boston, MA.

Leslie, K. F., Buchino, S., Chiaventone, L. A., Forristal, J., Lynch, T., \& LaJoie, A. S. (2013, March). Developing a targeted measles vaccination campaign through the mental models approach to risk communication. Poster Session at the Kentucky Public Health Association Annual Meeting, Louisville, KY. 
Chapleau, A., Seroczynski, A. D., Meyers, S., Lamb, K., \& Buchino, S. (2012). The effectiveness of a consultation model in community mental health. Occupational Therapy in Mental Health, 28, 379-395. doi:

10.1080/0164212X.2012.708609

Buchino, S., \& Schmidt, W. (2012). An evidence-based policy analysis of methods for integrating mental health services with medical services for Kentucky Medicaid managed care. Poster presented at Research!Louisville, 2012, Louisville, KY.

Chapleau, A., Seroczynski, A. D., Meyers, S., Lamb, K., \& Haynes, S. (2011). Occupational therapy consultation for case managers in community mental health: Exploring strategies to improve job satisfaction and self-efficacy. Professional Case Management, 16(2), 71-79.

Chapleau, A. M., Seroczynski, A. D., Lamb, K. J., Buchino, S. T., \& Meyers, S. K. (2007, April). Using an occupational therapy consultation model in a community mental health setting. Research presented at the $87^{\text {th }}$ Annual American Occupational Therapy Association Conference, St. Louis, MO.

Chapleau, A. M., Meyers, S.K., Seroczynski, A. D., Buchino, S. T., Lamb, K. J. (2006, April). Occupational therapy case management for persons with traumatic brain injury and mental illness. Poster presented at the $86^{\text {th }}$ Annual American Occupational Therapy Association Conference, Charlotte, NC.

LICENSURE and CERTIFICATION
National Board for Certification in Occupational Therapy, Inc.: Occupational Therapist Registered, 2004

Kentucky Board of Licensure for Occupational Therapy, 2006

A-ONE Certification, 2005

American Heart Association Healthcare Provider CPR Certification 


\section{ADDITIONAL TRAINING}

PROFESSIONAL SERVICE

PROFESSIONAL MEMBERSHIP
US Health Reform - The Affordable Care Act, The O'Neill Institute for National and Global Health Law at Georgetown University, July 2014.

Grant Writing Academy, University of Louisville School of Interdisciplinary and Graduate Studies, Fall 2013.

Kentucky Occupational Therapy Association Practice Chair (KOTA), 2011-2013.

Certified Presenter for Play to Win: You and Your Health Care Team, sponsored by a grant from the National Library of Medicine to Health Literacy Kentucky, 2012.

Faculty Advisor for Spalding University Student Occupational Therapy Association, 2011-2013.

Faculty Advisor for Pi Theta Epsilon, Beta Rho Chapter at Spalding University, 2011-2013.

Faculty Advisor for Spalding University's Best Buddies Chapter, 2011-2013.

Spalding University Undergraduate Admissions Committee, 2011-2013.

Faculty Advisor and Coordinator for occupational therapy student service learning trip to Appalachia, Summer 2011.

Presenter for Kentucky Medicaid Acquired Brain Injury Branch Fall Forum, 2009.

Presenter for Staying Alive: How To Be An Effective Caregiver caregiver education and support seminars, 2003 and 2004.

Kentucky Public Health Association (KPHA), $2011-$ Present.

American Occupational Therapy Association (AOTA), 2002-Present.

Kentucky Occupational Therapy Association (KOTA), 2007-2013. 
Phi Theta Epsilon Occupational Therapy Honor Society, Student President of Beta Rho Chapter at Spalding University.

Service Learning Chair of Spalding University Student Occupational Therapy Association (SUSOTA).

COMMUNITY SERVICE
Board Member and Volunteer, St. John Center, Louisville, Kentucky, 2013 - Present. Board Secretary and Program Committee Chair 2014-Present.

Chaperone, Bellarmine University Guatemala Service Trip, February 2015.

Volunteer for the Coalition for the Homeless' annual pointin-time count of homeless individuals in Jefferson County, Kentucky, 2013, 2014, 2015, 2016.

Organizer of the Smoketown and Shelby Park Generations Picnic, Louisville, Kentucky, August 2013.

Power Member, Network Center for Community Change, Louisville, Kentucky, 2013-2014.

Participant in Occupational Therapy Global Day of Service, 2012.

Judge for the St. Francis of Assisi Middle School Science Fair, 2012.

Interviewer for the Rx: Housing health assessment, September, 2012.

Call Leader for the Archdiocese of Louisville Building a Future of Hope Bicentennial Capital Campaign, St. Francis of Assisi Parish, Louisville, Kentucky, April-May 2010.

Parish Council, St. Francis of Assisi Parish, Louisville, Kentucky, 2009-2012; Chair 2010-2012. 
Fundraiser for Leukemia and Lymphoma Society's Team in Training, participating in the Bank of America Chicago Marathon, October 2008.

JustFaith Co-facilitator, St. Francis of Assisi Parish, Louisville, Kentucky, 2008-2009.

Citizens of Louisville Organized and United Together (CLOUT) Justice Ministry Network Member, Louisville, Kentucky, 2007-2012.

Art and Environment Committee Member, EcoStewardship Committee Member, Worship Committee Member and Liturgical Minister, St. Francis of Assisi

Parish, Louisville, Kentucky, 2006-2012.

Youth Ministry Coordinator, Holy Cross Parish, South Bend, Indiana 2005-2006.

Soup kitchen volunteer staff at Franciscan Shelter House, Louisville, Kentucky, 2002-2004.

Life and Justice Committee Member and Liturgical Minister, St. Francis of Assisi Parish, Louisville, Kentucky, $2002-2004$.

Kentucky Opera Guild, 2001—2004.

Tutor for the G.E.D. program at Marie Smith Urban Street Academy, Bronx, NY, 1999—2000.

Completed one year of post-graduate volunteer work through Holy Cross Associates, 1997-1998. 